UNIVERSIDADE DE BRASÍLIA

FACULDADE DE EDUCAÇÃO FÍSICA

PROGRAMA DE PÓS-GRADUAÇÃO STRICTU-SENSU EM EDUCAÇÃO FÍSICA

\title{
EFEITOS DE UM PROGRAMA DE TAI CHI CHUAN NO EQUILÍBRIO ESTÁTICO E DINÂMICO DE PESSOAS COM DOENÇA DE PARKINSON
}

Junhiti Nagazawa

BRASÍLIA 
EFEITOS DE UM PROGRAMA DE TAI CHI CHUAN NO EQUILÍBRIO ESTÁTICO E DINÂMICO DE PESSOAS COM DOENÇA DE PARKINSON

JUNHITI NAGAZAWA

Dissertação apresentada à Faculdade de Educação Física da Universidade de Brasília como requisito para a obtenção do grau de Mestre em Educação Física.

ORIENTADORA: PROF. DRA. LÍDIA MARA AGUIAR BEZERRA DE MELO 
Ficha catalográfica elaborada automaticamente, com os dados fornecidos pelo(a) autor(a)

\section{Nagazawa, Junhiti}

NN147e Efeitos de um programa de Tai Chi Chuan no equilíbrio estático e dinâmico de pessoas com doença de Parkinson / Junhiti Nagazawa; orientador Lidia Mara Aguiar Bezerra de Melo. -- Brasilia, 2016. $104 \mathrm{p}$.

Dissertação (Mestrado - Mestrado em Educação Fisica) -- Universidade de Brasilia, 2016.

1. Doença de Parkinson. 2. Tai Chi Chuan. 3. Equilíbrio estático. 4. Equilíbrio dinåmico. I. Aguiar Bezerra de Melo, Lidia Mara, orient. II. Título. 
JUNHITI NAGAZAWA

EFEITOS DE UM PROGRAMA DE TAI CHI CHUAN NO EQUILÍBRIO ESTÁTICO E DINÂMICO DE PESSOAS COM DOENÇA DE PARKINSON

Dissertação aprovada como requisito para obtenção do título de Mestre em Educação Física pelo Programa de PósGraduação da Faculdade de Educação Física da Universidade de Brasília.

Brasília-DF, 15 de dezembro de 2016

\section{BANCA EXAMINADORA}

Prof. a Dra. Lídia Mara Aguiar Bezerra De Melo

(Presidente - PPGEF/UnB)

Prof. Dr. Márcio de Moura Pereira

(Examinador externo)

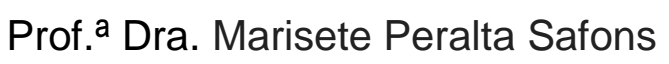

(Examinador interno - PPGEF/UnB)

Profa. Dra. Rita de Cassia P. Pinto Homem

(Examinador suplente - FEF/UnB) 


\section{AGRADECIMENTOS}

A Deus, pela vida e pela oportunidade de trilhar mais alguns passos em direção ao meu ideal. Aos meus pais, Yosikazu (in memoriam) e Miya, por todo o amor, apoio e incentivo, sendo pais exemplares e que se dedicaram ao máximo para a realização dos meus sonhos. Aos meus filhos, Henrique e Yvan, pela paciência em suportarem minhas loucuras. E aos demais familiares.

À professora, orientadora e amiga Dra. Lídia Mara Aguiar Bezerra de Melo, que me fez acreditar que, apesar da avançada idade, era possível realizar o sonho adiado, confiando em mim para realização deste projeto, sendo a minha inspiração e apoio para conclusão de mais um desafio da minha vida. Agradeço também por me mostrar que o mestrado não se resume ao título ou a trabalhos publicados, mas sim, ao processo de realização pessoal e à sensação de poder ajudar o próximo com conhecimentos adquiridos.

Ao Prof. Dr. Ricardo Jacó de Oliveira, Coordenador do Projeto de Extensão 'Atividade Física para Pessoas Portadoras de Doenças Neurodegenerativas', que, apesar de ser mais jovem do que eu, foi um pai para mim, me fazendo aprender muito com cada bronca, incentivo e cobrança, me fazendo acreditar no meu potencial.

Ao amigo e Prof. Dr. Márcio Moura Pereira, pelo incentivo ao me fazer acreditar que era possível ensinar Tai Chi Chuan para idosos, sendo um dos melhores professores de Tai Chi Chuan, loga e Dança que eu conheço, já que tive a oportunidade de praticar por algum tempo.

À Prof. a Dra. Marisete Peralta Safons, do Grupo de Estudos e Pesquisas sobre Atividade Física para Idosos (GEPAFI), por ter me dado a oportunidade de participar do grupo, onde tive contato com pessoas com Doença de Parkinson e me interessei pelo presente tema de pesquisa.

À Prof. a Dra. Rita de Cassia P. Pinto Homem, pelo apoio durante a dura jornada deste projeto, sempre sorridente e disposta a ajudar, desde a divulgação do projeto até a realização deste estudo, já que sempre esteve comigo, me incentivando a continuar e me ajudando muito a superar as dificuldades.

À Doutoranda Liana Mayara Caland, que me apoiou desde a ideia inicial do mestrado, colaborando no momento de preparo do meu Pré-Projeto para a seleção 
e continuando comigo até o final do meu trabalho. Espero que continue me ajudando nos futuros projetos.

À Dra. Candice Alvarenga, pelos conhecimentos médicos, cuidados, carinho e atenção de sempre, continuamente preocupada com a minha saúde. Se todos os médicos fossem como você o mundo seria muito mais humano.

Ao Prof. Ms. Samuel Estevam Vida, um grande colaborador que me ajudou muito na elaboração do projeto, mesmo antes da divulgação do projeto na mídia, estando sempre disposto a sanar minhas dúvidas, permanecendo me apoiando até a finalização do trabalho. Conto contigo para próximos projetos.

Às Doutorandas Sílvia Gonçalves Ricci Neri, Juliana Brenner e Ritielli Valeriano, bem como à Mestranda Lorena Cruz, pela colaboração e paciência em todos os momentos que precisei, sempre dispostas a me ajudar.

A todos os membros do grupo Viva Ativo e aos monitores que participaram do programa, em especial à Mestranda Camila Wells, Mestrando Sacha Clael e Doutorando Jose Ceni, pelo companheirismo e dedicação sem os quais não seria possível realizar este projeto.

Um agradecimento especial à minha amiga e colaboradora, graduanda Elaine Brandão que sempre esteve ao meu lado, ajudando e apoiando em meu projeto.

À Associação de Parkinson de Brasília, Clínicas e amigos que ajudaram a divulgar o projeto.

A todos os professores, funcionários e colegas do Programa de Pósgraduação em Educação Física da Universidade de Brasília, meu mais profundo agradecimento. 


\section{SUMÁRIO}

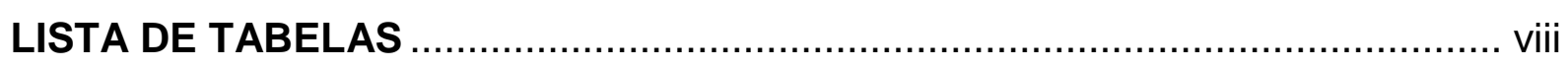

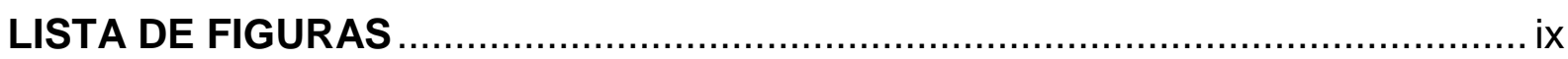

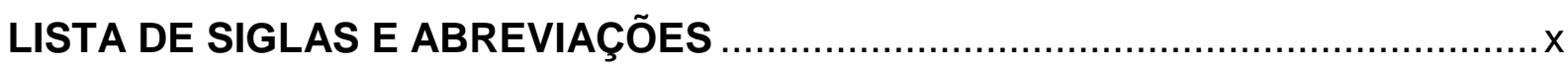

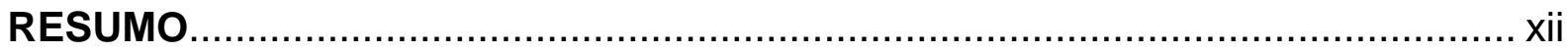

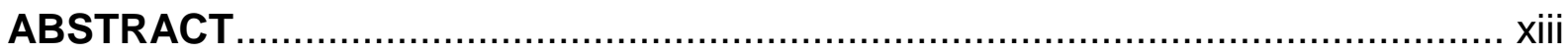

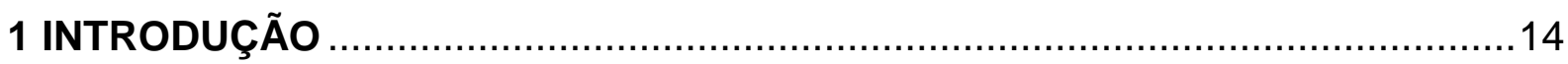

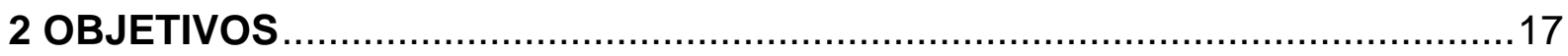

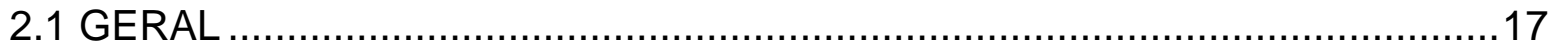

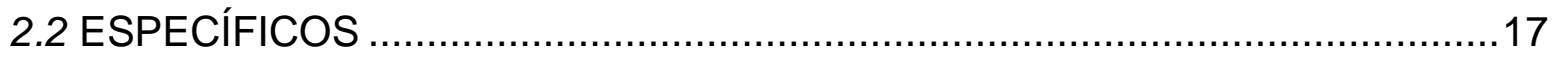

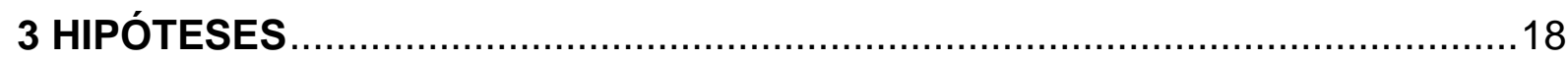

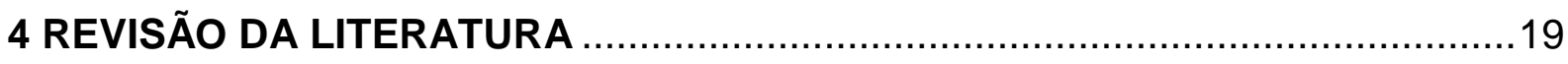

4.1 HISTÓRICO DA DOENÇA DE PARKINSON E ASPECTOS CLÍNICOS..........19

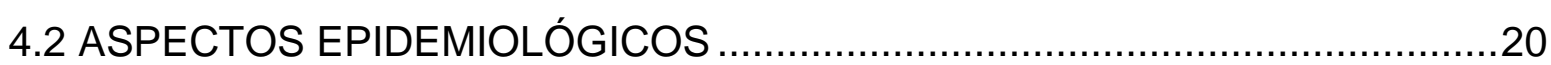

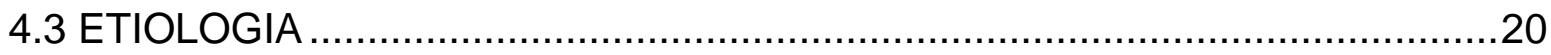

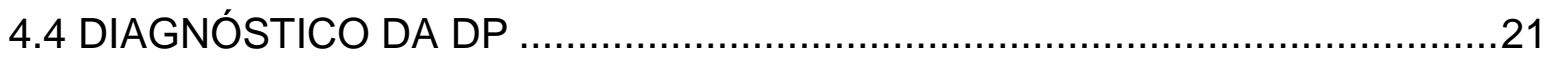

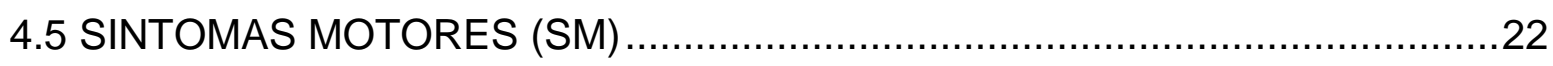

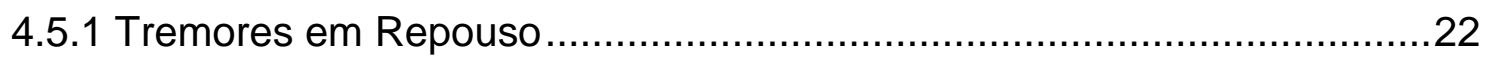

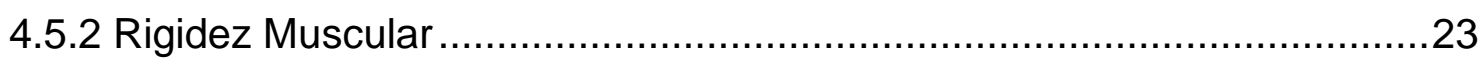

4.5.3 Bradicinesia, Hipocinesia e Acinesia ..............................................23

4.5.4 Instabilidade Postural .......................................................................24

4.6 SINTOMAS NÃO MOTORES ............................................................. 25

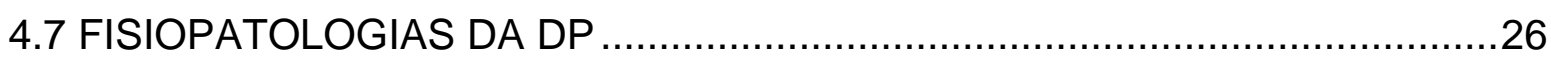

4.8 TRATAMENTO DA DOENÇA DE PARKINSON ...................................28

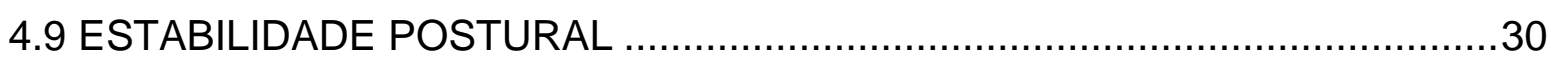

4.10 NÚCLEOS DA BASE E CONTROLE DE EQUILÍBRIO ..............................34

4.11 INSTABILIDADE POSTURAL NA DP .............................................. 34

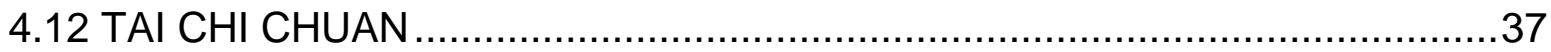

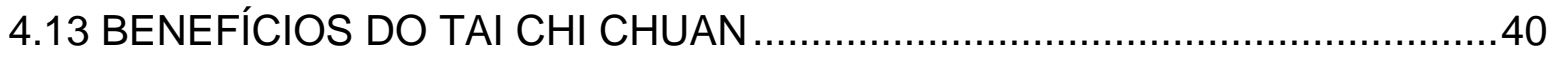


4.13.1 Benefícios Psicológicos do Tai Chi Chuan 41

4.14 TAI CHI CHUAN E FORÇA MUSCULAR NA DP ..................................... 41

4.15 TAI CHI CHUAN E EQUILÍBRIO EM DP .............................................. 42

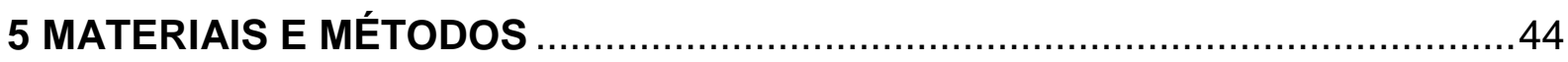

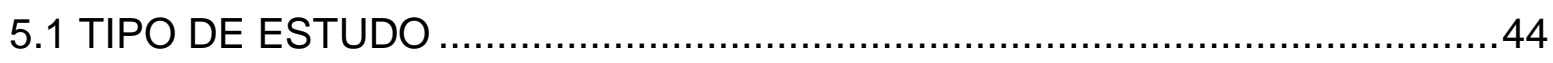

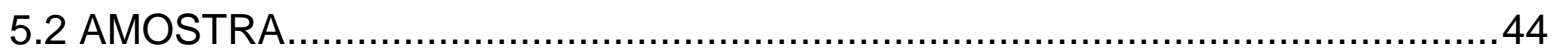

5.3 CRITÉRIOS DE INCLUSÃO E EXCLUSÃO..................................................... 45

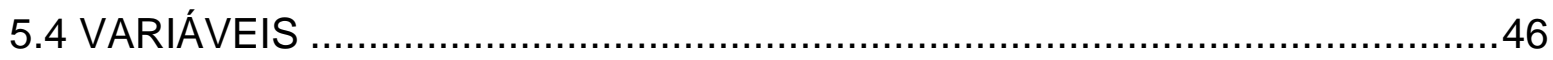

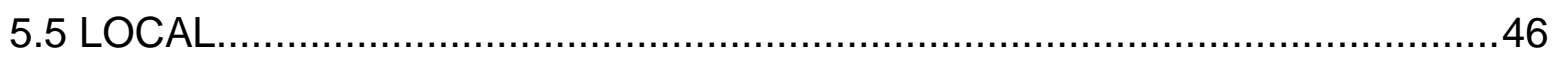

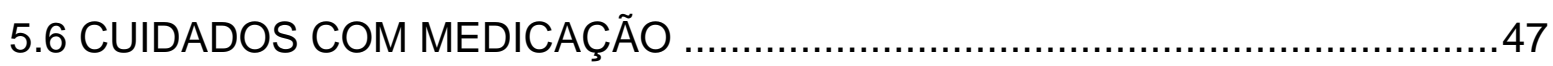

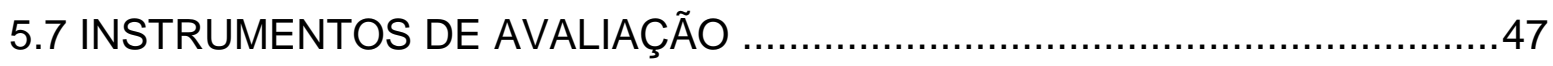

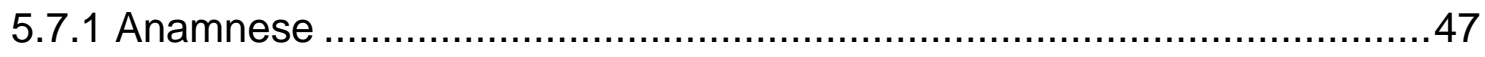

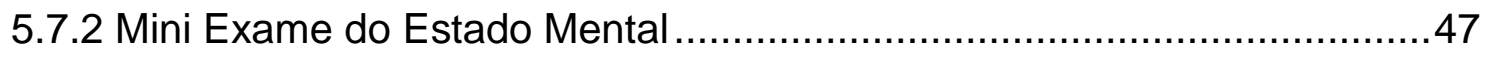

5.7.3 Avaliação do Exame Motor da Escala Unificada da Doença de Parkinson

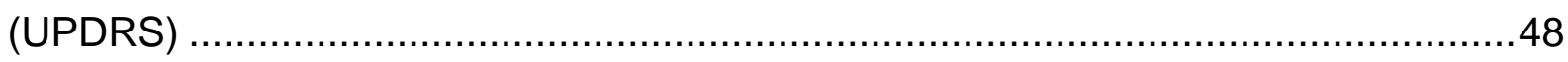

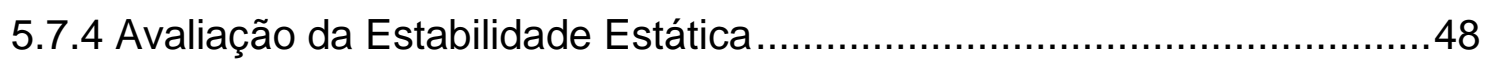

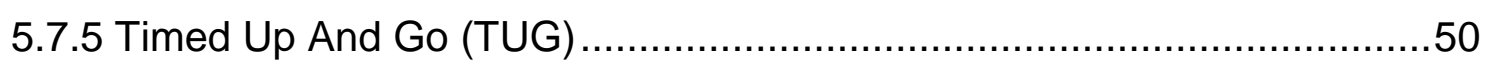

5.7.6 Escala de Equilíbrio Funcional de Berg (EEB) ...................................51

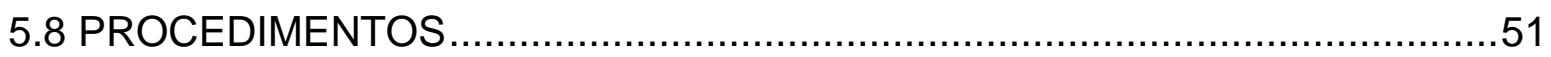

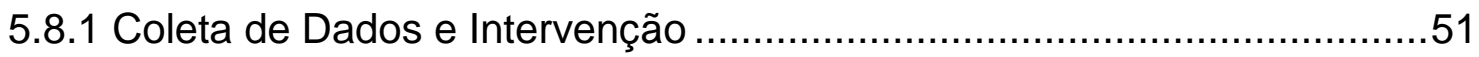

5.8.2 Intervenção Tai Chi Chuan ...............................................................

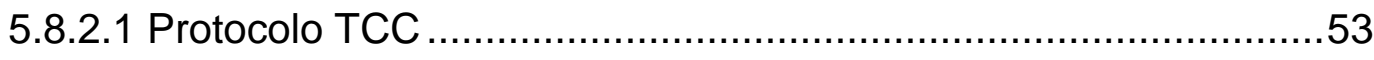

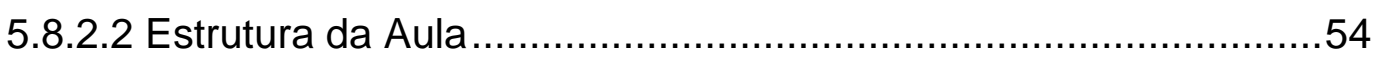

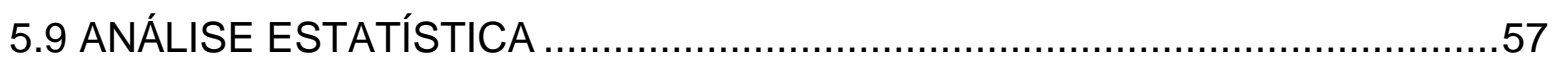

6 RESULTADOS

7 DISCUSSÃO

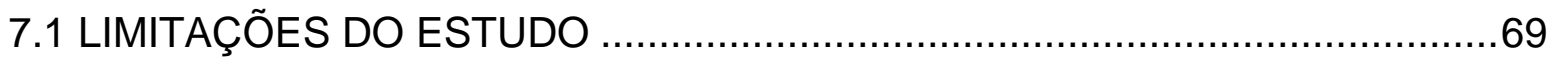

8 CONCLUSÃO

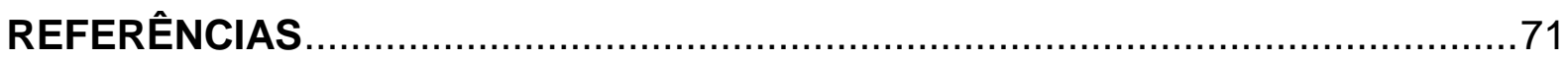


LISTA DE ANEXOS

.83 


\section{LISTA DE TABELAS}

Tabela 1 - Principais plataformas de força comercialmente disponíveis

Tabela 2 - Evolução histórica do TCC (Fonte - PEREIRA et al., 2004) 38

Tabela 3 - Caracterização descritiva da amostra. .59

Tabela 4 - Comparação da estabilidade postural dos grupos Controle e Tai Chi Chuam antes e após a intervenção. Dados expressos em média \pm desvio padrão e tamanho do efeito. .61

Tabela 5 - Comparação do equilíbrio funcional dos grupos Controle e Tai Chi Chuan antes e após a intervenção. Dados expressos em média \pm desvio padrão, delta percentual e tamanho do efeito .62 


\section{LISTA DE FIGURAS}

Figura 1 - Níveis da doença de Parkinson de acordo com a escala modificada de Hoehn e Yahr (SHENKMAN et al, 2001). 22

Figura 2 - Gráfico da orientação postural. 30

Figura 3 - Plataforma de força retangular mostrando as superfícies superior e inferior e a representação das forças obtidas por meio dos sensores em cada um dos cantos da plataforma (BARELA E DUARTE, 2011). .36

Figura 4- Representação esquemática de um arranjo experimental típico para aquisição e processamento do sinal com o uso de plataforma de força (BARELA E DUARTE, 2011)

Figura 5 - Fluxograma que demonstra a organização da amostragem e divisão de grupos.

Figura 6- Esquema sobre as posições dos pés e condições dos olhos. 49

Figura 7 - Teste Time Up and Go - (Fonte - RIKLI e JONES, 2008). .50

Figura 8 - Posição fundamental. .53

Figura 9 - Preparação no Tai Chi Chuan. Fonte: PEREIRA et al. (2008)..... .53

Figura 10 - Coreografias em duplas (Tai chi Tuishou), que simulam a defesa e o ataque da luta -(PEREIRA, et al, 2008). .54

Figura 11 - Movimentos do Tai Chi Chuan estilo Yang 24 movimentos - Fonte: http://taichibali.com/yang-tai-chi-24-forms/. Acessado em 10/12/2016. .55

Figura 12 - Relaxamento Tao Yin (Daoyin ou loga Taoista). Fonte dineyinsightsinsano.wordpress.com/2013/07/16/tao-yin/. 


\section{LISTA DE SIGLAS E ABREVIAÇÕES}

AP: Amplitude Antero Posterior

AVDs: Atividades da Vida Diária

BBS: Berg Balance Scale

CBCL: Critérios do Banco de Cérebro de Londres

CG: Centro de gravidade

CL: Corpo de Lewy

CO: Centro Olímpico

COP: Centro de Pressão

COPx: Centro de Pressão Antero Posterior

COPy: Centro de Pressão Médio Lateral

d.C.: Depois de Cristo

DBS: Deep Brain Stimulation

DP: Doença de Parkinson

EEB: Escala de Equilíbrio de Berg

FEF: Faculdade de Educação Física

FRS: Força de Pressão do Solo

GC: Grupo Controle

GE: Grupo Experimental

H\&Y: Escala de Hoehn e Yahr

HUB: Hospital Universitário de Brasília

IJ: Incisura Jugular

IMC: Índice de Massa Corpórea

MEEM: Mini Exame do Estado Mental

MS: Ministério da Saúde

NB: Núcleo da Base

OMS Organização Mundial da Saúde

REM: Rapid Eye Movement ("movimento rápido dos olhos")

SN: Sistema Nervoso

SNC: Sistema Nervoso Central

SNc: Sistema Nervoso Pars Compacta

SNM: Sintomas não Motores

SPSS: Statistical Package for the Social Sciences 
TCC: Tai Chi Chuan

TCLE: Termo de Consentimento Livre e Esclarecido

TUG: Timed Up and Go

TUG: Timed Up and Go Test

UDPRS III: Unified Parkinson's Disease Rating Scale III

UnB: Universidade de Brasília 


\title{
RESUMO
}

\section{EFEITOS DE UM PROGRAMA DE TAI CHI CHUAN NO EQUILÍBRIO ESTÁTICO E DINÂMICO DE PESSOAS COM DOENÇA DE PARKINSON}

\author{
Autor: JUNHITI NAGAZAWA \\ Orientadora: LÍDIA MARA AGUIAR BEZERRA DE MELO
}

Pessoas com Doença de Parkinson (DP) geralmente são acometidas por prejuízos na mobilidade e equilíbrio, pois quando submetidas às condições desafiadoras, sua coordenação para ajustar o equilíbrio torna-se mais complexa. A prática regular de Tai Chi Chuan (TCC) demanda movimentos em múltiplas direções, concentração e mentalização do controle da base de sustentação, bem como seu deslocamento (lento) com controle respiratório e manutenção da postura, favorecendo o aumento da força muscular de membros inferiores e aumentando a atenção à estabilidade durante a mudança de posição dos pés. Embora a prática de TCC demonstre melhora no equilíbrio de pessoas com DP, esta melhora precisa ser demonstrada através de avaliações sensíveis que analisem a resposta autonômica postural pela margem de estabilidade, a qual é prejudicada pela postura curvada na DP. Desta forma, com o intuito de verificar os benefícios do TCC para esta população, foi realizado um estudo quase experimental visando aferir o efeito de 12 semanas de treinamento de Tai Chi Chuan estilo Yang no equilíbrio dinâmico e na estabilidade postural de idosos com doença de Parkinson. Participaram da pesquisa 39 indivíduos com diagnóstico clínico de DP, sendo divididos em grupo experimental (Grupo TCC) com $n=23$ e média de idade de 67,17 $\pm 10,299$, e grupo controle (GC) com $n=16$ e média de idade de $68,94 \pm 10,421$. Todos os participantes foram submetidos à avaliação dos sintomas motores, do nível de severidade da doença, equilíbrio estático e dinâmico. $\mathrm{Na}$ análise estatística foi verificada a normalidade da amostra dos dois grupos pelo teste de Shapiro-Wilk e em seguida foi aplicada a ANOVA fatorial 2 way (pré e pós) X 2 grupos (controle e TCC) para verificar possíveis diferenças entre grupos e intra grupos, adotando um nível de significância de $p \leq 0,05$. O Grupo TCC realizou 12 semanas de treinamento e o GC manteve suas atividades habituais; após este período, todos foram avaliados novamente e não houve diferença estatisticamente significativa entre o GC e o Grupo TCC, mas houve diferença no equilíbrio estático e dinâmico no Grupo TCC após o treinamento $(F=6,110$ e $p=0,02)$. Verificou-se que após o treinamento com TCC houve uma melhora nas amplitudes de deslocamento do centro de pressão (COP) e na velocidade do COP. Houve uma melhora das amplitudes AP $(p=0,006)$ quando o equilíbrio é testado sem estímulo visual e $\mathrm{ML}(p=0,027)$ com base de apoio fechada e estímulo visual. A melhora na velocidade do COP foi verificada em todas as condições testadas. Conclui-se então, que o treinamento de TCC em 12 semanas é capaz de alterar positivamente o equilíbrio estático e dinâmico em indivíduos com DP. Diante disso, podemos afirmar que a prática do TCC não foi significativamente melhor quando comparada ao grupo controle; no entanto, mais ensaios clínicos com mais tempo de seguimento são necessários para confirmar os resultados atuais dos benefícios da prática do TCC para indivíduos com Doença de Parkinson. Devido à existência de poucos estudos abordando esta metodologia, são necessárias novas pesquisas nessa área.

Palavras-chave: Doença de Parkinson, Tai Chi Chuan, equilíbrio estático, equilíbrio dinâmico. 


\title{
ABSTRACT \\ EFFECTS OF A TAI CHI CHUAN PROGRAM ON STATIC AND DYNAMIC BALANCE OF PEOPLE WITH PARKINSON'S DISEASE
}

\author{
Author: JUNHITI NAGAZAWA \\ Advisor: LÍDIA MARA AGUIAR BEZERRA DE MELO
}

Usually people with Parkinson's disease (PD) are affected by impairments in mobility and balance, on this account when are subjected to challenging conditions, the more complex coordination becomes to adjust the balance. The regular practice of Tai Chi Chuan (TCC) demands movements in multiple directions, concentration and mentalization of the control of the base of support as well as its (slow) displacement with respiratory control and maintenance of the posture, favoring the increase of muscular strength of lower limbs, And increasing attention to stability during changing of foot position. Although the practice of TCC demonstrates an improvement in balance of people with PD, this improvement needs to be demonstrated through sensitive assessments through the analysis of postural autonomic response by the margin of stability which is imparired by the curved posture in Dini order to verify the benefits of TCC, a quasi-experimental study was carried out to verify the effect of 12 weeks of Yang Tai Chi Chuan training on the dynamic balance and postural stability of elderly patients with Parkinson's disease. A total of 39 individuals with clinical diagnosis of PD were divided into experimental group (TCC Group) with $n=23$ and mean age of $67.17 \pm 10.299$, and control group (CG) with $n=16$ and mean age of $68.94 \pm 10.421$. All participants were submitted to evaluation of motor symptoms, level of disease severity, static and dynamic balance. In the statistical analysis, the normality of the sample of the two groups was verified by the Shapiro-Wilk test and then the 2-way factorial ANOVA (pre and post) X 2 groups (control and TCC) was applied to verify possible differences between groups and intra groups Adopting a significance level of $p \leq 0.05$. The TCC Group performed 12 weeks of training and the CG maintained it usual activities, after this period all were reassessed and there was no statistically significant difference between the CG and the TCC Group, but there was a difference in the static and dynamic balance in the TCC Group after Training $(F=6.110$ and $p=0.02)$. There was an improvement in the pressure center displacement amplitudes (COP) and COP velocity after TCC training. There was an improvement in AP amplitudes $(p=0.006)$ when the balance was tested without visual stimulus and $M L(p=0.027)$ with closed support base and visual stimulus. The improvement in COP speed was verified under all conditions tested. It is concluded that the training of TCC in 12 weeks is able to positively alter the static and dynamic balance in individuals with PD. Therefore, we can say that the practice of TCC was not significantly better when compared to the control group, however, more clinical trials with longer follow-up are necessary to confirm the current results of Tai Chi for Parkinson's disease. Due to few studies addressing this methodology, further research is needed in this area.

Keywords: Parkinson's disease, Tai Chi Chuan, static balance, dynamic balance. 


\section{INTRODUÇÃO}

A Doença de Parkinson (DP) é uma doença neurodegenerativa crônica incurável que causa a "morte" dos neurônios dopaminérgicos do mesencéfalo (OXTBOY, WILLIANS, 2000; REIS, 2004). A manifestação dos distúrbios do movimento como marcadores da patologia é facilmente reconhecível pela tétrade clássica caracterizada pelo tremor em repouso, a instabilidade postural, a rigidez muscular e a bradicinesia (LIMONGI 2000; KERANEN et al., 2003; JANKOVIC, 2008; PAHWA 2007; GOBBI et al., 2010, BARBIERI et al., 2011; DIBBLE et al., 2015). Esta doença afeta uma em cada 100 pessoas com idade superior a 60 anos e quatro em cada 100 pessoas com idade superior a 80 anos. Existe a previsão de que ela atinja de oito a nove milhões de pessoas em 2030 nos países industrializados (SCHENKMAN et al., 2012). Segundo Barbosa et al., (2006), no Brasil a DP atinge $3,3 \%$ da população com mais de 60 anos.

Estudos demonstram que os sintomas clínicos da DP são tratados via terapia farmacológica feita à base de drogas neuroprotetoras como Levedopa ou L-Dopa, que visam evitar a diminuição progressiva de dopamina (HOEHN M. YAHR, 1967, LANG et al., 1998; SCHAPIRA et al., 2010). Moro et al., (2010) relatam que o uso prolongado de remédio provoca efeitos colaterais tais como: movimentos involuntários, dor no peito, constipação, perda de peso, falta de ar, depressão, ansiedade, confusão mental e fadiga, dentre outros.

Nesse sentido, a prática regular de exercício físico torna-se um tratamento coadjuvante, cujo objetivo é proporcionar habilidade para a pessoa com DP no autocuidado e na automanutenção, além de manter ou retardar a diminuição da capacidade funcional e melhorar ou manter a qualidade de vida (SILVA et al., 2011; CUQUSI et al., 2014; CANNING et al., 2015). Segundo Hirsch \& Farley (2009), existem cinco princípios-chave do exercício físico que aprimoram a plasticidade neural em relação à DP, a saber: a) atividade intensa maximiza a plasticidade sináptica; b) atividades complexas promovem maior adaptação estrutural; c) atividades gratificantes aumentam níveis de dopamina e promovem aprendizado e memória; d) neurônios dopaminérgicos são altamente responsivos ao exercício e à inatividade; e) se o exercício é introduzido no início da doença, a progressão pode ser retardada. 
Dentre os sintomas motores, a perturbação do controle postural dinâmico e estático ainda não está compreendida (STENO et al., 2015). A instabilidade postural resulta em um alto risco de quedas, se tornando fator determinante para a qualidade de vida, morbidade e mortalidade, principalmente em indivíduos com DP (PARK et al., 2015).

Sendo a prática regular de exercício físico coadjuvante no tratamento da DP, uma modalidade que está se mostrando eficaz devido aos benefícios físicos e psíquicos que promove, é o Tai Chi Chuan (TCC). Trata-se de uma prática milenar Chinesa a qual envolve movimentos coreografados combinados com exercícios de concentração e respiração, com ênfase no equilíbrio e flexibilidade, sendo de fácil adaptação e aprendizado por parte das pessoas com DP (KLEIN, 2008; WAHBEH et al., 2008; HACKNEY \& EARHART, 2009; Li et al., 2012; CHOI et al., 2013; NI et al. 2014; YANG et al., 2014).

A prática regular de TCC demanda movimentos em múltiplas direções, concentração e mentalização do controle da base de sustentação, bem como seu deslocamento - de forma lenta, com controle respiratório e manutenção da postura, favorecendo o aumento da força muscular de membros inferiores e a atenção à estabilidade durante a mudança de posição dos pés (MATTHEWS et al., 2008; GYLLENSTEN et al., 2010).

$\mathrm{Na}$ tentativa de justificar os efeitos do TCC nos sintomas motores, Yang et. al (2014) realizaram uma revisão sistemática e metanálise para avaliar a evidência da eficácia do TCC para as pessoas com DP; desta forma, foi possível verificar que a prática proporciona melhora no escore da função motora pelo UPDRS-III (Metanálise de dados contínuos (SMD), 20.57; 95\% Intervalo de confiança (Cl) 21.11 para 20.04; $p=0.03)$. No entanto, não suportam ou refutam essas alterações quando comparadas com outras terapias (SMD, 20.54; 95\% Cl 21.21 para $0.12 ; \mathrm{p}=0.11$ ). Quando analisada a velocidade da marcha, o TCC não demonstrou melhora na performance (SMD, 20.02; 95\% Cl 20.58 para $0.54 ; p=0.9$ ). Por outro lado, quando avaliadas variáveis relacionadas ao equilíbrio, a metanálise realizada demonstrou que o TCC aprimora apenas a Escala de equilíbrio de Berg (EEB) quando comparada com outras intervenções (SMD, $0.74 ; 95 \% \mathrm{Cl} 0.38$ para $1.10 ; \mathrm{p}=$ 0.0001 ), pois variáveis como equilíbrio unipodal, teste de alcance funcional e teste de TANDEN não demonstraram melhoras significativas. Por fim, para o equilíbrio dinâmico avaliado pelo teste Timed Up and Go (TUG), a prática de TCC foi eficaz na 
melhora da performance em indivíduos com DP quando comparada com outras atividades (SMD, 1.06; 95\% Cl 0.68 para 1.44; $p=0.00001)$.

Embora a prática de TCC demonstre melhora no equilíbrio de pessoas com DP, as avaliações das variáveis de equilíbrio podem ser mais sensíveis e melhor compreendidas se analisarmos a resposta autonômica postural pela margem de estabilidade a qual é prejudicada pela postura curvada na DP (PARK et al., 2015). Esta margem se dá pela diferença no deslocamento do centro de pressão (COP). Em vista disso, questiona-se se um programa de TCC seria eficaz, não somente nas variáveis de equilíbrio supracitadas, mas também na margem de estabilidade postural.

Devido às divergências metodológicas, como tempo de diagnóstico, classificação da doença, idade e variáveis coletadas (equilíbrio estático e dinâmico), os estudos proporcionaram resultados conflitantes no que concerne aos reais efeitos da prática desta modalidade. Portanto, o presente estudo servirá de início para uma metodologia mais sistematizada e adaptada às pessoas com DP.

Desta maneira, o TCC, por ser uma modalidade de intensidade leve a moderada, tem demonstrado melhora do equilíbrio, da velocidade de caminhada, do alcance funcional e promoção de estabilidade postural, além do benefício no controle mental e flexibilidade, melhorando a força e a potência muscular (COELHO et al., 2013). Some-se a isto, o fato de ser uma prática de fácil execução, baixo custo e acessível a todos, podendo ser adaptada para pessoas com doença de Parkinson.

Este estudo poderá contribuir com dados relevantes na investigação das possibilidades de estabilizar ou retardar o processo neurodegenerativo da DP, melhorando a qualidade de vida destes indivíduos, ao obter novas informações referentes ao comportamento de variáveis motoras relacionadas ao equilíbrio de portadores da DP. Portanto, as avaliações e análises que compõem este estudo poderão auxiliar no desenvolvimento de intervenções terapêuticas para o controle e estabilização dos distúrbios motores da DP.

Este estudo visa verificar com rigor metodológico se os movimentos do estilo proposto de TCC garantem uma prática segura e eficaz, adequada para pessoas com DP, excluindo assim, o efeito placebo. 


\section{OBJETIVOS}

\subsection{GERAL}

Verificar os efeitos de 12 semanas de um programa de treinamento de TCC do estilo Yang no equilíbrio estático e dinâmico em indivíduos com DP.

\subsection{ESPECÍFICOS}

- Analisar o efeito do treinamento de TCC no equilíbrio pela Escala de Equilíbrio de Berg e comparar com o grupo controle;

- Analisar o efeito do treinamento de TCC no equilíbrio dinâmico e comparar com o grupo controle por meio da Escala de Equilíbrio de Berg;

- Analisar o efeito do treinamento de TCC no equilíbrio estático e comparar com o grupo controle da plataforma de força AMTI. 


\section{HIPÓTESES}

$\mathrm{H}_{0}$ - A prática de TCC não altera o equilíbrio em indivíduos com DP. $\mathrm{H}_{1}$ - A prática de TCC altera o equilíbrio em indivíduos com DP. 


\section{REVISÃO DA LITERATURA}

\subsection{HISTÓRICO DA DOENÇA DE PARKINSON E ASPECTOS CLÍNICOS}

Em 1817, o médico James Parkinson, membro do Colégio Real de Cirurgiões, observou seis pessoas (homens com idade entre 50 a 72 anos) na rua e na clínica. Todos possuíam sintomas de tremor nas mãos e nos braços quando estavam parados sem realizar movimento, lentidão na caminhada, dificuldades na locomoção e aparente diminuição da força muscular. Além de uma tendência à inclinação do corpo à frente ao andar, possuindo também passos curtos, chegando a arrastar os pés (ANDRADE et al., 2010).

Após analisar os sintomas, verificou que se tratava de uma nova doença ainda não descrita na literatura medica até aquela época. Após pesquisa criteriosa, chegou à conclusão que era necessário um estudo mais profundo, resultando em sua publicação "Um ensaio sobre a paralisia tremula" (An essay on the Shaking Palsy), na qual descreveu a doença, sintomas, diagnóstico e tratamento.

Em 1860 o neurologista francês Jean Martin Charcot, em seu estudo, a descreveu como Doença de Parkinson (La maladie de Parkinson) em homenagem ao seu descobridor - James Parkinson, com quatro sinais da doença, sendo estes: tremor, rigidez, dificuldades de equilíbrio e lentidão dos movimentos (PANDEY S, 2012).

James Parkinson foi pioneiro em diagnosticar a doença, mas coube a Charcot adicionar conhecimentos mais profundos e esclarecedores acerca da DP. Charcot identificou que a DP estava associada com a substancia negra dos núcleos da base e recomendou a utilização de substancias anticolinérgicas no tratamento da DP.

O médico e farmacologista Arvid Carlsson, pesquisador de neurotransmissores (unidades químicas responsáveis pela transmissão de mensagens entre neurônios), em seus estudos no final da década de 50 , notou que a falta de neurotransmissores dopaminérgicos poderia ser a causa da DP. Na década seguinte, Ehringer e Hornkievicz descreveram a redução de dopamina nos gânglios da base em pessoas de DP, o que possibilitou o tratamento da DP pela reposição deste neurotransmissor (ANDRADE et al., 2010). 


\subsection{ASPECTOS EPIDEMIOLÓGICOS}

Recentes estudos da Organização Mundial da Saúde (2006) relatam que a DP atinge uma proporção de 150 a 180 casos a cada 100.000 habitantes, relatando que em todo o mundo existe em torno de quatro milhões de pessoa que sofram com DP. No Brasil, a proporção de acometidos está em torno de 150 casos por 100.000 habitantes, estimando-se que exista cerca de 300.000 pessoas com DP, uma vez que a incidência de tal enfermidade vem aumentando progressivamente com 0 envelhecimento da população. A prevalência da DP está em torno de $2 \%$ da população com idade acima de 65 anos, sendo que o início da manifestação acontece por volta dos 55 anos de idade, atingindo o indivíduo em plena atividade laborativa e aproveitamento da vida (REIS, 2004).

O sexo masculino é mais afetado que o sexo feminino em proporção de 3:2, ou seja, três homens para duas mulheres, segundo estudo de JANKOVIC (1997) e FAHN \& PRZEBORSKI (2010).

\subsection{ETIOLOGIA}

A DP é uma doença neurológica crônica de progressão lenta, não sendo fatal nem contagiosa, cuja causa ainda é desconhecida (OXTOBOY, WILLIANS 2000; REIS, 2004), não existindo uma cura definitiva, apesar dos avanços da tecnologia, medicina e pesquisas, permanecendo com uma etiologia obscura. Estudos clínicos reforçam que o surgimento da doença está associado a fatores ambientais, estresse oxidativo, anormalidades mitocondriais, envelhecimento, genética e outros fatores. $O$ processo de envelhecimento é considerado uma de suas principais causas, uma vez que causa a aceleração da perda de neurônios dopaminérgicos (REBELLATTO et al., 2006).

Dados epidemiológicos apontam para possíveis associações com exposições em ambientes rurais que utilizam água de poço, uso de pesticidas e em regiões industriais, onde há vestígios de metais pesados (TANNER et al., 2009).

Segundo o estudo de LEES et al. (2009), a genética molecular tem sido importante na exploração de proteínas, vias metabólicas e processos celulares. Estudos de genomas demostram o risco moderado para DP, que inclui 
polimorfismos dos genes da alfa-sinucléia, repetições ricas em leucina quinase 2 (LRRK2) e ácido gama aminobutírico (LEES, HARDY, REVESZ, 2009).

Genes hereditárias da DP são denominadas "PARK" e são numeradas sequencialmente, sendo PARK 1,3,4 e 5 de transmissão autossômica dominante (AD), PARK 6 e 7 de transmissão autossômica recessiva (AR) e PARK 2 de transmissão essencialmente recessiva (SCHAPIRA, TOLOSA, 2010).

\subsection{DIAGNÓSTICO DA DP}

O diagnóstico clínico normalmente é feito pelo neurologista adotando critérios do banco de cérebro de Londres (HUGHES et al, 1992). Estes critérios foram acatados e republicados pelo Ministério da Saúde, uniformizando a avaliação clínica brasileira para diagnostico da DP (Brasil Mds, 2010). O diagnóstico pode também ser complementado por exames de Ressonância Magnética Funcional e imagens de transportadores de dopamina, utilizando $\beta$-CIT SPECT ou fluordopa PET (Positron Emission Tomography), que tem demonstrado acurácia superior a $70 \%$ de eficácia (SCHRAG, BEN-SHLOMO e QUINN, 2002).

A DP pode ser classificada em estágios de 1 a 5 , conforme a Escala Modificada de Hoehn \& Yahr, sendo o estágio 1 caracterizado por nenhuma incapacidade funcional, apesar de existir um acometimento funcional, e o estágio 5 caracterizado pelo total acometimento do desempenho funcional (Figura 1). 


\begin{tabular}{|c|c|c|}
\hline Estágio & Escala Hoehn \& Yahr & Escala modificada Hoehn \& Yahr \\
\hline 1 & $\begin{array}{l}\text { Envolvimento unilateral, } \\
\text { normalmente com mínima ou } \\
\text { nenhuma incapacidade } \\
\text { funcional. }\end{array}$ & Somente envolvimento unilateral \\
\hline 1,5 & & Envolvimento unilateral e axial \\
\hline 2 & $\begin{array}{l}\text { Envolvimento bilateral ou } \\
\text { médio sem comprometimento } \\
\text { do equilíbrio }\end{array}$ & $\begin{array}{lcc}\text { Envolvimento } & \text { bilateral } & \text { sem } \\
\text { comprometimento do equilíbrio } & \end{array}$ \\
\hline 2,5 & & $\begin{array}{l}\text { Doença bilateral leve com recuperação } \\
\text { em teste do empurrão (empurra-se } \\
\text { bruscamente o paciente para trás a } \\
\text { partir dos ombros, o paciente dá mais } \\
\text { que três passos, mas recupera o } \\
\text { equilíbrio sem ajuda). }\end{array}$ \\
\hline 3 & $\begin{array}{l}\text { Doença } \text { bilateral: } \\
\text { incapacidade leve a } \\
\text { moderada com reflexos } \\
\text { posturais comprometidos; } \\
\text { fisicamente independente. }\end{array}$ & $\begin{array}{l}\text { Doença bilateral leve a moderada; } \\
\text { alguma instabilidade } \\
\text { fisicamente independente. }\end{array}$ \\
\hline 4 & $\begin{array}{l}\text { Doença severamente } \\
\text { incapacitante; ainda é capaz } \\
\text { de andar ou ficar sem ajuda. }\end{array}$ & $\begin{array}{l}\text { Incapacidade grave; } \\
\text { Ainda é capaz de andar ou ficar sem } \\
\text { ajuda. }\end{array}$ \\
\hline 5 & $\begin{array}{l}\text { Confinado na cama ou na } \\
\text { cadeira de rodas, a não ser } \\
\text { que receba ajuda. }\end{array}$ & $\begin{array}{l}\text { Confinado na cama ou na cadeira de } \\
\text { rodas, a não ser que receba ajuda. }\end{array}$ \\
\hline
\end{tabular}

Figura 2 - Níveis da doença de Parkinson de acordo com a escala modificada de Hoehn e Yahr (SHENKMAN et al, 2001).

\subsection{SINTOMAS MOTORES (SM)}

Segundo LUNDY-EKMAN (2002) o sintoma inicial da DP normalmente se manifesta de forma unilateral, evoluindo para o lado contralateral com o avanço da doença.

\subsubsection{Tremores em Repouso}

O tremor de repouso é um dos principais sinais de manifestação que ocorre em pessoas acometidas pela DP. É definido como movimentos rítmicos, oscilatórios, com surtos involuntários de 4 a 6 ciclos por segundo, que se manifestam na parte distal dos membros superiores e inferiores. O tremor da DP geralmente é descrito 
como tremor de repouso, estático ou não intencional, agravando-se com estresse emocional, que diminui com movimento voluntário e durante o sono (JANKOVIC, 2008; LEES; HARDY; REVESZ, 2009; O'SULLIVAN \& SCHMITZ 1993).

\subsubsection{Rigidez Muscular}

É uma anormalidade motora da DP, com aumento persistente do tônus muscular, da contratilidade muscular basal e do tônus axial (DOHERTY et al., 2011), que ocorre devido à diminuição de ação muscular, caracterizado pela resistência à movimentação passiva, que pode ser continua ou intermitente, dando a impressão de que os braços e pernas estão presos, dificultando e retardando os movimentos. Tal alteração é conhecida como "Sinal da Roda Dentada", sendo que a concentração mental ou tensão emocional podem aumentar a intensidade da rigidez (HONG et al., 2007).

A rigidez pode ser percebida junto com dor, como por exemplo, a manifestação de ombro doloroso, que é uma das manifestações mais freqüentes de DP, mas normalmente é diagnosticada como artrite, bursite ou dano no manguito rotador (STAMEY et al., 2007). Normalmente a rigidez ocorre na musculatura flexora, provocando alterações na postura, com antero-flexão do tronco e semiflexão dos membros (HONG et al., 2007).

Devido às limitações e lentidão dos movimentos, a rigidez muscular diminui o desempenho funcional nas AVDs, como nas atividades de higiene, alimentação e vestimenta.

\subsubsection{Bradicinesia, Hipocinesia e Acinesia}

Conhecida como um dos principais sintomas clínicos da DP, a bradicinesia caracteriza-se por aspectos como lentidão e pobreza de movimentos, pela dificuldade na iniciação e desenvolvimento dos movimentos voluntários, redução na amplitude, lentidão, a qual é determinada pela impossibilidade de comandar a ação muscular, ou seja, a vontade de realizar movimento não é obedecida, o que pode comprometer movimentos mais finos e delicados, como manejo de pequenos 
objetos, abotoar e desabotoar roupas, escrever (caligrafia torna micrográfica) e escovar dentes (JANKOVIC, 2008).

Algumas das características da bradicinesia são: expressão facial que demostra imobilidade ou rigidez, pobreza na expressão de emoções (hiponímia ou face em máscara/congelada), fala lenta e quieta (hipofonese) com perdas do ritmo e melodia e presença de disartria (LEES; HARDY; REVESZ, 2009).

Alguns estudos apontam que a bradicinesia pode levar as pessoas com DP a um quadro crônico de fraqueza muscular, porque é um dos fatores principais para redução na prática de atividades físicas, desde o início da doença. A inatividade física pode resultar na diminuição das fibras do tipo II que geram força em maior magnitude (SPEELMAN et al., 2011).

A hipocinesia é a redução ou limitação dos movimentos automáticos e pode ser considerada como a maior dificuldade encontrada na troca de movimentos, ou seja, iniciar um movimento e pará-lo a fim de começar um novo movimento (JANKOVIC, 2008). Também compromete a qualidade do movimento de balançar dos braços durante a deambulação e dificulta a manutenção de um movimento repetitivo, como abrir e fechar as mãos (GOBBI et al., 2006)

Acinesia ou freezing (congelamento) é uma hesitação no início da marcha que evolui para a perda rápida de movimentos dos membros inferiores, o que é considerado um dos sintomas mais incapacitantes da DP, sendo uma das principais causas de queda (MACHT et al., 2007).

\subsubsection{Instabilidade Postural}

A instabilidade postural é definida como uma deficiência das ações reflexas posturais tanto no equilíbrio como também no ajuste de postura em caráter antecipatório e compensatório (JANKOVIC, 2008).

Com a instabilidade postural, a pessoa geralmente fica em uma posição curvada e os reflexos posturais (reações de endireitamento, equilíbrio e extensão protetora) estão todos diminuídos. Quando não há equilíbrio, a pessoa, na maioria dos casos, chega a cair, o que pode acarretar lesões graves (SAMII, NUTT e RANSOM, 2004). A manifestação da instabilidade postural aparece geralmente nas 
fases mais avançadas na DP, quando as outras características clínicas já estão evidentes (PAIVA, 2011).

\subsection{SINTOMAS NÃO MOTORES}

Apesar de sintomas motores serem as característcas cardinais da DP, estudos têm demonstrado que os sintomas não motores (SNM) têm maior importância quando avaliados nas medidas relacionadas à qualidade de vida, às taxas de institucionalização e nos fatores econômicos das políticas de saúde, até porque é possível correlacionar os SNM com o avançar da idade e a gravidade da doença (FINDLEY, et al, 2002).

Com o passar do tempo, os efeitos colaterais dos medicamentos que tratam os sintomas motores podem induzir ou agravar os SNM como hipotensão ortostática, alucinações, sonolência excessiva ou insônia e, assim, interferir de forma significativa na qualidade de vida destes indivíduos (YORITAKA et al, 2014).

Os principais sintomas não motores da DP estão relacionados aos seguintes aspectos:

a) neuropsiquiátricos e mentais (apatia, ansiedade, depressão, alucinações, ataques de pânico, delirium, alterações cognitivas);

b) desordens do sono (desordens do sono REM, síndrome das pernas inquietas, insônia);

c) fadiga de origem central ou periférica;

d) sensoriais (dores, distúrbios olfatórios, hiposmia, distúrbios visuais);

e) disfunções autonômicas (incontinência urinária, disfunção sexual, hipotensão ortostática, sudorese);

f) gastrointestinais (salivação, disfagia, constipação, náusea, vômitos, refluxos);

g) sintomas não motores comportamentais e não comportamentais induzidos por medicações dopaminérgicas;

h) flutuações não motoras (que podem estar relacionadas a disfunções autonômicas, cognitivas (psiquiátricas), sensoriais (dor), entre outros (HALLIDAY; LEES; STERN, 2011; LEES; HARDY; REVESZ, 2009). 


\subsection{FISIOPATOLOGIAS DA DP}

A fisiopatologia da doença de Parkinson pode ser considerada como uma afecção neurodegenerativa progressiva, caracterizada pela presença de disfunções monoaminérgicas múltiplas, incluindo déficits dos sistemas dopaminérgicos, colinérgicos, serotoninérgicos e noradrenérgicos (TEIVE, 2005). Os sistemas dopaminérgicos junto com os neurônios de melanina sofrem despigmentação, sendo que quanto mais clara a substância negra, maior é a perda de dopamina. Esta despigmentação provoca a depleção do neurotransmissor dopamina, resultando na degeneração de neurônios dopaminérgicos da substância negra que se projetam para o estriado, onde está o controle do processamento da informação pelos gânglios da base, com a redução da atividade das áreas motoras do córtex cerebral, desencadeando diminuição dos movimentos voluntários (PIERUCCINI-FARIA et al. 2006).

Mecanismos fisiopatológicos da DP demonstram que o estriado, além de receber projeções glutamatérgicas excitatórias corticais, também recebe projeções dopaminérgicas de neurônios localizados na SN pars compacta (SNc), que exercem efeito excitatório, através da ativação de receptores da dopamina. A perda de neurônios dopaminérgicos na SNc, as inclusões intraneuronais de corpos de Lewy (CL) e a severa deficiência de receptores da dopamina no caudado, putâmen, globo pálido e núcleo subtalâmico são característicos da DP (BEZARD et al., 2003).

Com o avanço da DP, os neurônios se degeneram e desenvolvem corpos citoplasmáticos inclusos, que são os chamados corpos de Lewy, sendo estes corpos de inclusão citoplasmática dos eosinófilos, existentes na substância negra do mesencéfalo, os quais se aglomeram em grande quantidade (REBELATTO et al. 2006).

De uma maneira geral, define-se com clareza a existência de uma perda neuronal progressiva no grupo de células ventro-laterais, da parte compacta da substância negra do mesencéfalo (PALERMO et al. 2009).

Hoje em dia, com o avanço tecnológico na anatomia e na neuro-imagem, sabe-se que esta degeneração no $\mathrm{SN}$ ocorre bem depois que a doença já está instalada, apresentando início insidioso e de lenta progressão pelo SN, sendo que, normalmente, quando se conclui o diagnóstico a doença já está em franca ascensão (HALLIDAY; LEES; STERN, 2011). Alteração nigral clássica da DP está sempre 
acompanhada de uma fisiopatologia dita extranigral, caracterizada por acometimentos nos núcleos dorsal motor dos nervos glossofaríngeo e vago, formação reticular, região da rafe, complexos coeruleous-subcoeruleous, núcleo magnocelular do bulbo, e muitos subnúcleos da amígdala e tálamo (HALLIDAY; LEES; STERN, 2011; RASCOL et al., 2011; BRAAK et al., 2003).

Atualmente, a fisiopatologia da DP é caracterizada por seis estágios, (BRAAK, et al, 2003), descritos de acordo com a localização e o aparecimento de neurites (inflamação dos nervos) e corpos de Lewy (HALLIDAY; LEES; STERN, 2011; BRAAK et al., 2003, 2005, 2006), os quais serão descritos a seguir.

Estágios 1 e 2: a lesão é virtualmente confinada ao bulbo, com um acometimento de neurônios de projeção dos núcleos motores dos nervos cranianos IX e X, formação reticular, região da rafe, complexos coeruleous-subcoeruleous e regiões olfatórias anteriores.

Estágios 3 e 4: A degeneração é exteriorizada para regiões do tronco encefálico sem presença de lesões corticais (estágio 3) ou com afecção inicial da porção antero-medial temporal do mesocórtex (estágio 4). A principal característica do estágio 3 é a afecção dos neurônios da SNc, embora ainda não detectável macroscopicamente pela sua despigmentação, pois o acometimento é restrito a neurônios de projeção mielinizados dos subnúcleos posterolateral e posteromedial. Esta degradação, quando aumentada de intensidade a ponto de ser observada macroscopicamente, caracteriza o estágio 4. Também já há acometimento dos neurônios de projeção do núcleo pedunculopontino, porção basal do telencéfalo, núcleos tuberomamilar hipotalâmicos, amígdala e tálamo. A degradação dos núcleos olfatórios é mais intensa neste estágio, sendo que a grande característica deste é a degradação do mesocórtex anteromedial temporal. Neste momento, de acordo com inúmeros autores, a fase pré-sintomática se torna uma fase clinicamente reconhecível da doença, por meio da manifestação dos sinais e sintomas motores.

Estágios 5 e 6: São estágios mais avançados, característicos de um acometimento severo cerebral, incluindo áreas corticais. Há um aumento da intensidade da lesão em todas as áreas supracitadas e as afecções dos neurônios dopaminérgicos da SNc e das áreas olfatórias são bem detectáveis. A partir do mesocórtex temporal, as lesões atingem áreas do neocórtex, ínsula, córtex cingulado anterior e áreas pré-frontais. A principal característica do estágio 6 é o acometimento de quase todo o neocórtex, áreas pré-motoras, córtex motor primário, 
áreas sensoriais primária e de associação, com participação de áreas auditivas primárias como o giro de Heschl's. Estas lesões em áreas límbicas importantes (amígdala, formação hipocampal, mesocórtex anteromedial temporal) juntamente com lesões em áreas extensas do neocórtex, parecem justificar o declínio das faculdades intelectuais observadas principalmente em fases mais adiantadas da DP.

\subsection{TRATAMENTO DA DOENÇA DE PARKINSON}

Até agora não existe um tratamento eficaz para curar, prevenir ou impedir a progressão da DP. Atualmente são utilizados tratamentos medicamentosos, cirúrgicos e reabilitação, sendo que o mais utilizado ainda é o tratamento farmacológico com utilização da levedopa, um precursor da dopamina; porém, está documentado na literatura que a dosagem maior e uso prolongado da terapêutica dopaminérgica, embora melhore a função motora, provoca efeitos adversos como discinesias (movimentos involuntários), flutuações motoras, disfunção neuropsiquiátricos como demência e depressão, contribuindo para a perda da qualidade de vida (CLARK et; al., 2005,DORSEY, 2007).

O tratamento cirúrgico para DP teve início em 1994 e é destinado às pessoas que estão sofrendo muito com incapacidades físicas (tremores severos e refratários à terapia) e com o uso prolongado de medicamentos com aumento progressivo de dosagem, o que vem provocando efeitos colaterais diversos e perda crescente na eficácia. O procedimento cirúrgico indicado é a Estimulação Cerebral Profunda (Deep Brain Stimulation - DBS) que consiste na implantação de um dispositivo medico conhecido como marca-passo cerebral que envia impulsos elétricos para áreas específicas do cérebro, diminuindo sintomas motores como tremor, rigidez e bradicinesia (KRINGELBACH, 2007; GEORGE 2010).

O tratamento medicamentoso e neurocirúrgico não impede a progressão dos sintomas que prejudicam o equilíbrio, a fala e a locomoção, com a consequente diminuição das condições de realização das AVDs; sendo assim, é importante explorar outras opções de tratamento que podem ser adjuntas ao tratamento medicamentoso e cirúrgico em indivíduos com DP. O exercício físico parece ter pouco impacto na progressão da doença; entretanto, possui um efeito significativo na melhora da funcionalidade, qualidade de vida e prevenção de doenças como 
hipertensão, diabetes, artrose em doença de Parkinson, Alzheimer entre outras (PAHWA \& LYONS, 2007).

O Colégio Americano de Medicina Esportiva (2010) recomenda que uma pessoa idosa deva praticar exercícios fiscos para prevenir e combater as doenças crônicas, demência, depressão e sedentarismo. Dentre os tipos de atividades recomendadas, estão aquelas que envolvam atividades aeróbicas, treinamento de força, flexibilidade e equilíbrio em intensidade leve/ moderada.

Os exercícios físicos para idosos, além de trabalharem a aptidão física e, por consequência, melhorarem a saúde e a qualidade de vida, devem constituir-se em atividades agradáveis, prazerosas e integrativas, visando o bom desempenho das AVDs (SAFONS, PEREIRA e COSTA, 2011).

A Sociedade Brasileira de Medicina do Esporte fornece alguns exemplos práticos de Atividades Físicas e as quantifica num gasto basal de 2.000 Kcal semanais, como podemos ver a seguir:

1-Atividades leves: arrumar a casa, jogar bocha, caminhar vagarosamente;

2-Atividades moderadas: caminhar rapidamente $(5 \mathrm{Km} / \mathrm{h})$, jardinagem, ciclismo $(09 \mathrm{~km} / \mathrm{h})$, dançar, jogar basquete, vôlei adaptado, dança de salão, e TAI CHI CHUAN;

3-Atividades intensas: correr (08 km/h), jogar futebol, nadar;

4-Muito intensas: correr (09 km/h), jogar frescobol.

Em concordância com tais recomendações, o Tai Chi Chuan tem sido recomendado por seus benefícios relacionados à estabilidade postural, equilíbrio dinâmico e mobilidade funcional (HACKNEY, 2007, LI et al., 2012)).

A simplicidade dos movimentos do TCC auxilia na reabilitação para pessoas idosas devido à facilidade de aprendizado, além de trabalhar a maioria das articulações do corpo, sendo uma atividade de baixo risco e impacto, promovendo melhora na alta eficácia, qualidade de vida e mobilidade funcional (HARTMAN et al., 2000).

O estudo de Ll et al. (2012) dá evidências de que a prática de TCC como um tratamento complementar para pessoas com DP pode lhes permitir participar mais plenamente nas suas atividades de vida diária. Os exercícios fisicos como alongamento/flexibilidade, treinamento de força (musculação), Tai Chi Chan (TCC) e dança, são considerados tratamentos complementares da DP, porque têm demonstrado que retardam a deterioração do equilibrio e funções motores, 
melhoram a função cognitiva e prolongam a independência funcional na medida em que melhoram as AVDs. (LIMA, et al., 2013).

\subsection{ESTABILIDADE POSTURAL}

A estabilidade postural parece ser um processo estático, porém, a gravidade provoca oscilações contínuas no alinhamento do corpo, requerendo a atuação do sistema de controle postural para manter a postura ereta e estável (LUNDY-EKMAN, 2008), objetivando a orientação postural e o equilíbrio.

A orientação postural envolve o alinhamento ativo do tronco e da cabeça com relação à gravidade, superfícies de suporte, campo visual e referências internas.

Já o equilíbrio é denominado como estabilidade postural, o que envolve a coordenação de estratégias de movimento para manter o centro de massa corporal sobre a pequena base de apoio fornecida pelos pés durante desestabilizações auto iniciadas ou provocadas (HORAK, 2006). Na figura 2 acima, são demonstrados importantes recursos para o controle da postura: controle dinâmico, processo cognitivo, movimentos estratégicos, estratégias sensoriais e orientação no espaço. No centro da figura, o gráfico demonstra o avanço da idade e a incidência (PAULISTA, 2013).

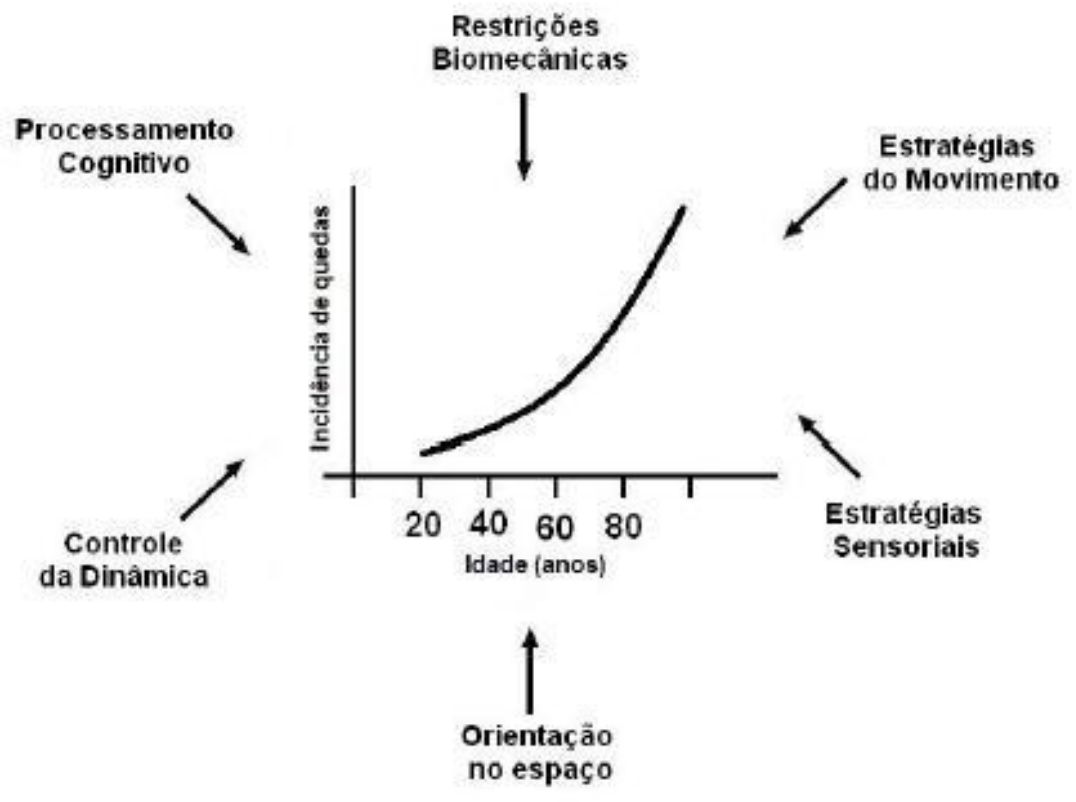

Figura 2 - Gráfico da orientação postural. 
O controle postural é a capacidade que o ser humano tem de exercer suas atividades e manter o corpo em equilíbrio em situações de repouso (equilíbrio estático) e movimento, quando submetido a diversos estímulos (equilíbrio dinâmico), proporcionando estabilidade e orientação (LÓPEZ \& FERNÁNDEZ, 2004)

O processamento do controle postural inicia-se com a orientação, quando as informações sobre a sua trajetória e posição do corpo no espaço são fornecidas por meio de diferentes sistemas sensoriais (visual, vestibular e somato sensorial/proprioceptivo). Assim, o SNC recebe e integra essas informações aferentes, gerando respostas efetivas e reguladas no tempo para a ação estabilizadora. A execução das respostas programadas pelo SNC é feita pelo sistema efetor, composto pelo sistema musculoesquelético (CHANDLER e GUCCIONE, 2002).

Respostas efetivas e reguladoras têm como função a manutenção da estabilidade corporal por meio dos movimentos corretivos e antecipatórios, escolhidos conforme o tipo e amplitude das perturbações impostas ao corpo, a experiência prévia do indivíduo e as demandas determinadas pela tarefa e pelo ambiente (HORAK, 2006).

Os sistemas sensoriais disponibilizam ao SNC informações específicas sobre o movimento e a posição do corpo, sendo que cada sistema fornece uma estrutura de referência específica para o controle postural.

O sistema visual baseia-se nas características externas do ambiente e informa a posição e o movimento de partes do corpo em relação às outras partes e aos objetos circunjacentes do ambiente físico, ajudando a orientar o corpo no espaço, ao referenciar os eixos verticais e horizontais dos objetos ao seu redor (RICCl et. al., 2012).

Já o sistema vestibular é, ao mesmo tempo, um sistema sensorial e motor que envia informações sobre o movimento da cabeça e a direção da gravidade e sobre movimentos óculo-cefálicos (LUNDY-EKMAN, 2008); é sensível a acelerações lineares e angulares, podendo ser divido em três componentes:

- Sistema sensorial periférico que consiste nos órgãos receptores, os quais são divididos em três canais semicirculares que têm a função de detecção de movimentos de rotação da cabeça provenientes da aceleração angular e dois órgãos otolíticos que registram o movimento da aceleração linear e fornecem informações sobre a posição da cabeça em relação à gravidade. As informações de dois órgãos 
otoliticos e três canais semicirculares são aferências sensoriais periféricas transmitidas pelo nervo vestibular, que é um nervo vestíbulo-coclear - VIII nervo craniano - até o processador central composto pelo sistema vestibular central (LUNDY-EKMAN, 2008).

- Processador central, que é formado por quatro núcleos vestibulares localizados bilateralmente na junção da ponte com o bulbo, e por seis vias vestíbulocerebelo e córtex vestibular, que recebem informações proprioceptivas, auditivas, visuais e táteis, além de informações vestibulares (LUNDY-EKMAN, 2008). A partir desses núcleos, as informações são direcionadas para várias regiões: do córtex vestibular passando antes pelo tálamo, por meio de vias vestíbulo-tálamo-corticais, que influenciam na conscientização da posição da cabeça e de seu movimento em conjunto com estímulos visuais e proprioceptivos; vestíbulo-cerebelo, por meio das vias vestíbulo-cerebelares, que recebem informações vestibulares, processando e devolvendo aos núcleos vestibulares para influenciar nos movimentos oculares e nos músculos posturais; núcleos do III, IV, VI e XI nervos cranianos e colículo superior, através do fascículo longitudinal medial, influenciando no movimento coordenado dos olhos e da cabeça; medula espinhal, pelo tratos vestíbulo-espinhais medial e lateral, e irá influenciar na postura; formação reticular, pelas vias vestíbuloautônomas, controlando náuseas e vômitos.

Após o processamento central, o mecanismo de resposta motora entra em ação e repassa as informações aos músculos extraoculares e aos músculos posturais da cabeça e do corpo (LUNDY-EKMAN, 2008).

O sistema vestibular cumpre muitas funções diferentes no controle postural e, ao detectar a posição e o movimento da cabeça, utiliza essas informações para a orientação postural da cabeça e do corpo. A resposta eferente do sistema vestibular estabiliza o olhar através de um movimento gerado pelo reflexo vestíbulo-ocular, enquanto que o controle da posição do centro de massa corporal, tanto nas posições estáticas quanto dinâmicas, bem como a estabilização da cabeça durante movimentos posturais, são obtidos por conexões recíprocas entre os núcleos vestibulares e a medula espinhal, formação reticular, colículo superior e cerebelo (LUNDY-EKMAN, 2008).

Pessoas com deficiências na função vestibular apresentam percepções anormais do movimento. Normalmente relatam que sentem como se estivessem girando ou balançando ou que a sala parece girar ao redor deles. Também podem 
adotar uma postura inclinada, enquanto insistem estar alinhado verticalmente (HERDMAN, 2002).

A deficiência do sistema vestibular pode provocar a labirintite (tontura), que, em virtude do processo natural de envelhecimento, pode provocar quedas (MORETTIN et al., 2007).

O sistema somato sensorial/proprioceptivo é o conjunto de vários receptores que percebem a posição e a velocidade de todos os segmentos corporais, seu contato com objetos externos, inclusive com o solo, além da orientação da gravidade (DUARTE, 2000), que informa os movimentos do corpo e se refere à superfície de sustentação e ao movimento dos segmentos corporais entre si, através de sensores que estão na pele, músculos, tendões, ligamentos, tecidos conectivos das articulações e órgãos internos (WIECZOREK, 2003).

O SNC tem como função selecionar, em diferentes condições, os dados sensoriais mais apropriados para organizar os movimentos corporais, sendo que, de forma geral, os sistemas mais requisitados são o sistema visual e somato sensorial, já que o vestibular atua quando é necessário resolver o conflito de informações sensoriais equivocadas (RICCl et. al., 2012). A deficiência em um destes sistemas poderá causar uma instabilidade postural (UMPHRED, 2009), que pode comprometer as AVDs, devido à dificuldade de realizar trocas posturais.

As pessoas mais afetadas pela instabilidade postural e dificuldades de mobilidade são pessoas com doenças neurodegenerativas como portadores de DP (GRIMBERGEN et. al., 2009; BRONTE-STEWART et. al., 2002).

A manutenção da estabilidade postural em pessoas com DP é analisada por estar relacionada com a mobilidade, como dificuldade de marcha, aumento nas incidências de quedas, disfunções motoras, dificuldades nas AVDs e perda da QVRS (RODRIGUEZ, 2013). Geralmente, a estabilidade postural é verificada na posição estática, sobre diferentes bases de sustentação, com e sem restrição da visão. As variáveis mais analisadas são aquelas relacionadas à velocidade de oscilação do centro de pressão (COP), à amplitude de deslocamentos anteroposteriores (AP) e à amplitude de deslocamento mediolateral (ML). Os valores altos destes testes são indicativos de comprometimento no controle postural, o que pode ocasionar quedas (PIRRTOLA \& ERA 2006). 


\subsection{NÚCLEOS DA BASE E CONTROLE DE EQUILÍBRIO}

Os núcleos da base (NB) são agrupamentos de estruturas cerebrais compostos pela substância negra (porção compacta e porção reticulada), núcleo caudado, putâmen, globo pálido e núcleo subtalâmico - localizado na base do cérebro, que controlam a atividade motora por meio da regulação de impulsos neuromotores que facilitam sua atividade tônica, auxiliando o planejamento e a execução de movimentos sequenciados, como a marcha (GOOBI et al., 2006). Os NB recebem e enviam sinais excitatórios do córtex sensório-motor, cerebelo e do tálamo.

As funções dos NB no controle postural ainda são pouco conhecidas e muito complexas, sendo que algumas das mais importantes são: o armazenamento e a execução automática de planos autônomos, a flexibilidade motora (comportamento de adaptação às mudanças ambientais), a integração somato sensorial, a regulação do tônus muscular, o controle de respostas posturais automáticas e cognitivas, a motivação e alguns dos aspectos emocionais do comportamento (VISSER e BLOEM 2008), além de agirem como controladores do sistema de distribuição de erro (BAEV et al., 2002).

Os NB auxiliam o córtex motor no controle de movimentos por meio de duas vias: a indireta e a direta. A via indireta está envolvida com a iniciação e/ou com a finalização de movimentos; já a via direta, além da iniciação, é responsável pela manutenção do programa motor durante a ação (GRILLNER et al., 2005).

Como a DP é decorrente da degeneração dos neurônios dopaminérgicos da substância negra - parte compacta que provoca um desequilíbrio da atividade inibitória e/ou excitatória do córtex motor, a DP provoca vários comprometimentos motores. Os NB têm uma função principal na formulação e geração de padrões locomotores que garantam a estabilidade dinâmica, liberando graus de liberdade do movimento de acordo com as demandas ambientais (TAKAKUSAKI et al., 2004).

\subsection{INSTABILIDADE POSTURAL NA DP}

A instabilidade postural é umas das principais queixas dos indivíduos com DP (BASSETO et. al., 2008; LAMÔNICA et. al., 2003) e a perda do controle postural nesses pacientes está relacionada com as respostas motoras posturais anormais 
(BRONTE-STEWART, 2002); porém, o mecanismo dessa alteração ainda não está totalmente esclarecido. Estudos buscam compreender se o sistema de controle postural desses pacientes está comprometido em nível de sistemas sensoriais e de integração das informações pelo SNC, ou em nível do sistema efetor.

Segundo LUNDY-EKMAN (2008), a instabilidade postural na DP está relacionada com déficit decorrente da hipocinesia e rigidez do sistema efetor. Já MELNICK (2009) acredita na alteração no processamento dos estímulos sensoriais e, SOARES (2010), defende que alterações no controle postural envolvem distúrbios do processamento motor, informações sensoriais e de coordenação motora.

Os indivíduos com DP na fase inicial apresentam instabilidade postural reduzida ou quase nula, sendo que, com o avanço da doença, o comprometimento da marcha (festinação) é agravado, apesar dos tratamentos farmacológicos. Este comprometimento da marcha caracteriza-se pela alteração do centro de pressão e centro de massa, encurtamento da passada e diminuição da velocidade e por uma tendência a inclinar-se para frente (HELY et. al., 2008; BOONSTRA et.al., 2008).

A posturografia é um método para mensuração da instabilidade postural que auxilia na análise do aspecto funcional do desequilíbrio corporal (VISSER et al., 2008; NEPOMUCENO et al., 2010), o qual utiliza a plataforma de força para mensurar a medida e registro contínuo da oscilação do corpo, descrevendo as posições do centro de pressão (CP) em função do seu deslocamento na superfície, cujos resultados são obtidos a partir da amplitude ântero-posterior (AP) e médiolateral (ML), (DUARTE, 2000).

A posturografia é uma forma de avaliar e quantificar as variações produzidos pelo corpo na tentativa de manter a postura estática. Os testes são aplicados em vários protocolos para a base de suporte (base fechada, base aberta), com manipulação da visão (olhos abertos e olhos fechados), sendo que o tempo de aquisição de dados varia muito com o protocolo e o objetivo do estudo; porém, de maneira geral, o tempo de permanência na plataforma varia de 20 a 60 segundos (DAVID \& MOTA, 2009).

Normalmente a plataforma é colocada no chão, com sua superfície superior nivelada com o solo, para que seja possível posicionar-se normalmente sobre ela. As plataformas de força retangulares medem geralmente as três componentes da FRS (força de reação do solo). 
Plataforma de força (Figura 3) é composta por duas superfícies rígidas, uma superior e outra inferior, interligadas pela placa sobre sensores de força do tipo célula de carga, com cada um dos quatros sensores distribuídos simetricamente para medir três componentes de força, que são: Fx (amplitude médio-lateral), Fy (amplitude ântero-posteior) e Fz (vertical) (BARELA; DUARTE, 2011).

O centro de pressão (COP) é obtido a partir das componentes da FRS e das componentes do momento de força, ponto de aplicação da resultante das forças verticais que age sobre a superfície de suporte. $\mathrm{O}$ dado do $\mathrm{CP}$ refere-se à uma medida de posição definida por duas coordenadas na superfície da plataforma, que são identificadas em relação à orientação do indivíduo que se encontra sobre a plataforma: direção ântero-posterior (AP) e direção médio-lateral (ML).

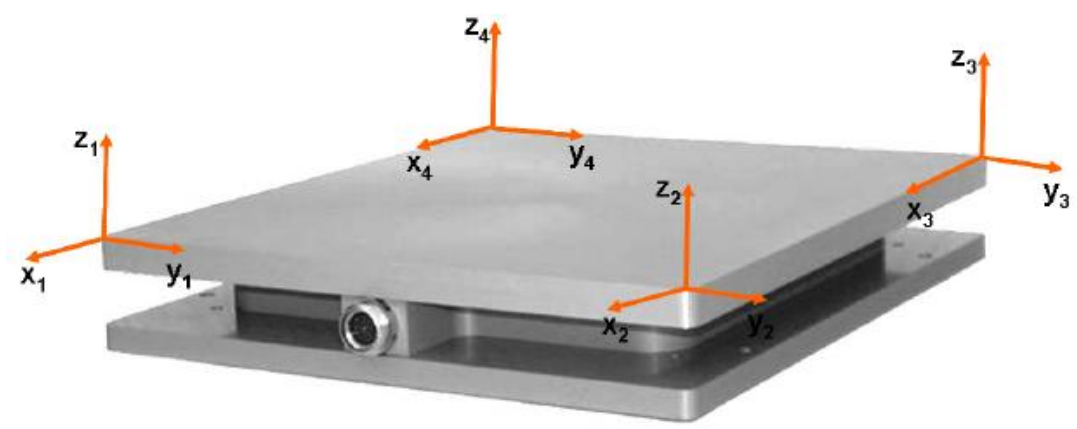

Figura 3 - Plataforma de força retangular mostrando as superfícies superior e inferior e a representação das forças obtidas por meio dos sensores em cada um dos cantos da plataforma (BARELA E DUARTE, 2011).

Existem vários fabricantes de plataformas de força, como AMTI, Bertec e Kistler, EMG System e Cefise, que fabricam um dos dois tipos de plataforma de força: a de cristal artificial e a de células de carga (strain gauges). A plataforma de força de cristal artificial utiliza transdutores de força de quartzo, os quais têm a propriedade de gerar um sinal elétrico, quando submetidos à uma carga mecânica (Nigg \& Herzog, 2007). Já a plataforma de força de células de carga utiliza transdutores do tipo strain gauge, que é um dispositivo elétrico que tem sua resistência elétrica variada em função da deformação mecânica. Porém, apesar de algumas diferenças entre os componentes destas plataformas de força, tais diferenças não interferem na análise dos resultados. 
Tabela 1 - Principais plataformas de força comercialmente disponíveis.

\begin{tabular}{llcc}
\hline \multicolumn{1}{c}{ Fabricante } & \multicolumn{1}{c}{ Tipo } & $\begin{array}{c}\text { Dimensões } \\
(\mathrm{mm})\end{array}$ & $\begin{array}{c}\text { Amplificadores } \\
\text { Internos }\end{array}$ \\
\hline AMTI & Células de carga & $464 \times 508$ á $610 \times 1220$ & Não \\
Bertec & Células de carga & $464 \times 508$ á $900 \times 900$ & Sim \\
Kistler & Cristal piezoelétrico & $500 \times 500$ á $600 \times 900$ & Sim \\
EMG System & Células de carga & $500 \times 500$ & Sim (1 modelo) \\
Cefise & Células de carga & $600 \times 600$ & Não
\end{tabular}

Para obtenção de dados fidedignos a instalação correta da plataforma é essencial, devendo esta ser fixada em superfície rígida e plana, sem qualquer tipo de vibração, devendo a superfície superior ficar no mesmo nível do piso, para que o voluntário possa locomover-se com segurança.

Para aquisição de dados é necessário, além da plataforma de força, um computador que contenha software compatível, condicionador de sinais (amplifica e filtra os sinais) e conversor A/D que converte o sinal analógico (sinal contínuo no tempo) da plataforma de força para sinal digital (sinal discreto, definido apenas em certos intervalos de tempo), para ser processado pelo computador.

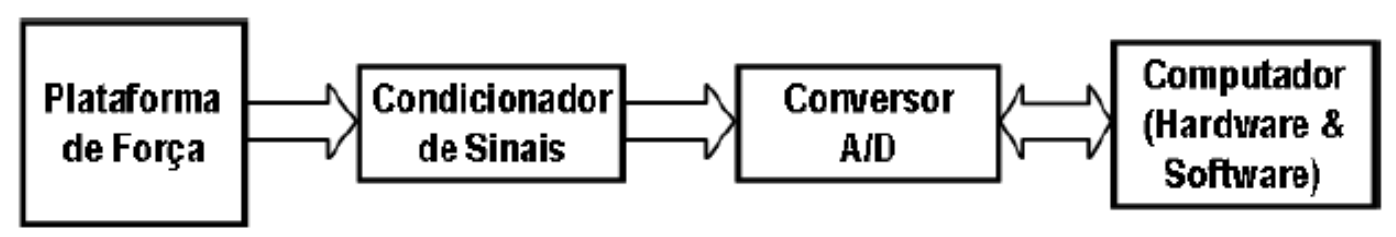

Figura 4- Representação esquemática de um arranjo experimental típico para aquisição e processamento do sinal com o uso de plataforma de força (BARELA E DUARTE, 2011).

\subsection{TAI CHI CHUAN}

O Tai Chi Chuan (Taijiquan/Mandarim e 太極拳/Chinês), onde as letras/ideogramas significam respectivamente: Tai (太) supremo, grandioso; Chi (極) viga mestre, eixo, ápice, extremidade, polo ou origem; Chuan (拳): punho, golpe, 
boxe, luta marcial (KURAMOTO 2006), é classificado como uma Ginástica Taoísta e como estilo de Kung Fu - Wushu.

Inicia-se com uma lenda, quando o monge observou uma luta entre uma garça e uma serpente, quando a ave tentava atacar a serpente várias vezes; porém, devido à agilidade, flexibilidade e precisão dos movimentos, a serpente sempre conseguia livrar-se dos ataques, desviando-se e esquivando-se. Observando a luta, o monge percebeu que flexibilidade e suavidade podem superar rigidez e dureza, levando a enfatizar a harmonia entre o flexível (Yin) e o forte (Yang), para desenvolvimento do equilíbrio da mente e do corpo, incluindo o controle da respiração, movimentos naturais e a prática da meditação (Meditação em movimento), que recebeu o nome de Tai Chi Chuan (PEREIRA, 2005). A estruturação formal do TCC só ocorreu no século XIII d.c., com o trabalho do sacerdote taoísta Zhang San Feng, que sistematizou o TCC Estilo Wudang a partir da síntese entre o Kung fu Shaolin e a Ginástica Taoísta. No final de década de 50 todos os estilos foram classificados como esportes pelo Comitê Esportivo Nacional da China (órgão equivalente ao Ministério dos Esportes), e sua prática supervisionada por Professores de Educação Física, com o objetivo de popularizar e regulamentar a prática, o que resultou na criação do TCC estilo Yang com 24 movimentos simplificados. Tal criação e regulamentação foi publicada em vários cadernos pedagógicos oficiais e traduzidos para vários idiomas com o nome Wushu - Guia Chinês para Saúde e Preparo Físico da Família. (TUNG, 1981), conforme ilustra a tabela 2.

Tabela 2 - Evolução histórica do TCC (Fonte - PEREIRA et al., 2004).

\begin{tabular}{|c|c|c|c|c|}
\hline Fase & Período & Local & Magistério & Características \\
\hline Estruturação & Séc.VII- XVII d.c. & Templo & Monges & $\begin{array}{c}\text { Arte Marcial, } \\
\text { Treinamento } \\
\text { religioso }\end{array}$ \\
\hline Disseminação & Séc.XVII- XX d.c. & Família & $\begin{array}{l}\text { Mestres e } \\
\text { Leigos }\end{array}$ & Arte Marcial \\
\hline Disseminação & Séc.XVII-XX d.c. & Família & $\begin{array}{c}\text { Mestres e } \\
\text { Leigos }\end{array}$ & Arte Marcial \\
\hline Formalização & 1956 & Escola & Professores & $\begin{array}{c}\text { Arte Marcial, } \\
\text { Exercício Físico e } \\
\text { Exercício } \\
\text { Terapêutico }\end{array}$ \\
\hline
\end{tabular}


O conceito da saúde é diferente para as culturas ocidentais e orientais. Para os ocidentais a saúde é "O estado completo de bem estar físico, mental e social (VERAS, 1998); para os orientais, como os chineses, a saúde está relacionada com o sistema de energia que deve estar em harmonia com o mapa do corpo, que é uma estrutura básica onde a energia é colocada em primeiro lugar na sequência que se segue: energia (chi) $\rightarrow$ sangue $\rightarrow$ células $\rightarrow$ tecidos $\rightarrow$ órgãos $\rightarrow$ funções $\rightarrow$ relações $\rightarrow$ todo (KIT, 1996). Assim, para os chineses uma vida calma para idosos não significa estagnação física e por isso o TCC pode ser aprendido e praticado por pessoas com idade avançada (TSANG, 2003).

O TCC chegou ao Brasil em 1960, trazido por Wong Sun Keung; atualmente sua prática é muito difundida, devido a ser uma atividade física de fácil aprendizado, segura, eficaz e de baixo custo. Hoje o TCC é praticado em todo o país em academias, escolas, parques, escolas, praças e, principalmente, em projetos sociais voltados para pessoas idosas (MATIDA et al., 2013).

A partir da regulamentação profissional da Educação Física (1998), a cultura física popular e tradicional foi estimulada, incluindo as artes marciais, o que tornou a presença do Educador Físico obrigatória durante o processo de ensino e aprendizagem de qualquer modalidade (CONFEF, 2002).

O TCC é uma arte marcial que envolve movimentos lentos e controlados, com manutenção de diferentes posturas que envolvem a rotação do tronco, flexão e extensão do quadril e dos joelhos, a distribuição de peso através de movimentos coordenados dos braços e de um alinhamento e controle postural; além disso, os exercícios exigem atenção, concentração e controle de respiração, o que beneficia o equilíbrio em pessoas com DP (COELHO et al., 2013).

A prática de TCC estilo Yang de 24 movimentos simplificados foi trazida pelo mestre Wong Sun Keung na década de 60 para as cidades de São Paulo e Rio de Janeiro, onde existia uma considerável quantidade de imigrantes chineses. É caracterizada como uma atividade de baixo risco, com boa eficiência para a saúde, de baixo custo, que não requer equipamentos ou vestimentas especiais e pode ser praticada em qualquer lugar, como parques, escolas, academias, praças, em programas específicos para populações especiais, sendo que, em sua grande maioria, são oferecidos gratuitamente por profissional de educação física especializado (XAVIER, 2008). 
Segundo LAN et al. (2002), o TCC proporciona benefícios na função cardiorrespiratória, aumento da força, da flexibilidade, melhora do equilíbrio, aumento do VO2, melhora no perfil psicossocial. Além disso, a prática durante longo prazo ajuda a minimizar o declínio do desempenho funcional, a demência e os efeitos do sedentarismo, melhorando a mobilidade e diminuindo as dores.

\subsection{BENEFÍCIOS DO TAI CHI CHUAN}

O primeiro estudo na literatura científica documentando as respostas fisiológicas do TCC foi publicado por BROWN (1989). Desde então, os potenciais efeitos benéficos do TCC têm sido investigados, tanto do ponto de vista físico quanto psicológico (SUN, XU \& XIA, 1989).

LAN et al., (1998) num programa de TCC com estilo Yang com duração de um ano com frequência de cinco vezes por semana, demonstrou que a prática regular do TCC é eficiente para condicionamento físico dos idosos.

LI et al. (2001) demonstraram que a prática regular do TCC teve feitos positivos no controle do equilíbrio e da flexibilidade em pessoas com DP, em comparação com grupo controle (sedentário), apresentando resultados melhores nos testes de flexibilidade "sentar e alcançar" e no equilíbrio unipodal, tanto na perna direita quanto na esquerda, com olhos fechados.

LAN et al., (2002) num programa de TCC com estilo Yang cuja duração foi de seis meses com frequência de cinco vezes por semana, demonstraram que a prática regular do TCC melhora a força muscular dos extensores de joelho e o equilíbrio postural, evitando quedas.

PEREIRA et al., (2008), demostraram que idosas que praticaram TCC estilo Yang durante doze semanas, em um programa cuja frequência era de três vezes por semana, tiveram resultados superiores no equilíbrio postural e no teste de apoio unipodal, melhorando a força nos músculos extensores do joelho.

Porém, LELARD et al., (2010), compararam durante três meses um programa de TCC e um programa de treinamento de equilíbrio em um grupo de idosos, com uma frequência de duas vezes por semana, e concluíram que o período de intervenção foi insuficiente para verificar melhorias posturais e melhoria na marcha em ambos os grupos nas condições de olhos abertos e olhos fechados. Na condição 
de olhos fechados foram verificados piores valores quando comparados com olhos abertos em ambos os grupos. Porém, ao verificarem a diferença entre a condição de olhos abertos e fechados em ambos os grupos, concluíram que o treinamento de TCC pode diminuir os efeitos deletérios do envelhecimento na ausência da informação visual sobre o controle postural.

O recente estudo de $\mathrm{Jl}$ et al., (2015) A Meta-Analysis on the Efficacy of Tai Chi in Patients with Parkinson's Disease between 2008 and 2014, avaliou evidências sobre o efeito do Tai Chi para a doença de Parkinson (DP) em nove estudos, os quais demostraram resultados favoraveis na função motora e equilibrio no teste TUG, BBS, apoio unipodal; no entanto, não há evidências que o TCC melhora a velocidade de marcha, comprimento do passo e qualidade de vida.

\subsubsection{Benefícios Psicológicos do Tai Chi Chuan}

Nos estudos de Kutner et al. (1997) e Gomes et al. (2004), praticantes de TCC demonstraram aumento da confiança no equilíbrio e na realização de movimentos. Entre os efeitos notados nas AVDs estão: redução do estresse, sensação de vigor e força, melhor coordenação e equilíbrio, diminuição da ansiedade, aumento da percepção do corpo e de diferentes facetas do bem-estar, fazer coisas que achavam que não eram capazes, melhor percepção da dor, aumento da atenção e confiança, relaxamento, melhor desempenho mental e senso de realização.

\subsection{TAI CHI CHUAN E FORÇA MUSCULAR NA DP}

Com o avanço da idade e com a pouca atividade física, a força muscular vai apresentando uma redução gradual, acompanhada pela perda da massa muscular (sarcopenia), que se inicia na terceira década de vida e acelera a partir da quinta década, acompanhada pelo aumento da gordura, principalmente na região abdominal (BARBOSA et al., 2001).

Segundo MATSUDO et al. (2001), a perda da massa muscular e consequentemente da força muscular acontece a uma taxa de $15 \%$ por década entre os 60 e 80 anos e $30 \%$ por década a partir dos 80 anos; ao mesmo tempo, a 
progressão das perdas de massa muscular faz com que, aos 90 anos, o indivíduo chegue a diminuir em até $50 \%$ sua massa em relação aos valores da juventude, provocando a deterioração do desempenho funcional, além de aumentar a incidência de doenças crônicas como diabetes e osteoporose, os distúrbios do equilíbrio e da marcha e também o aumento de quedas.

Devido a problemas neurológicos, a mobilidade e a estabilidade postural ficam comprometidas e levam à diminuição do condicionamento físico e, consequentemente, à obesidade, dores articulares, constipação, dificuldades nas AVDs, isolamento social e depressão (SETHI, 2002).

Estudos têm demonstrado a eficiência do exercício físico em portadores de DP, com o aumento da aptidão física e da capacidade de deambulação, promovendo maior autonomia nas AVDs por um maior período de tempo (STANKOVIC et al., 2004 e SMIDT 2005). O ganho de força nos membros inferiores ajuda a melhorar o desempenho em diversas atividades diárias, tais como levantar da cadeira, sair da cama, caminhar, subir e descer escada, entrar e sair de automóveis, desviar de obstáculos, além de melhorar o equilíbrio e o controle postural, o que previne quedas. A fraqueza primária é a consequência das alterações dos padrões de ativação eletrofísica de grupamentos de músculos agonistas e antagonistas, que provocam incapacidade de coordenar as unidades motoras; já a fraqueza secundária acontece devido à inatividade física decorrente da progressão da doença e do avançar da idade. Paralelamente, o fortalecimento dos membros superiores ajuda nas tarefas de cuidados pessoais, na arrumação da casa e no transporte de objetos, auxiliando na manutenção da independência funcional para as AVDs e melhorando a qualidade de vida (RIKLI, 2007).

Portadores de DP normalmente aparentam ter menos força muscular do que os indivíduos saudáveis de mesma faixa etária, segundo o estudo da O'BRIEN et al.(2008), sendo que a fraqueza muscular pode ser de efeitos primários e secundários da condição neurodegenerativa da DP.

\subsection{TAI CHI CHUAN E EQUILÍBRIO EM DP}

Segundo SHUMWAY-COOK \& WOOLLACOTT (2010), o equilíbrio pode ser definido como uma habilidade de controlar e corrigir o centro da massa em reação à 
base de sustentação, que pode ser em movimento (equilíbrio dinâmico) ou em repouso (equilíbrio estático). As manutenções do equilíbrio dependem da integração e coordenação de subsistemas sensoriais, que são o sistema visual, proprioceptivo e vestibular (SHUMWAY-COOK \& WOOLLACOTT, 2010).

Com o avanço da idade, a estabilidade postural diminui, provocando dificuldade da mobilidade e aumento nas quedas. Para melhorar o equilíbrio tem sido indicada a prática de exercício físico, em particular o TCC (ROBERTSON et al., 2001).

O TCC é considerado pela literatura como uma atividade física tradicional chinesa constituída de movimentos graciosos e com uma sequência contínua, de modo que o corpo sempre mude de posição. Como resultado, temos movimentos em pé com baixo centro de gravidade, os quais proporcionam uma coordenação respiratória com controle mental aliado aos movimentos. Assim, há uma interação contínua entre a mente e os movimentos corporais, proporcionando benefícios na força de membros inferiores, flexibilidade, capacidade respiratória, equilíbrio postural e redução de quedas (KURAMOTO 2006; PEREIRA et al., 2008). 


\section{MATERIAIS E MÉTODOS}

\subsection{TIPO DE ESTUDO}

A pesquisa foi caracterizada, quanto à sua natureza, como uma pesquisa aplicada que, de acordo com Thomas e Nelson (2012), tende a remeter a problemas e resultados imediatos que poderão ser utilizados em ambientes reais. O estudo caracterizou-se como uma pesquisa quantitativa, conforme Serapioni (2000). A abordagem quantitativa atua em níveis de realidade e tem como objetivo trazer à luz dados, indicadores e tendências observáveis. A pesquisa foi quase-experimental, com grupo controle (THOMAS \& NELSON, 2012).

\subsection{AMOSTRA}

A amostra de conveniência foi composta por indivíduos com Doença de Parkinson, residentes no Distrito Federal e entorno, por meio de chamada pública nos centros de tratamento de distúrbios de movimentos, Associação de Parkinson de Brasília e clínicas particulares.

Depois da divulgação do projeto nas redes sociais, contatos e distribuição de panfletos nas clínicas e Associação de Parkinson de Brasília, foram contatados 52 indivíduos com DP, sendo que cinco não demostraram interesse em participar do programa, (ver figura 5).

Após a triagem foram recrutados 47 indivíduos com diagnóstico de DP para avaliação inicial, porém houve perda amostral já que três indivíduos não preencherem os critérios de inclusão, dois relataram dificuldade no deslocamento (transporte), um foi fazer tratamento no exterior e dois por agravamento da doença, o que resultou em 39 indivíduos que foram distribuídos de forma aleatória em grupo experimental $(n=23)$ e grupo controle $(n=16)$. Participaram do programa os indivíduos com classificação da doença entre os estágios 1 a 3 (H\&Y), fisicamente aptos e dispostos a cumprir o programa de amostragem por conveniência. 
Recrutamento de Amostras

- Contato telefônico após divulgação de panfletos do projeto nas redes sociais, clinicas e Associação de Parkinson de Brasília $(\mathrm{n}=52)$

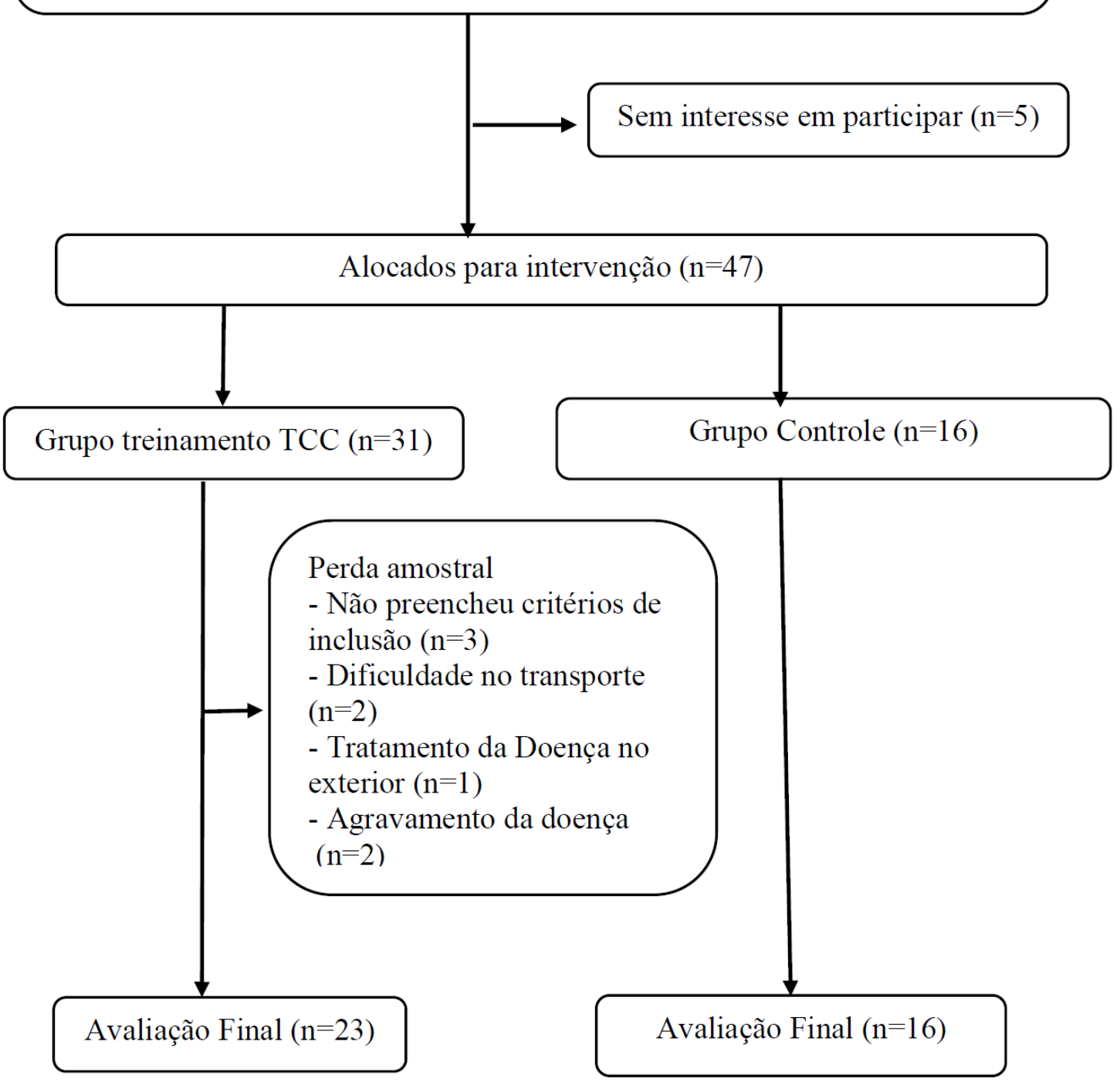

Figura 5 - Fluxograma que demonstra a organização da amostragem e divisão de grupos.

O estudo foi aprovado no Comitê de Ética em Pesquisa com Seres Humanos da Faculdade de Ciências da Saúde da UnB, o qual é reconhecido pela Comissão Nacional de Ética em Pesquisa, através do parecer de № 52721415.2.9999.0030.

\subsection{CRITÉRIOS DE INCLUSÃO E EXCLUSÃO}

Os critérios de inclusão foram: 
1- Diagnóstico clínico da DP de acordo com os CBCL - Critérios de Banco de Dados de Cérebro de Londres (HUGHES et al., 1992);

2- Participar dos testes pré e pós intervenção;

3- Apresentar classificação entre os estágios 1 a 3 na escala de H\&Y;

4- Estar clinicamente estável, sem comprometimento cognitivo (MME);

5- Capacidade de andar/caminhar (deambular) e manter-se em pé de forma independente e segura;

6- Disponibilidade para participação das atividades propostas pelo programa;

7- Residir no Distrito Federal e/ou Entorno.

Os critérios de exclusão foram:

1- Patologias traumato-ortopédicas;

2- Obesidade extrema $(\mathrm{IMC}>40)$;

3- Uso de marca-passo cardíaco;

4- Artroplastia de joelho ou quadril;

5- Fratura óssea ou lesão muscular nos últimos 12 meses;

6- Ter realizado a prática de TCC nos últimos 06 meses;

7- Problemas de locomoção.

\subsection{VARIÁVEIS}

Variável independente: Tai Chi Chuan.

Variáveis dependentes: equilíbrio estático e dinâmico (velocidade do COP, amplitude AP e Amplitude ML).

Variável controle: Estágio da doença.

\subsection{LOCAL}

Os procedimentos para avaliação pré e pós foram executados em três visitas: visita "A", para avaliação da composição corporal e avaliação da estabilidade postural, a qual foi realizada no laboratório de Análise do Movimento Humano (Faculdade de Educação Física - UnB); visita "B", para realização de testes 
funcionais de equilíbrio dinâmico (TUG) e de Escala de Equilíbrio de Berg, realizada no Centro Olímpico da UnB.

Os testes foram efetuados no período matutino, entre 08:00 horas e 12:00 horas, divididos em dois pólos, o que permitiu atender dois voluntários por hora, tendo sido agendados 6 voluntários por dia, por motivo de segurança.

As intervenções de Tai Chi Chuan foram realizadas na sala de dança do Centro Olímpico da UnB, duas vezes por semana (segunda e quarta), no período matutino. Por motivo de segurança, a turma foi divida em duas, uma com 16 indivíduos e outra com 15 indivíduos.

\subsection{CUIDADOS COM MEDICAÇÃO}

Todos os participantes foram testados e treinados no estado ON de medicação, ou seja, participaram dos testes e treinamentos entre $1 \mathrm{~h}$ e 1,5h após o uso dos medicamentos para a DP, visando minimizar as dificuldades sobre a performance.

\subsection{INSTRUMENTOS DE AVALIAÇÃO}

\subsubsection{Anamnese}

Os questionários foram respondidos pela pessoa ou cuidador/familiar responsável e eram compostos das seguintes informações:

1 - Identificação e característica;

2 - Condição Clínica.

\subsubsection{Mini Exame do Estado Mental}

Para avaliação do estado cognitivo foi utilizado o Mini Exame do Estado Mental (MEEM), que é um questionário para verificar a presença ou não de confusão mental crônica (demência); tal instrumento constitui-se de 10 itens divididos em sete 
categoriais: orientação para tempo, orientação para local, registro de três palavras, atenção e cálculo, recordação das três palavras, linguagem e praxia (realização de movimentos/gestos coordenados e eficazes) viso-construtivo (ROBISNSON \& MCHUGH, 1975). O escore do MEEM varia de 0 a 30 pontos, sendo que valores mais baixos apontam para possível déficit cognitivo.

Foi estabelecido como critério para inclusão no estudo o escore $>24$ pontos, mas, já que o teste sofre influência do nível de escolaridade, os escores para inclusão foram ajustados para $>13$ pontos, para indivíduos analfabetos (BRUCKI et al., 2003).

\subsubsection{Avaliação do Exame Motor da Escala Unificada da Doença de Parkinson (UPDRS)}

Para avaliar e monitorar sintomas motores da DP foi utilizado o questionário UPDRS seção III (FAHN et. al., 1987), composto por 14 itens (voz, expressão facial, tremor em repouso, tremor postural ou ação nas mãos, rigidez, bater dedos continuamente (polegar no indicador), movimentos de mão, movimentos rápidos alternados das mãos, agilidade da perna, levantar da cadeira, postura, marcha, estabilidade postural e bradicinesia e hipocinesia corporal. Cada item tem pontuação de 0 (normal) a 4 (pior deficiência), com uma pontuação total máxima de 56 pontos.

\subsubsection{Avaliação da Estabilidade Estática}

A avaliação da estabilidade estática foi realizada no Laboratório de Análise do Movimento Humano da FEF-UnB, utilizando uma plataforma de força Accusway Plus da marca AMTI (Advanced Medical Technology Inc, Watertown, MA), com capacidade de até $180 \mathrm{~kg}$ e dimensões de $50 \times 50 \mathrm{~cm}$.

Os testes foram efetuados com plataforma devidamente calibrada conforme a orientação do fabricante, tendo sido utilizado o software AMTI Balance Clinic, com frequência de amostragem de $100 \mathrm{~Hz}$ e os dados sendo filtrados a um filtro passabaixas de $10 \mathrm{~Hz}$.

$\mathrm{Na}$ avaliação, as participantes foram submetidas a quatro condições experimentais, testadas em ordem aleatória (figura 5): 
- Base aberta com olhos abertos (BAOA);

- Base aberta com olhos fechados (BAOF);

- Base fechada com olhos abertos (BFOA) e;

- Base fechada com olhos fechados (BFOF).
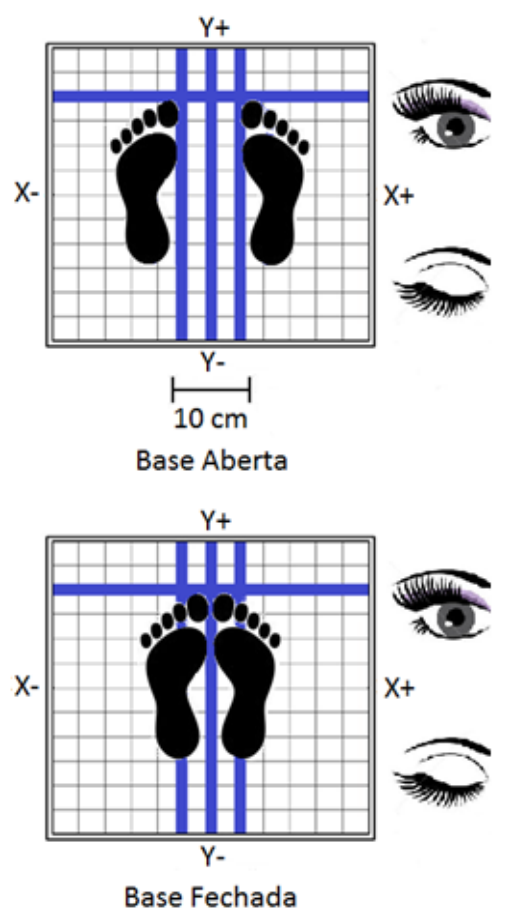

Figura 6- Esquema sobre as posições dos pés e condições dos olhos.

Os voluntários foram posicionados no centro da plataforma de força, com braços relaxados ao lado do corpo e descalços, a uma distância de 2 metros do ponto fixo marcado na parede na altura dos olhos e foram instruídos para olhar fixamente no ponto marcado com postura estática durante 30 segundos. Foram feitas três medições para cada protocolo, num intervalo aproximando de 30 segundos e, para auxiliar no posicionamento, foram feitas marcações com fita crepe sobre a plataforma, uma linha na direção da ML e três linhas na direção AP.

A linha do eixo $X$ na plataforma indicava o limite anterior dos pés e as linhas do eixo $Y$ indicavam a abertura da base de suporte.

$\mathrm{Na}$ condição de base aberta, os voluntários deveriam posicionar os seus pés de forma que a borda medial dos mesmos ficasse próxima às linhas laterais, as quais estavam afastadas a uma distância de $10 \mathrm{~cm}$. Já na condição de base fechada, por sua vez, os pés deveriam ficar justapostos sobre a linha intermédia. 
Durante a aferição o avaliador sempre se posicionava do lado da plataforma para auxiliar na segurança daqueles participantes que demonstravam comprometimento do equilíbrio.

Para interpretação da estabilidade postural foi selecionada a plataforma de força Accusway Plus da marca AMTI (Advanced Medical Technology Inc, Watertown, MA), com capacidade de $180 \mathrm{~kg}$ e dimensões de $50 \times 50 \mathrm{~cm}$ para mensuração de três variáveis: Velocidade de COP, que é a velocidade do deslocamento do centro de pressão da pessoa sobre a plataforma, Amplitude - AP COPx, que mede a variação do centro de pressão no sentido ântero-posterior e Amplitude ML COPy: que mede a variação do centro de pressão no sentido médio-lateral.

\subsubsection{Timed Up And Go (TUG)}

Este teste foi utilizado para avaliar a bradicinesia na marcha (DIBBLE et al., 2009), a mobilidade funcional e o equilíbrio dinâmico (PODSIALDO e RICHARDSON, 1991); é mensurado o tempo gasto para o indivíduo levantar de uma cadeira com $45 \mathrm{~cm}$ de altura, com encosto, sem apoio para braço, caminhar 2,44 metros medidos desde a ponta da cadeira até a parte anterior do marcador $=$ cone, caminhar de volta até a cadeira e sentar-se (RIKLI e JONES, 2008), sendo que o objetivo é caminhar o mais rápido possível (sem correr) em volta do cone, voltar para a cadeira e sentar-se. Foram registradas 3 tentativas, sendo que o menor tempo foi utilizado para avaliar o desempenho.

Instrumentos: cronômetro, fita métrica, cone (ou outro marcador) e cadeira com encosto, sem apoio para braços, com uma altura de aproximadamente $43 \mathrm{~cm}$ até $\mathrm{o}$ assento, como ilustra a figura 7 .

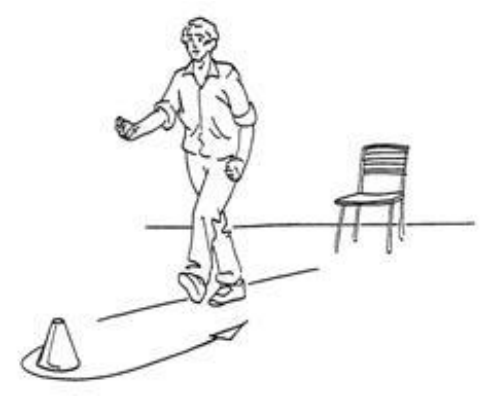

Figura 7 - Teste Time Up and Go - (Fonte - RIKLI e JONES, 2008). 


\subsubsection{Escala de Equilíbrio Funcional de Berg (EEB)}

A escala de equilíbrio de Berg é utilizada para avaliar o equilíbrio e risco de quedas, avaliando habilidades funcionais do indivíduo em 14 testes: sentar, levantar, permanecer em pé, alcançar, transferir-se de uma cadeira para outra, girar $360^{\circ}$, pegar um objeto no chão, olhar sobre os ombros à direita e à esquerda, ficar sobre apoio unipodal, ficar parado com um pé à frente do outro e simular subida em degrau com o pé direito e esquerdo.

Cada item da escala é composto por cinco alternativas que variam de 0 a 4 pontos, sendo 0 a incapacidade máxima da realização da tarefa e 4 a realização perfeita da tarefa (BERG,1992), tendo uma pontuação máxima de 56 pontos, que significa baixo risco de queda e um índice menor ou igual a 36 pontos que significa $100 \%$ do risco de cair.

De acordo com Berg (1989) esta escala possui alta confiabilidade (0.96) com relação a outros testes funcionais de equilíbrio, como: "Timed Up and Go" (0.76) e Escala de Equilíbrio de Tinetti (0.91).

Escala de Berg foi traduzida por Miyamoto et al., (2004) para o português, os quais concluíram que sua versão brasileira é confiável para a avaliação funcional do equilíbrio de idosos brasileiros.

\subsection{PROCEDIMENTOS}

\subsubsection{Coleta de Dados e Intervenção}

A coleta de dados ocorreu de acordo com o seguinte cronograma:

$1^{\text {a }}$ semana - Acolhimento dos voluntários e demonstração do programa.

$2^{\text {a }}$ à $4^{\text {a }}$ semanas - Coleta de dados e bateria de pré-testes (desempenho funcional, questionários, plataforma de força, Escala de equilíbrio de Berg)

$5^{\mathrm{a}}$ à $18^{\mathrm{a}}$ semana - Foram realizadas as intervenções de TCC e alongamento, com frequência de duas vezes por semana e 1 h de duração cada aula (PEREIRA et al., 2008). 
$19^{\mathrm{a}}$ e $21^{\mathrm{a}}$ semanas - Coleta de dados e bateria de pós-testes (desempenho funcional, questionários, composição corporal, plataforma de força, Escala de equilíbrio de Berg)

\subsubsection{Intervenção Tai Chi Chuan}

Após o período de triagem os voluntários foram divididos em dois grupos, de forma aleatória, a saber: Grupo experimental ( $G E / n=23)$ e Grupo controle $(\mathrm{GC} / \mathrm{n}=16)$. O período de familiarização com os exercícios foi de duas semanas, seguidas de 12 semanas da prática de Tai Chi Chuan (TCC), tendo sido o protocolo usado de acordo com a metodologia apresentada por Pereira et al., (2010), com estilo Yang de 24 movimentos adaptados para população com necessidades especiais. A intensidade foi leve, com exercícios e coreografias simples e pouca mudança de direção.

Durante a familiarização e treinamento foram expostos a história, os fundamentos e os benefícios do TCC para a saúde, além de demonstrados movimentos de cumprimento e de preparação (meditação) para a prática do TCC (PEREIRA et al., 2008) como ilustra a figura 8:

1- Posição Wu Chi; (coluna ereta, respiração e concentração no centro de equilíbrio).

2- Posição fundamental: flexionar o joelho e afastar a perna esquerda;

3 - Posição Abraçar a Árvore;

4- Posição buscar a energia Yang (mãos buscam o céu);

5- Posição Buscar a energia Yin (mãos buscam a terra);

6- Posição recolher as energias Yin e Yang ao centro Tai Chi (umbigo, centro do equilíbrio);

7 - Posição fundamental (coluna ereta, respiração e concentração no centro de equilíbrio). 


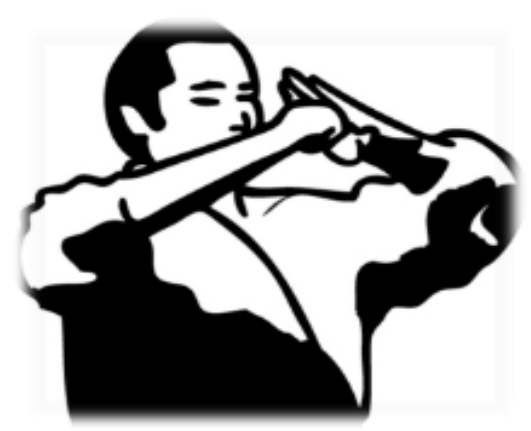

Figura 8 - Posição fundamental.

Durante a semana de familiarização os voluntários realizaram movimentos repetitivos, com sequência de movimentos, controle de respiração e de postura (figura 9).

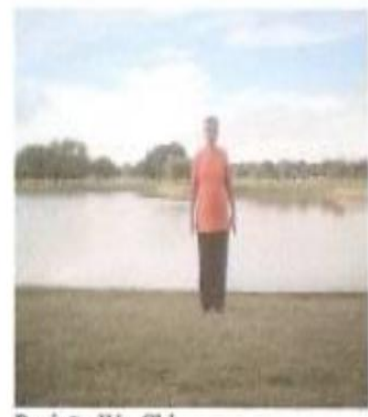

Posiçâo Wu Chi

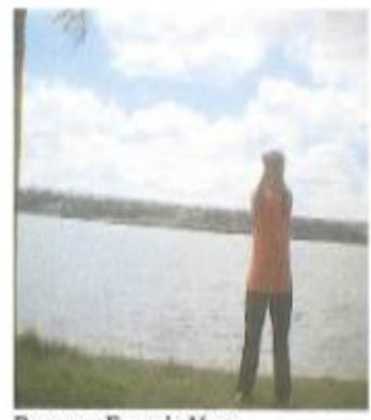

Buscar a Energia Yang

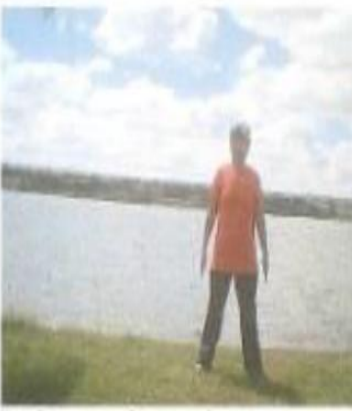

Posiçảo Fundamental: separar Pema Esquerda

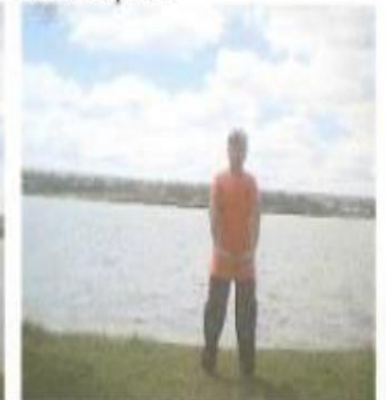

Buscar a Energia Yin

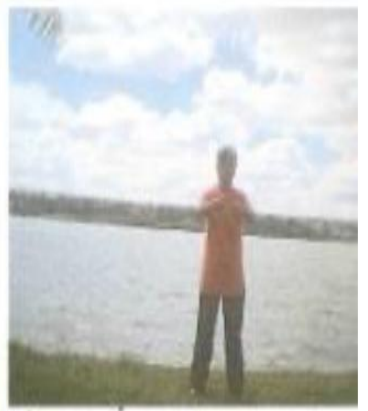

Abraçar a Arvore

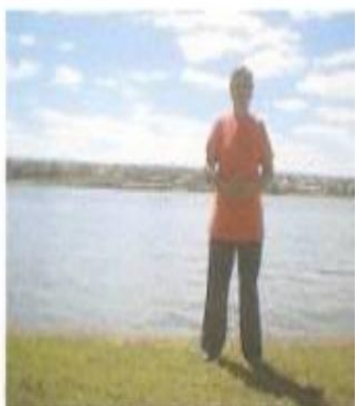

Recolher as Energias Yin e Yang ao Centro Tai Chi (umbigo)

Figura 9 - Preparação no Tai Chi Chuan. Fonte: PEREIRA et al. (2008).

\subsubsection{Protocolo TCC}

Os programas de TCC serão no estilo Yang, terão duração de 12 semanas com aulas de 50 minutos cada e com uma frequência de duas práticas semanais, as 
quais serão ministradas dentro do padrão convencional da aula de Educação Física. Serão compostas por exercícios simples, coreografias curtas com poucas mudanças de direção e com característica progressiva. Foi solicitado aos participantes o uso de roupas confortáveis e calçados adequados para a prática de exercício físico.

\subsubsection{Estrutura da Aula}

a) Aquecimento com duração de 10 minutos, onde foram utilizados exercícios "Ba Duan Jin", Yijinjing - "Alongamento e Flexibilidade", e Lian Kung - (18 movimentos terapêuticos), com exercícios educativos que enfatizaram 0 alongamento muscular, a flexibilidade e também os exercícios respiratórios (PEREIRA et al., 2009).

b) A prática dos movimentos específicos do TCC teve duração de 30 minutos, com características de concentração mental, controle da respiração, movimentos lentos e fluidez. As práticas do TCC foram compostas de três movimentos coreografados com várias repetições a cada semana (oito séries de 3 movimentos cada), que foram acrescidos a novas sequências de movimento assim que os participantes assimilaram os movimentos anteriores; também foram utilizadas coreografias em duplas (Tai chi Tuishou), que simulam, a defesa e ataque da luta como demostra a figura 10.

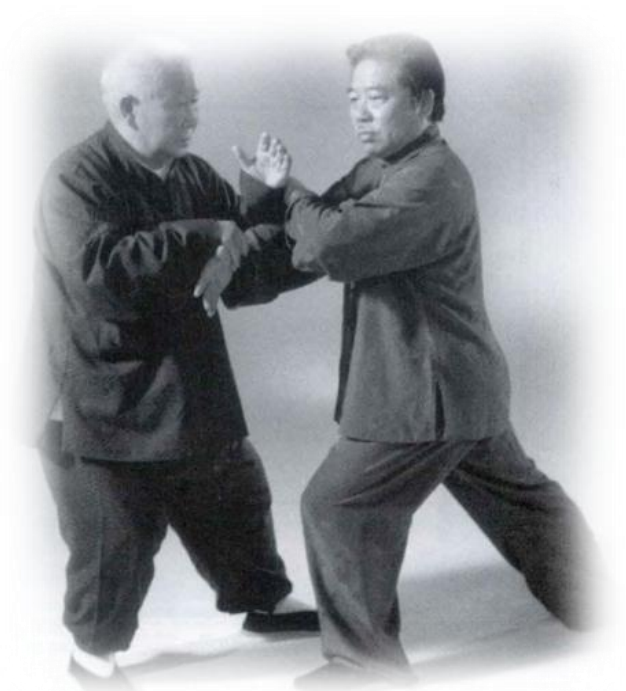

Figura 10 - Coreografias em duplas (Tai chi Tuishou), que simulam a defesa e o ataque da luta -(PEREIRA, et al, 2008). 
A sequência de exercícios da prática de TCC estilo Yang foi composta por 24 movimentos apresentados na figura 11, com seguinte estrutura:

1-Preparação (Openig);

2-Risca da Crina do Cavalo Selvagem (Part horse Mane);

3-Grou Branco Bate as Asas (White Crane Spreads Wings);

4-Coçar os Joelhos (Brush Knee Twist Stop);

5-Dedilhar o Alaúde (Play teh Harp/Lute);

6-Garça Branca Estende as Asas Atrás (White Crane Extends. Behind Wings);

7-Agarrar a Cauda do Pássaro à Esquerda (Left Grasp Birds Tail);

8-Agarrar a Cauda do Pássaro à Direita (Right Grasp Birds Tail);

9-Chicote simples à Esquerda (Left Single Whip);

10-Acenar Mãos nas Nuvens (Wave Like Clouds);

11-Chicote simples à Direita (Right Single Whip);

12-Afagar o Cavalo (High Pat on Horse);

13-Chutar com o Calcanhar Direito (Right Hell Kick);

14-Bater nas Orelhas com os Dois Punhos (Punch Ears);

15-Chutar com o Calcanhar Esquerdo (Left Hell Kick);

16-Serpente Descendo à Esquerda (Lower Movement On Left Leg);

17-Serpente descendo à Direita (Lower Movement On Left Leg);

18-Passar a Lança para a Direita e para a Esquerda (Work at Shutles);

19-Agulha no Fundo do Mar (Needle at Sea Bottom);

20-Defesa com os Dois Braços (Flash the Arm);

21-Virar-se para Golpear (Turn Block);

22-Recuar e Empurrar (Parry and Punch);

23-Braços Cruzados ao Peito (Cross Hands);

24-Conclusão (Close). 


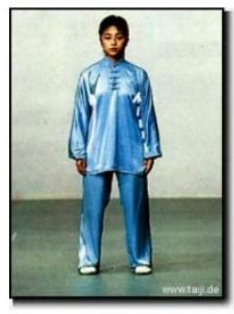

1. Opening

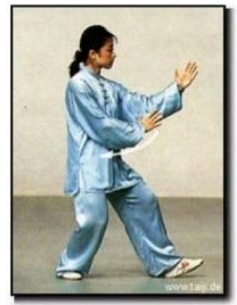

5. Play the Lute

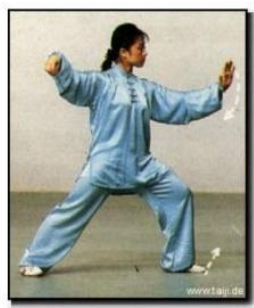

9. Single Whip

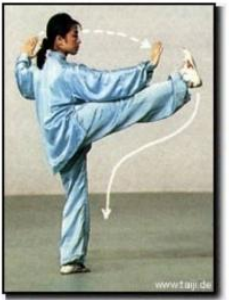

13. Right Heel Kick

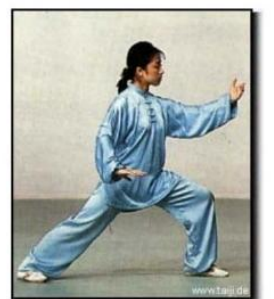

2. Part the Horse's Mane $x 3$

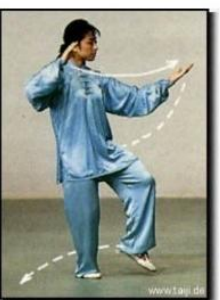

6. Retreat and Repluse Monkey x4

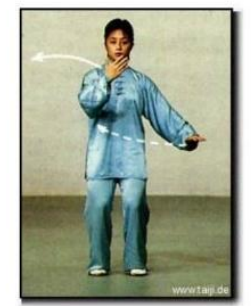

10. Wave Hands Like Clouds $\times 3$

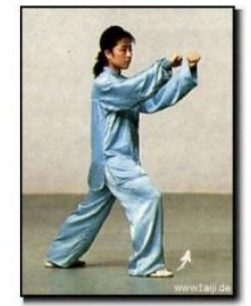

14. Double Punch to the Ears

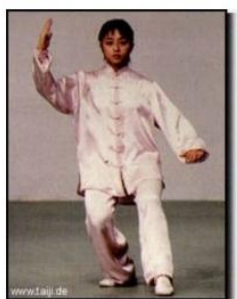

3. White Crane Spreads Wings

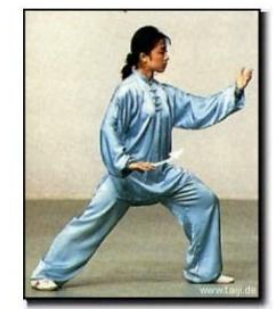

7. Left Grasp the Bird's Tail

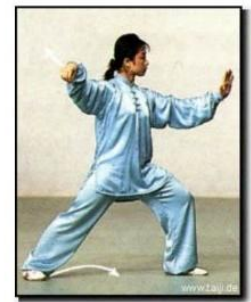

11. Single Whip

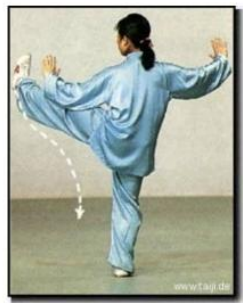

15. Left Heel Kick

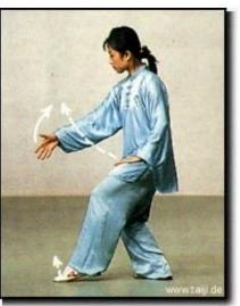

. Fair Lady Works the Shu Golden Pheasant Stands on Right Leg

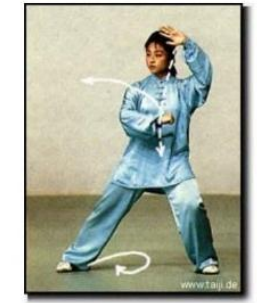

21. Turn Body, Deflect, Parry, Punch Left and Right

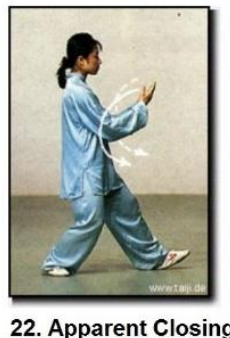

22. Apparent Closing

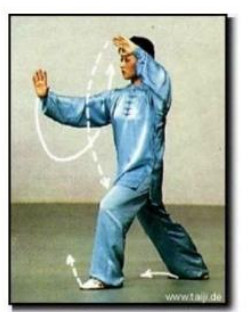

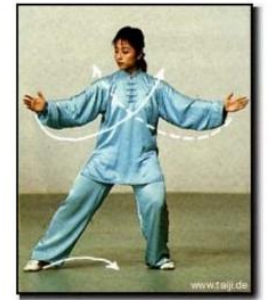

23. Cross Hands

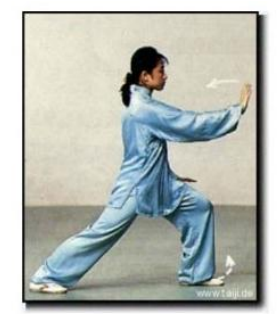

4. Brush Knee and Push $\times 3$

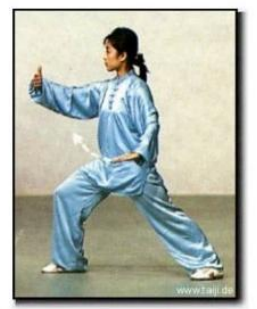

8. Right Grasp the Bird's Tai

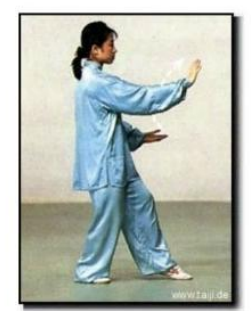

12. Pat the High Horse

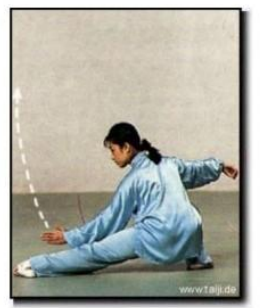

16. Left Snake Creeps Down Golden Pheasant Stands on Left Leg

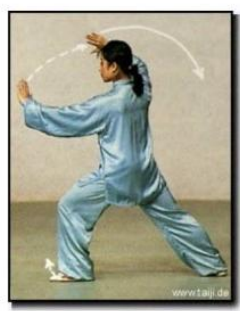

20. Fan through the Back

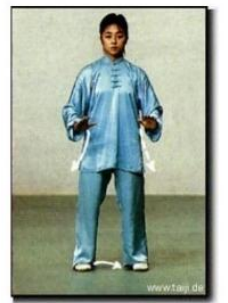

24. Closing

Figura 11 - Movimentos do Tai Chi Chuan estilo Yang 24 movimentos - Fonte: http://taichibali.com/yang-tai-chi-24-forms/. Acessado em 10/12/2016. 
c) O relaxamento teve a duração de 05 minutos, com atividades de descontração psíquica e muscular, por meio de exercícios de soltura e de meditação Tao Yin (Daoyin ou loga Taoista), que é composta por alongamentos suaves associados a exercícios respiratórios e visualizações, fazendo das imagens o objeto da meditação (GONGBAO, 1998; QING, 1999), como ilustra a figura 12.

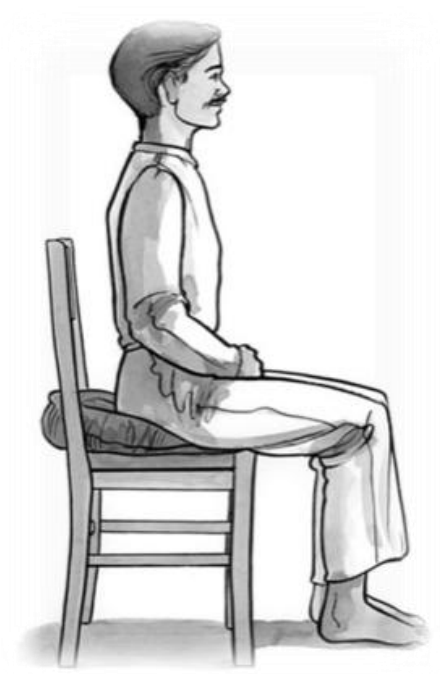

Figura 12 - Relaxamento Tao Yin (Daoyin ou loga Taoista). Fonte dineyinsightsinsano.wordpress.com/2013/07/16/tao-yin/.

Durante a intervenção foram monitorados eventos adversos, como quedas, dor muscular, tontura, desmaios, hipertensão ou hipotensão.

\subsection{ANÁLISE ESTATÍSTICA}

Os dados descritivos da amostra foram expressos como média desvio padrão para as variáveis quantitativas e frequências relativas para dados categóricos. A verificação da normalidade dos dados foi obtida pelo teste de Shapiro-Wilk e a homogeneidade das variâncias foi calculada por meio do teste de Levene.

Para os dados que apresentaram a distribuição normal uma ANOVA fatorial 2 way (pré e pós) X 2 GRUPO (controle e TCC) foi calculada para verificar possíveis diferenças entre grupos e intra grupos. Já para os dados sem distribuição normal, foi adotada uma ANOVA de Friedman e posteriormente, para análise de diferenças intra grupos, o teste de Wilcoxon para amostras pareadas e para verificar as 
diferenças entre grupos teste de U-Man-Whitney para grupos independentes com correção de Bonferroni foram performados.

Para verificar possíveis efeitos clínicos da prática, o cálculo do tamanho do efeito se deu pelo $D$ de Cohen (. Para análises de dados será utilizado Software Statistical Package for the Social Sciences (SPSS- versão 22) para Windows e 0 nível de significância adotado será de $p \leq 0,05$. 


\section{RESULTADOS}

A tabela 3 descreve as características da amostra do Grupo Controle $(n=16)$ e Grupo TCC (n=23).

Tabela 3 - Caracterização descritiva da amostra.

\begin{tabular}{lcc}
\hline & GRUPO TCC $(\mathrm{n}=23)$ & $\begin{array}{c}\text { GRUPO CONTROLE }(\mathrm{n}=16) \\
\text { Média } \pm \mathrm{DP}\end{array}$ \\
\hline Idade (anos) & $68,94 \pm 10,421$ & $67,17 \pm 10,299$ \\
Estatura $(\mathrm{m})$ & $1,6547 \pm 0,07772$ & $1,6635 \pm 0,09819$ \\
Massa corporal $(\mathrm{kg})$ & $74,309 \pm 13,3189$ & $73,348 \pm 14,5853$ \\
UPDRS III (pts.) & $36,83 \pm 14,43$ & $35,67 \pm 13,65$ \\
MEEM (pts.) & $26 \pm 3,72$ & $27 \pm 2,26$
\end{tabular}

TCC - grupo Tai Chi Chuan; $\mathrm{m}$ - metros; kg - quilogramas; UPDRS-III - Avaliação do Exame Motor da Escala Unificada da Doença de Parkinson; pts. - pontos; MEEM - Mini Exame do Estado Mental.

A Tabela 4 demonstra os resultados da ANOVA, sendo que para tratamentos paramétricos houve interação do "tempo" $(F=6.110, p=0.02)$ para a variável BAOF na Amplitude $A p_{\text {ocope }}$ e o teste de post hoc confirmou diferença entre pré e pós intervenção no grupo TCC ( $p=0.006)$. Ainda foi observada diferença significante entre pré e pós intervenção, também no grupo TCC na variável BFOA na Amplitude $\mathrm{ML}_{\text {copy }}(\mathrm{p}=0.027)$.

$\mathrm{Na}$ tabela 4, para dados não paramétricos, a ANOVA de Friedman acusou interação para as variáveis EEB $\left(\chi^{2}(1)=11.645, p=0.001\right)$, para BAOA na Velocidade do COP $\left(\chi^{2}(1)=12.448, p=0.000\right)$, para BAOF na Velocidade do COP $\left(\chi^{2}(1)=12.448, p=0.000\right)$, para BFOF , também na Velocidade do COP $\left(\chi^{2}(1)=\right.$ 7.759, $p=0.005)$ e para BFOA na Velocidade do $\operatorname{COP}\left(\chi^{2}(1)=12.448, p=0.000\right)$. Com isso, o teste de Wilcoxon para amostras relacionadas demonstrou diferença entre pré e pós intervenção no grupo TCC para as variáveis:

- BAOA na Velocidade do $\operatorname{COP}(z=-3.419$ e $p=0.001)$

- BAOF na Velocidade do $\operatorname{COP}(z=-3.506$ e $p=0.000)$

- BFOA na Amplitude $\operatorname{AP}_{\text {copx }}(z=-2.199$ e $p=0.028)$

- BFOF na Velocidade do COP $(z=-3.027$ e $p=0.001)$ 
Por outro lado, o teste de Wilcoxon para amostra relacionada demonstrou diferença significativa entre pré e pós teste para o grupo Controle nas variáveis:

- BAOA na Velocidade do COP $(z=-2.401$ e $p=0.016)$

- BAOF na Velocidade do COP $(z=-1.956$ e $p=0.05)$

- BFOA na Velocidade do COP $(z=-2.045$ e $p=0.041)$

Na tabela 5 são demonstradas as comparações entre grupos no pré e pós teste para as variáveis de EEB e TUG. Para dados não paramétricos a ANOVA de Friedman acusou interação para a variável EEB $\left(\chi^{2}(1)=11.645, p=0.001\right)$; assim, após a análise do teste de Wilcoxon para amostras relacionadas, observou-se uma diferença significante entre pré e pós intervenção no grupo TCC para EEB ( $z$ = 3.045 e $p=0.002$ ). Porém, não foi observada nenhuma diferença entre ou intra grupos para a variável TUG. 
Tabela 4 - Comparação da estabilidade postural dos grupos Controle e Tai Chi Chuam antes e após a intervenção. Dados expressos em média \pm desvio padrão e tamanho do efeito.

\begin{tabular}{|c|c|c|c|c|c|c|}
\hline & \multicolumn{3}{|c|}{ Grupo controle } & \multicolumn{3}{|c|}{ Grupo TCC } \\
\hline & PRÉ & PÓS & & PRÉ & PÓS & \\
\hline & MÉDIA $\pm \mathrm{DP}$ & MÉDIA $\pm \mathrm{DP}$ & $\begin{array}{c}\text { D de } \\
\text { Cohen }\end{array}$ & MÉDIA $\pm \mathrm{DP}$ & MÉDIA $\pm \mathrm{DP}$ & $\begin{array}{l}\text { D de } \\
\text { Cohen }\end{array}$ \\
\hline \multicolumn{7}{|l|}{ BAOA } \\
\hline Velocidade do COP $(\mathrm{cm} / \mathrm{s})$ & $1.949 \pm 0.793$ & $1.320^{\dagger} \pm 0.463$ & 1.001 & $2.545 \pm 1.488$ & $1.262^{*} \pm 0.466$ & 1.313 \\
\hline Amplitude AP (copx) (cm) & $1.553 \pm 0.871$ & $1.468 \pm 0.523$ & 0.121 & $1.712 \pm 0.69$ & $1.432 \pm 0.561$ & 0.440 \\
\hline Amplitude ML (copy) (cm) & $2.320 \pm 0.781$ & $2.071 \pm 0.549$ & 0.374 & $2.387 \pm 0.585$ & $2.124 \pm 0.532$ & 0.470 \\
\hline \multicolumn{7}{|l|}{ BAOF } \\
\hline Velocidade do COP $(\mathrm{cm} / \mathrm{s})$ & $2.389 \pm 1.002$ & $1.756^{\dagger} \pm 0.413$ & 0.894 & $2.920 \pm 1.411$ & $1.719^{*} \pm 0.832$ & 1.070 \\
\hline Amplitude AP (copx) (cm) & $1.938 \pm 0.782$ & $1.777 \pm 0.636$ & 0.227 & $2.065 \pm 0.744$ & $1.582^{*} \pm 0.563$ & 0.739 \\
\hline Amplitude ML (copy) (cm) & $2.593 \pm 0.517$ & $2.827 \pm 0.571$ & -0.430 & $2.919 \pm 0.827$ & $2.801 \pm 0.825$ & 0.142 \\
\hline \multicolumn{7}{|l|}{ BFOA } \\
\hline Velocidade do COP $(\mathrm{cm} / \mathrm{s})$ & $2.878 \pm 1.171$ & $2.302^{\dagger} \pm 0.817$ & 0,579 & $2.733 \pm 1.155$ & $1.746 \pm 0.530$ & 1,154 \\
\hline Amplitude AP (copx) (cm) & $2.851 \pm 0.702$ & $3.175 \pm 1.081$ & -0.363 & $2.788 \pm 0.640$ & $3.170^{*} \pm 0.832$ & -0.519 \\
\hline Amplitude ML (copy) (cm) & $2.256 \pm 0.419$ & $2.433 \pm 0.612$ & $-0,343$ & $2.639 \pm 0.763$ & $2.273^{\star} \pm 0.536$ & 0.563 \\
\hline \multicolumn{7}{|l|}{ BFOF } \\
\hline Velocidade do COP (cm/s) & $3.646 \pm 1.274$ & $3.415 \pm 1.112$ & 0,193 & $3.947 \pm 2.028$ & $2.897^{*} \pm 1.344$ & 0.622 \\
\hline Amplitude AP (copx) (cm) & $4.069 \pm 1.190$ & $4.269 \pm 0.961$ & $-0,311$ & $4.066 \pm 1.254$ & $3.974 \pm 1.221$ & 0.074 \\
\hline Amplitude ML (copy) (cm) & $3.100 \pm 0.603$ & $3.668 \pm 0.875$ & $-0,768$ & $3.491 \pm 1.053$ & $3.423 \pm 0.935$ & 0,068 \\
\hline
\end{tabular}

BAOA: Base aberta com olhos abertos; BAOF: Base aberta com olhos fechados; BFOA: Base fechada com olhos abertos; BFOF: Base fechada com olhos fechados; COP: Centro de pressão; AP: Anteroposterior; ML: Mediolateral; TCC - grupo Tai Chi Chuan.

${ }^{*}$ Diferença intra-grupo TCC $\mathrm{p}<0.05 ;{ }^{\dagger}$ Diferença intra grupo GC $p<0.05$. 
Tabela 5 - Comparação do equilíbrio funcional dos grupos Controle e Tai Chi Chuan antes e após a intervenção. Dados expressos em média \pm desvio padrão, delta percentual e tamanho do efeito.

\begin{tabular}{|c|c|c|c|c|c|c|c|c|c|c|}
\hline & \multicolumn{6}{|c|}{ Grupo controle } & \multicolumn{4}{|c|}{ Grupo TCC } \\
\hline & \multicolumn{2}{|c|}{ Pré } & \multicolumn{2}{|c|}{ Pós } & \multirow{2}{*}{$\begin{array}{c}\text { D de } \\
\text { Cohen }\end{array}$} & \multicolumn{2}{|c|}{ Pré } & \multicolumn{2}{|c|}{ Pós } & \multirow{2}{*}{$\begin{array}{c}\text { D de } \\
\text { Cohen }\end{array}$} \\
\hline & média & DP & média & $\mathrm{DP}$ & & média & $\mathrm{DP}$ & média & DP & \\
\hline $\begin{array}{l}\text { EEB } \\
\text { (pts.) }\end{array}$ & 45,87 & $\pm 9,031$ & 48,86 & $\pm 8,018$ & -0.350 & 49,48 & 3,883 & $52,68^{*}=$ & $\pm 2,626$ & -0.983 \\
\hline TUG (s) & 7,233 & $\pm 1,393$ & $7,277 \pm$ & $\pm 1,543$ & -0.021 & 7,977 & 2,371 & $7,775=$ & $\pm 2,427$ & 0.084 \\
\hline
\end{tabular}

EEB: Escala de Equilíbrio de Berg; TUG: Timed Up and Go.; TCC - grupo Tai Chi Chuan; ${ }^{*}$ Diferença intra grupo TCC $p<0.05$; pts. - pontos; $s$ - segundos. 


\section{DISCUSSÃO}

Indivíduos com DP têm apresentado deficiências no equilíbrio que afetam a estabilidade estática e dinâmica, já que os músculos de sustentação sofrem uma perda de força progressiva.

O TCC é comumente recomendado para idosos com e sem doença neurológica que apresentem alterações de sintomas relacionadas com a mobilidade do envelhecimento (LI et al., 2012, WU et al.,2016). Estudos que envolvem DP geralmente utilizam testes funcionais para inferir a estabilidade postural e dinâmica, como escala de BERG (GAO et al., 2014) Timed Up and Go (ZHANG et al., 2015), e a plataforma de força (HACKNEY et al., 2008) além dos questionarios UPDRS -III, AVDs, PDQL e QOL (HACKNEY et al., 2009, CHEON et al., 2013).

O Tai Chi se apresenta como terapia adjunta ao tratamento da doença de Parkinson (BRASIL, 2010), sendo que, a partir da meta-análise conduzida por Zhou et. al. (2014) é possível perceber a eficácia da modalidade no incremento de tarefas motoras e da estabilidade postural. Entretanto, ainda existem críticas em relação aos protocolos que utilizam o Tai Chi, as quais se dão visto que o rigor metodológico e estatístico dos estudos que têm sido publicados não atinge os níveis de qualidade esperados, bem como a falta de acompanhamento pós-intervenção para assegurar que as alterações foram de fato eficientes.

De acordo com DUARTE (2010), as variáveis de velocidades do COP, COPy e COPx se complementam a fim de mensurar a capacidade do indivíduo em estar estável. Em vista disto, quanto maior o deslocamento em qualquer um dos sentidos, maior o nível de instabilidade. Desta maneira, esperava-se que as avalições pósintervenção apresentassem diminuições numéricas das variáveis aferidas em todas as posições do protocolo.

$\mathrm{Na}$ posição BAOF, a diminuição da amplitude do deslocamento anteroposterior (COPy) sugere uma menor compensação de equilíbrio por parte das articulações do tornozelo, joelho e quadril. Além disso, (LENT, 2005) indica que a visão é um importante sentido na manutenção da estabilidade postural, sendo esperada uma maior instabilidade na execução da tarefa com olhos fechados quando comparado com a mesma tarefa realizada com olhos abertos. Não foi verificada diferença significativa na mesma variável na posição com olhos abertos. 
Mesmo assim, nota-se que o valor pré da posição BAOA foi menor que o valor pré da posição BAOF.

Nesta perspectiva, infere-se que 12 semanas de prática do TCC podem contribuir para um incremento da estabilidade postural frente a uma condição desafiadora. Entende-se que a redução da amplitude do deslocamento do centro de pressão observada no grupo experimental apresenta importante significado clínico.

Estudos demonstram que uma maior amplitude de deslocamento na posição ML (MAKI et al., 1994; LORD et al., 1999; MELZER et al., 2004; PIIRTOLA e ERA, 2006) está relacionada com maior risco de quedas e que a instabilidade AP aumenta as chances de lesões graves após a ocorrência das mesmas (KURZ et al., 2013).

O protocolo TCC salientou deslocamento de peso e influência do tornozelo para mover efetivamente o centro de gravidade em relação aos limites de estabilidade, para fortalecer a dorsiflexão e flexão plantar; essas caractirísticas foram utilizadas para melhorar o equilibrio estático e dinâmico para controle postural e capacidade de marcha.

O TUG (KENNY et al., 2011; MOYER, 2012; NICE, 2013) vem sendo utilizado na prática clínica durante a avaliação do equilíbrio e do risco de quedas. Alguns autores sugerem que alterações no tempo de execução do teste podem predizer maior ou menor risco de quedas, a saber, quanto maior o tempo de execução, maior o risco de queda (CHRISTOFOLETTI et al., 2006).

No presente estudo não foi observada diferença significativa entre as avaliações pré e pós-intervenção. Tal fato pode ser explicado pelo baixo valor da avalição pré-intervenção. Neri (2016) avaliou idosas sem comprometimento neurológico que apresentaram valores próximos ao achado, caracterizando o desempenho como satisfatório.

A EEB também é uma avaliação do equilíbrio, mas permite avaliar separadamente aspectos como alcance funcional, habilidade para girar em torno de si mesmo, capacidade de sentar, levantar, pegar objetos do chão e transferência de peso, entre outras habilidades motoras. Com o avanço da doença, é esperado que ocorra o declíno do equilíbrio juntamente com a agilidade. Apesar de ser uma doença degenerativa, estudos já demonstraram que o Tai Chi foi eficiente para recuperar níveis de estabilidade postural em indivíduos por ela acometidos (HACKNEY et al., 2008; GAO et al., 2014; ZHANG et al., 2015). 
Os resultados obtidos neste estudo apresentaram um incremento significante da avaliação pré para a avaliação pós no grupo TCC. Houve um aumento de 3,2 pontos no score da escala de BERG. Soares et. al, (2008) defendem que um aumento de dois pontos na escala significa uma diminuição de $20 \%$ no risco de quedas, respaldando a eficiência da prática do Tai Chi.

É observado em individuos com DP que o avanço da idade está associado com a degradação da estabilidade estática e dinâmica de indivíduos acometidos; porém, ainda assim, estudos demonstram que é possível recuperar níveis de equilibrio através da pratica de TCC (LI et.al., 2012).

Pela escala de H\&Y, os destúrbios na estabilidade postural começam a partir do nível 3, quando o indivíduo, apesar de ainda ser independente, já demonstra certa instabilidade postural, recorrendo à utilização de acessórios para locomoção, como andador e muletas.

Neste estudo foram investigados os efeitos do programa de TCC duas vezes por semana durante 12 semanas, tendo tal prática demonstrado eficácia no incremento do equilíbrio estático e dinâmico em testes funcionais em indivíduos com Doença de Parkinson leve a moderada. Após a intervenção, participantes do programa demostraram melhoria na velocidade do COP, Amplitude do AP e amplitude do ML.

Não foram observados eventos adversos graves durante a intervenção do TCC, o que indica a segurança e eficácia desta intervenção para pessoas com DP.

Clinicamente, a melhoria no equilibrio indica aumento no desempenho de AVDs, como levantar, deslocar para pegar e levar um objeto de um armario para outro, transição de posição sentada para posição em pé (e, de posição em pé para sentado) e caminhar com segurança, o que reduz a probabilidade de queda (LI, et al., 2012).

A análise do equilíbrio estático e dinâmico se deu através da apuração da quantidade de oscilações na posição ortostática na plataforma de força Accusway Plus da marca AMTI (Advanced Medical Technology Inc, Watertown, MA), que avaliou a velocidade do $\operatorname{COP}(\mathrm{cm} / \mathrm{s})$ e amplitude AP $\left(\mathrm{Cop}_{\mathrm{x}}\right)$ e $\mathrm{ML}\left(\mathrm{Cop}_{\mathrm{y}}\right)$ em repouso.

A avaliação de velocidade do COP e amplitude AP (Anteroposterior) e ML (médiolateral) com BAOA (Base aberta com olhos abertos), BAOF (Base aberta com olhos fechados), BFOA (Base fechada com olhos abertos), BFOF (Base fechada 
com olhos fechados), demostrou que houve melhora no resultado comparando com pré e pós a intervenção do TCC, bem como com relação ao Controle.

Após pesquisa nos bancos de dados sobre o tema, encontramos poucos estudos que tenham avaliado o programa/intervenção de TCC no equilíbrio estático e dinâmico em indivíduos com DP, principalmente no que diz respeito à plataforma de força. Em estudos analisados na literatura houve melhora significativa de grupos que praticaram TCC quando comparados a grupos controle. Essas melhoras foram referentes aos sintomas motores da doença de Parkinson, como equilibrio estático e dinâmico.

Corroborando com os achados do presente estudo, na revisão sistemática de Liu et al., (2010), com 19 estudos prospectivos (2000 a 2007), com TCC estilo Yang, verificou-se que os praticantes de TCC tiveram resultados melhores na postura, flexibilidade, alcance funcional, velocidade de passo, medo de queda, TUG e escala de equilíbrio de Berg em comparação com grupo controle.

Já no estudo realizado por $\mathrm{Li}$ et al., (2012), foram observadas melhoras no equilíbrio, controle direcional, comprimento de passo, velocidade de marcha, alcance funcional e diminuição de incidência de quedas no grupo que praticou TCC $(n=65$, média de idade $=69$ anos) por seis meses quando comparados aos grupos de treinamento de força $(n=65$, média de idade $=69)$ e alongamento $(n=65$, média de idade = 69). Os testes utilizados foram TUG e posturografia dinâmica computadorizada (Balance Master System, NeuroCom) para avaliar o equilibrio.

Em um estudo de Jung et al., (2013), um grupo $(n=11$, média de idade $=60$ anos) que praticou TCC por 12 semanas, demonstrou melhora na função motora, no tempo de reação e no equilíbrio (teste de apoio uni podal) quando comparados ao grupo controle $(\mathrm{n}=9$, média de idade $=65$ anos); por outro lado, os autores concluíram que são necessários futuros estudos para definir melhor a eficácia do TCC para DP.

O estudo de $\mathrm{Nl}$ et al. (2014) que avaliou a eficácia e segurança do TCC para pessoas com DP, em meta-análise com nove ensaios clínicos randomizados, de oito a 24 semanas de prática do TCC com estilo Yang, observou melhora no desempenho do equilíbrio, da mobilidade e diminuição de queda. Os testes utilizados para avaliar o equilíbrio foram EEB, TUG e teste de alcance funcional. Concluiu-se que a prática é eficiente e segura para pessoas com DP na fase inicial, 
porém sugere estudos mais aprofundados, com amostra com tamanho maior e tempo de prática mais longo.

Em uma revisão sistemática e meta-análise de Yang et al., (2014), foram analisados sete ensaios clínicos com intervenção dos exercícios de TCC estilo Yang por 24 semanas. Tais ensaios demonstraram melhoria na função motora, equilíbrio e mobilidade funcional, mas não houve melhoria na velocidade de marcha nem no comprimento de passo. Foram utilizados TUG, EEB, e teste de alcance para avaliar o equilibrio. Os autores recomendam mais estudos, com tempo maior de intervenção, no intuito de verificar parâmetros seguros do TCC para DP.

No estudo do Li et. al., 2007, o Tai Chi Chuan demostrou melhora da marcha (TUG - 9.38 segundos para 8.02 segundos) e Alcance funcional (22.42 centímetros para 25.38 centímetros) e caminhada rápida de 50 pés (16.32 segundos para 14.02 segundos). Segundo o autor, o exercício foi adequado, sem dificuldades para aprendizagem, com custo baixo, sem necessidade de espaços sofisticados e tão pouco de equipamentos, além de não ser doloroso e/ou prejudicial, o que mostra que os beneficios superam os custos. A maioria dos participantes expressou um desejo de continuar com exercícios baseados no Tai Chi Chuan.

A melhora do equilibrio e da mobilidade foi demonstrada pelo estudo de Hackney \& Earhart, 2008 na Escala de Equilíbrio de Berg. O grupo Tai Chi Chuan melhorou 3,3 pontos, enquanto o grupo controle regrediu por uma média de 0,5 pontos ( $P<0,001)$, no TUG melhorou seu tempo por uma média de 1,0 segundo, enquanto o grupo controle melhorou 0,1 segundo $(P<0,093)$.

No estudo de Hackney \& Earhart 2008, com 33 indivíduos com DP, 17 no Grupo TCC e 16 no Grupo Controle, com escore de Hoehn \& Yahr variando 1,5 a 3, durante 20 sessões, o grupo TCC demonstrou resultados melhores em Escala de Equilibrio de Berg, UPDRS III, TUG, em relação ao controle, mas ambos os grupos não apresentaram melhora no teste de postura.

No estudo de Kim et al., 2011, com 10 indivíduos com DP com idade entre 70 e 80 anos com intervenção de TCC durante 12 semanas, os participantes aumentaram significativamente a velocidade do COP e amplitude AP e ML. Os participantes da TCC demonstraram aumento no AP (122\%) e ML $(130 \%)$ deslocamento do COP.

No estudo de Li et. al., 2012, demonstrou-se que o Tai Chi Chuan é mais eficaz do que um treinamento resistido e alongamentos em pacientes com doença 
de Parkinson, nos desfechos primários. O grupo de TCC teve um desempenho significativamente melhor no alcance funcional $(2.2 \mathrm{~cm}, p=0,007)$, TUG $(1,00$ segundo), e UPDRS III (5.07 pontos, $p<0.001$ ), a taxa de incidência de queda $67 \%$ menor. Não foi observado nenhum evento adverso grave durante o treinamento de Tai Chi Chuan, indicando a segurança e eficiência do mesmo como intervenção complementar no tratamento de pessoas com Doença de Parkinson.

O estudo de Amano et. al., 2013, comparou efeito de TCC na dinâmica do controle postural durante o início da marcha e desempenho da marcha em indivíduos com DP em 2 projetos (Primeiro projeto Tai chi $(n=12)$ versus Qi-Gong Meditação ( $n=9) 2 X$ semana e segundo projeto TCC $(n=15)$ versus Controle $(n=9) 3$ $X$ semana durante 16 semanas). Resultados biomecânicos na avaliação do controle postural demostraram que TCC não foi eficaz para melhorar o equilíbrio, porém, houve melhorias na Escala de Equilíbrio de Berg, e controle postural direcional, após a prática de TCC em pessoas com DP.

No estudo de Gao et. al., 2014 foi pesquisado o equilíbrio e a prevenção de quedas em pessoas com doença de Parkinson, tendo sido utilizados os seguintes questionários: Escala de Equilibrio de Berg (EEB), Unificadas Disease Rating Scale de Parkinson (UPDRS) parte III e teste de aptidão funcional (TUG). O grupo de Tai Chi Chuan melhorou em relação ao grupo controle na EEB (46.03 $\pm 10.5245 .97 \pm 9.14$ 0.984), mas não havia nenhuma diferença na pontuação da UPDRS III (31.86 111.49 30.62 $\pm 9.90 \mathrm{P}=0.678)$ e TUG $(10.89 \pm 3.1711 .58 \pm 2.83 \mathrm{P}=0.439)$.

Um estudo com 6 meses de follow-up mostrou que as quedas e a média dos tempos de quedas foram significativamente menores no Grupo Tai Chi Chuan, demostrando que a prática do Tai Chi Chuan como prevenção de quedas em pacientes com DP foi eficiente.

No recente estudo de Zhang et. al., 2015 comparou-se o Tai chi Chuan (estilo Yang) com exercício multimodal (Bicicleta ergonométrica, trinamento de fortalecimento axial, musculação nos membros superiores e inferiores); ambos os grupos tiveram melhorias significativas em UPDRS III, comprimento da passada, velocidade de marcha. O grupo TCC apresentou um decréscimo de 1.91 segundos $(p=0,016)$ no TUG e 3.30 pontos ( $P=0,037)$ em UPDRS III, entre o pré e pós-teste. Já no grupo de treinamento multimodal: melhorias médias de 4.00 pontos $(P=$ 0,001) em UPDRS III, e decréscimo de 2.13 segundo ( $P$ G 0,001) no TUG entre o 
pré e pós-teste. Porém, o estudo constatou que o treinamento de exercício multimodal foi mais fácil de aprender do que a prática do Tai Chi Chuan.

A maioria dos estudos analisados demonstrou ganhos com a prática do TCC, quando comparado ao controle, havendo melhoras signiciatvas nos sintomas motores da doença de Parkinson.

Para além dos resultados e discussão apresentados, vale ressaltar que não foram observados eventos adversos graves durante a intervenção do TCC, o que indica a segurança desta intervenção para pessoas com DP.

\subsection{LIMITAÇÕES DO ESTUDO}

No que se refere à amostra, este estudo leva em conta o risco de perda amostral devido à dificuldade em recrutar e fidelizar os indivíduos selecionados no programa de TCC.

Outro problema que pode implicar em perda amostral é a dificuldade de locomoção até o local da intervenção, devido ao comprometimento da mobilidade e dependência em relação aos acompanhantes ou cuidadores. 


\section{CONCLUSÃO}

O treinamento de TCC com duração de 12 semanas parece demonstrar evidência de melhora significativa no equilíbrio estático apenas no grupo praticante, mas não quando comparado com o grupo controle. Neste estudo demostrou-se que os voluntários que participaram de um programa de 12 semanas de TCC tiveram melhoria na velocidade do COP para as variáveis de BAOA, BAOF e BFOF; bem como na Amplitude AP da variável BAOF e BFOA e na Amplitude ML da variável BFOA. Todas estas diferenças foram confirmadas pelos valores do tamanho do efeito que variavam de "médio a grande".

Não foi observada alteração significativa que relatasse melhora no equilíbrio dinâmico pelo TUG, entre pré e pós-teste, bem como entre grupos. No entanto, houve uma melhora estatisticamente significativa no grupo que praticou TCC, na variável EEB.

Conclui-se então que o treinamento de TCC em 12 semanas é capaz de alterar positivamente o equilíbrio estático e dinâmico em indivíduos com DP. A prática de TCC não foi significativamente maior quando comparada ao grupo controle, que executou exercícios e terapias habituais. No entanto, mais ensaios clínicos randomizados, com maior tempo de seguimento, são necessários para confirmar os resultados atuais de benefícios da prática do Tai Chi Chuan para pessoas com DP.

Devido à existência de poucos estudos abordando tal tema, fazem-se necessárias novas pesquisas nesta área. Estudos recomendam a prática de TCC, podendo ser implementada como terapia alternativa para pessoas com DP, especialmente quando o objetivo é melhorar a função motora e equilíbrio estático e dinâmico para pessoas com DP. 


\section{REFERÊNCIAS}

ANDRADE LAF, BARBOSA ER, CARDOSO F, TEIVE HAG, coordenadores. Doença de Parkinson: Estratégias atuais de tratamento. $1^{\text {a }}$ ed. São Paulo: Omnifarma; 2010

BAEV, K. V. et al. Physiology and pathophysiology of cortiço basal ganglia thalamocortical loops: theoretical and practical aspects. Prog Neuropsychopharmacol Biol Psychiatry, v. 26, n. 4, p. 771-804, May 2002.

BARBIERI, F. A., RINALDI, N. M., SANTOS, P. C., LIRANI-SILVA, E., VITORIO, R., TEIXEIRA- ARROYO, C. Functional capacity of Brazilian patients with Parkinson's disease (PD): Relationship between clinical characteristics and disease severity. Arch Gerontol Geriatr., 2011

BARBOSA, A.B.; SANTAREM, J.M.; JACOB FILHO, W.; MEIRELLES, E.S.; MARUCCI, M.F.N. Comparação da gordura corporal de mulheres idosas segundo antropometria, bioimpedância e DEXA. Arch Latioam Nutr 2001; 51: 4956 .

BARBOSA, M.T. et al. Parkinsonism and Parkinson's disiase in the ederly: a community-basead survery in Brazil (the Bambui study). Movement Disoders, New York, v.21, n.6, p.800-808, 2006.

BARELA, A.M.F, DUARTE, M. Utilização da plataforma de força para aquisição de dados cinéticos durante a marcha humana. Brazilian Journal of Motor Behavior, 6 , 56-61, 2011.

BASSETO, J.M, ZEIGELBOIM, B.S, JURKIEWICZ, A.L, KLAGENBERG, K.F. Achados otoneurológicos em pacientes com doença de Parkinson. Ver Bras Otorrinolaringol, 74(3): 350-5, 2008.

BEDARD M, FELTEAU M, GIBBONS C, KLEIN R, MAZMANIAN D, FEDYK K, KLEIN R, RICHARDSON J, PARKINSON W, MINTHORN-BIGGS MB. Pilot evaluation of a mindfulness-based intervention to improve quality of life among individuals who sustained traumatic brain injuries. Disability and Rehabilitation: An International, Multidisciplinary Journal. 2003;25:722-731

BERG KO, WOOD-DAUPHINÉE SL, WILLIAMS JI, MAKI B. Measuring balance in the elderly: validation of an instrument. Can J Public Health. 1992; (83): S7-11.

BERG, K.O.; WOOD-DAUPHINEE, S.L.; WILLIAMS, J.I. et al. Measuring balance in the elderly: validation of an instrument. Canadian Journal of Public Health, v.83, n.2

BEZARD E, GROSS CE, BROTCHIE JM. Presymptomatic compensation in Parkinson's disease is not dopamine-mediated. Trends in Neuroscience 2003; 26 (4):215-221 . 
BOONSTRA, ANNE M.; SCHIPHORST PREUPER, HENRICA R.; RENEMAN, MICHIEL F.; POSTHUMUS, JITZE B.; STEWART, ROY E. Reliability and validity of the visual analogue scale for disability in patients with chronic musculoskeletal pain. International Journal of Rehabilitation Research: June 2008 - Volume 31 - Issue 2 pp 165-169

BRAAK, H.; DEL TREDICI, K.; RÜB, U.; DE VOS, R.A.I.; JANSEN STEUR, BRADLEY, W. G.; DAROFF, R. B.; FENICHEL, G. M.; MARSDEN, C. Neurology in Clinical Practice: Principles of diagnosis and management, 4 ed, v. 1, 2004.

BRASIL MDS. Protocolos Clínicos e Diretrizes Terapêuticas - Doença de Parkinson. 2010; $1: 606$

BRONTE-STEWART, HELEN M.; MINN, A. YURIKO; RODRIGUES, KAMALA; BUCKLEY, ELLIE L.; NASHNER, LEWIS M. Postural instability in idiopathic Parkinson's disease: the role of medication and unilateral pallidotomy. Brain, v. 125, n. 9, p. 2100-2114, 2002.

BROWN, D.D. Cardiovascular and ventilatory responses during formalized Tai Chi Chuan exercise. Research Quarterly for Exercise and Sport, v. 60. p. 246-250, 1989.

BRUCK SONIA, RICARDO NITRINI, PAULO CARAMELLI, PAULO H.F. BERTOLUCCI, IVAN H. OKAMOTO. Sugestões Para o Uso Do Mini Exame do Estado Mental no Brasil. Arq Neuropsiquiatr 2003;61(3-B):777-781

CANNING C.G.; SHERRINGTON C.; LORD SR.; CLOSE J.C.; HERITIER S.; HELLER G.Z.; HOWARD K.; ALLEN N.E.,;LATT M.D.; MURRAY S.M.; O'ROURKE S.D.; PAUL S.S.; SONG J.; FUNG V.S. Exercise for falls prevention in Parkinson disease: a randomized controlled trial. American Academy of Neurology 2014. 304-12.

CHANDLER, J. M, GUCCIONE, A. A. Equilíbrio e quedas no idoso: questões sobre a avaliação e o tratamento. In: GUCCIONE, A. A. Fisioterapia Geriátrica. Rio de Janeiro: Guanabara Koogan. cap. 13, p. 265-77, 2002.

CHOI H. J., GARBER C. E, JUN T, W., JIN, CHUNG Y. S., KANG. H. J., Therapeutic effects of tai chi in patients with Parkinson's disease. ISRN Neurolology, 2013.

CHRISTOFOLETTI G., OLIANI MM., GOBBI LTB., GOBBI S. Risco de Quedas em Idosos com Doença de Parkinson EdDemência e Alzheimer: Um Estudo Transversal. Rev. bras. fisioter., São Carlos, v. 10, n. 4, p. 429-433, out./dez. 2006

COELHO, F.G.M, GOBBI, L.T.B., GOBBI, S., Exercício Físico no Envelhecimento Saudável e Patológico: Da Teoria à prática. Editora CRV, Curitiba 2013.

COHEN, J. (1988) - Statistical power analysis for the behavioral sciences. $2^{\underline{a}}$ ed. Hillsdale, New Jersey: Lawrence Erbaum 
CONFEF - Conselho Federal de Educação Física. Resolução CONFEF no 046/2002. Rio de Janeiro: Confef, 2002

DAVID, A.C, MOTA, C.B. Equilíbrio postural de atletas da seleção brasileira feminina de canoagem velocidade. Revista Brasileira de Biomecânica2009;9(18):22-8.

DIBBLE, L. E. et al. High intensity eccentric resistance training decreases bradykinesia and improves Quality Of Life in persons with Parkinson's disease: a preliminary study. Parkinsonism Relat Disord, v.15, n. 10, p. 752-7, 2009.

DOHERTY K.M.; VAN DE WARRENBURG B.P.; PERALTA M.C.; SILVEIRAMORIYAMA L., AZULAY JP, GERSHANIK O.S.; BLOEM B.R. Postural deformities in Parkinson's disease. Lancet Neurol. 2011 Jun;10(6):538-49

DORSEY ER, CONSTANTINESCU R, THOMPSON JP, et al. Projected number of people with Parkinson disease in the most populous nations, 2005 through 2030. Neurology. Jan 30 2007;68(5):384-386.

DUARTE M. Análise estabilográfica da postura ereta humana quasi-estática. São Paulo. [livre-docência]. São Paulo (SP): Universidade de São Paulo; 2000

E.N.H.; BRAAK, E. Staging of Brain Pathology Related to Sporadic Parkinson's Disease. Neurobiol Aging, v. 24, p. 197-211, 2003.

FAHN S, ELTON RL, members of the UPDRS Development Committee. Unified Parkinson's disease Rating Scale. In: Fahn S, Marsden CD, Calne D, Goldstein M (eds). Recent developments in Parkinson's disease. Florham Park NJ, USA: Macmillan Healthcare Information 1987:153-163.

FAHN S, PRZEDBORSKI S. PARKINSONISM. In: Merritt's Neurology. Rowland LP, Pedley TA (Eds.). Pp751-769. Lippincott Williams and Wilkins, New York, New York, USA, 2010.

FINDLEY L.J.: The economic impact of Parkinson's disease. Parkinsonism RelatDisord. 2007;13:8-12.

GAO Q, LEUNG A, Y. YANG et al., "Effects of Tai Chi on balance and fall prevention in Parkinson's disease: a randomized controlled trial," Clinical Rehabilitation, vol. 28, no. 8, pp. 748- 753, 2014.

GAO Q., LEUNG. A., YANG. Y., "Effects of Tai Chi on balance and fall prevention in Parkinson's disease: a randomized controlled trial," Clinical Rehabilitation, vol. 28, no. 8, pp. 748- 753, 2014.

GEORGE, R.J. et al. A meta-regression of the long-term effects of deep brain stimulation on balance and gait in PD. Neurology, v.75, p. 1292-1299, 2010

GOBBI, L.T.B., TEIXEIRA-ARROYO, C., HAMANAKA, A.Y.Y., BARBIERI, F.A., VITÓRIO, R., OLIVEIRA-FERREIRA, M.D.T. Envelhecimento, Doença de Parkinson e Exercício. In FARINATTI, P. Envelhecimento e Exercício, 2010. 
GOMES, L., PEREIRA, M.M., ASSUMPÇÃO, L.O.T. TAI CHI CHUAN: a new exercise modality for elderly. R. bras. Ci.e Mov. 2004; 12(4): 89-94

GONGBAO, Y. Quigong chinês ilustrado. São Paulo: Rocca, 1998.

GRILLNER S.; HELLGREN J.; MÉNARD A.; SAITOH K.; WIKSTRÖM M.A. Mechanisms for selection of basic motor programs - roles for the striatum and pallidum. Trends in Neuroscience, v.28, p.364-70, 2005.

GRIMBERGEN, Y.A, LANGSTON, J.W, ROOS, R.A, BLOEM, B.R. Postural instability in Parkinson's disease: the adrenergic hypothesis and the locus coeruleus. Expert Rev Neurother. 2009;9(2):279-90.

GYLLENSTEN AL, HUI-CHAN CW, TSANG WW (2010) Stability limits, single-leg jump, and body awareness in older Tai Chi practitioners. Arch Phys Med Rehabil 91: 215-220

HALLIDAY, G.; LEES, A.; STERN, M. Milestones in Parkinson's Disease - Clinical and Pathologic Features. Mov Disord, v. 26, n. 6, p. 1015-1021, 2011.

HARTMAN, C.A. et al. Effects of T'ai Chi training on function and quality of life indicators in older adults with osteoarthritis 5 . Journal of the American Geriatric Society, v. 48, p. 1553-9, 2000

HELY, MARIESE A.; REID, WAYNE G. J.; ADENA, MICHAEL A.; HALLIDAY, GLENDA M.; MORRIS, JONH. The Sydney multicenter study of Parkinson's disease: the inevitability of dementia at 20 years. Movement Disorders, v. 23, n. 6, p. 837844, 2008.

HERDMAN, Susan J. Reabilitação Vestibular. São Paulo: Manole, 2002.

HOEHN M, YAHR M. Parkinsonism, onset, progression and mortality. Neurology. 1967; 17:427-42. [PubMed: 6067254]

HONG M, PERLMUTTER JS, EARHART GM. Enhancement of rigidity in Parkinson's disease with activation. Movement disorders: official journal of the Movement Disorder Society. Jun 15 2007;22(8):1164-1168

HORAK FB, FRANK J, NUTT J. Effects of dopamine on postural control in parkinsonian subjects: scaling, set, and tone. J Neurophysiol 1996;75:2380-2396

HORAK FB. Postural orientation and equilibrium: what do we need to know about neural control of balance to prevent falls? Age and Ageing, v. 35-S2, p. ii7- ii 11, 2006.

HUGHES AJ, DANIEL SE, KILFORD L, LEES AJ. Accuracy of clinical diagnosis of idiopathic Parkinson's disease: a clinico-pathological study of 100 cases. Journal of neurology, neurosurgery, and psychiatry. Mar 1992; 55(3):181-184. 
HYEONG-DONG KIM, TAE-YOU KIM, HYUN DONG JAE, SEON-TAE SON, The Effects of Tai Chi Based Exercise on Dynamic Postural Control of Parkinson's Disease Patients while Initiating Gait. J. Phys. Ther. Sci. 23: 265-269, 2011

JANKOVIC J. Os distúrbios extrapiramidais. In: Bennett JC, _PLUM F. Tratado de medicina interna. Rio de Janeiro, Guanabara-Koogan, 1997. p.2254-59.

JANKOVIC J. Parkinson Disease; Clinical Features and Diagnostics. J Neurol Neurosurg Psychiartry, v. 79, p. 368-376, 2008.

JI Z., TAO Y.,2QIAN G., XIAO C. YA. A Meta-Analysis on the Efficacy of Tai Chi in Patients with Parkinson's Disease between 2008 and 2014, Hindawi Publishing Corporation Evidence-Based Complementary and Alternative Medicine

JINHU C., ZHENLONG G., LIQIN W., GUANGYAO O., BOQING M., YANQIN W. Meta-Analysis: Overweight, Obesity, and Parkinson's Disease, International Journal of Endocrinology Volume 2014Junho de 2010.

HYE-JUNG CHOI, CAROL EWING GARBER, TAE-WON JUN, YOUNG-SOO JIN, SUN-JU CHUNG, AND HYUN-JOO KANG. Therapeutic Effects of Tai Chi in Patients with Parkinson's Disease.IRSN Neurol 2013

KENNY ER, O'BRIEN JT, FIRBANK MJ, BLAMIRE AM. 2013. Subcortical connectivity in dementia with Lewy bodies and Alzheimer's disease. British $\mathbf{J}$ Psychiat: J Ment Sci 203: 209-214.

KERANEN, T., KAAKKOLA, S., SOTANIEMI, K., LAULUMAA, V., HAAPANIEMI, T., JOLMA, T., ET AL. (2003). Economic burden and quality of life impairment increase with severity of PD. Parkinsonism Relat Disord, 9(3), 163-168.

KRINGELBACH, M.L. Princípios translacional de estimulação profunda do cérebro. Nature Reviews Neuroscience, v. 8, p. 623-635, 2007.

KURAMOTO, A.M.; Terapeutic benefits of tai chi exercise: research review. Wisconsin Medical Journal.v.105,n.7,p.42 a 46,2006

KURZ, I.; ODDSSON, L.; MELZER, I. Characteristics of balance control in older persons who fall with injury-A prospective study. Journal of Electromyography and Kinesiology, v. 23, n. 4, p. 814-819, 2013. ISSN 1050-6411.

KUTNER, N.G.; BARNHART, H.; WOLF, S.L.; MCNEELY, E.; XU, T. Self-report benefits of Tai Chi practice by older adults. The Journals of Gerontology. Series B, Psychological Sciences and Social Sciences, v. 52B, n. 5, p. 242-246, 1997.

LAMÔNICA, D. A. C, FUKUSHIRO, A. P, MIGUEL, H. C. A importância do processo terapêutico fonoaudiológico em portador de Síndrome Parkinsoniana:estudo de caso. Salusvita, Bauru, v. 16, n.1, p. 125-133, 2003.

LAN AE, LOZANO AM. Parkinson's disease. First of two parts. N Engl J Med. 1998; 339:1044-53. [PubMed: 9761807] 
LEES, A.JY, J.; REVESZ, T. Parkinson's disease. Lancet, v. 373, p. 2055-

LELARD, T,; DOUTRELLOT, P.L.; DAVID, P.; AHMAIDI, S.,Effects of a 12-week Tai Chi Chuan program versus a balance training program on postural control and walking ability in older people. Archives Physiology Medical Rehabil, v.;91,p.914,2010

LI F, HARMER P, FITZGERALD K, et al. Tai Chi and postural stability in patients with Parkinson'sdisease. N Engl J Med. 2012; 366:511-519. [PubMed: 22316445]

LI, J.X.; HONG Y.; CHAN, K.M. Tai chi: physiological characteristics and beneficial effects on health. British Journal of Sports Medicine, v.35, n. 3, p.148-156, 2001.

LIMONGI, J. C. P. Conhecendo Melhor a Doença de Parkinson. 1a ed. São Paulo, 2000.

LIU X, MILLER YD, BURTON NW, BROWN WJ. A preliminary study of effects of tai chi and Qigong medical exercise on indicator of metabolic syndrome glycemic control health-related quality of life and psychological health in adults with elevated blood glucose. Br J Sport Med. 2010;44(10):704-9.

LÓPEZ JR, FERNÁNDEZ NP. Caracterización de la interacción sensorial en posturografía. Acta Otorrinolaringol Esp. 2004; 55:62-6

LORD, S. R. et al. Lateral stability, sensorimotor function and falls in older people. Journal of the American Geriatrics Society, v. 47, n. 9, p. 1077-1081, 1999. ISSN 1532-5415.

LUNDY-EKMAN, Laurie. Neurociência: Fundamentos para a Reabilitação. Rio de Janeiro: Elsevier, 2008

LUNDY-EKMAN, L. Neurociência: fundamentos para a reabilitação.; Nature Letters, Vol 463, 28 January 2010,doi:10.1038/nature08636

M. A. HIRSCH', B. G. FARLEY. Exercise and neuroplasticity in persons living with Parkinson's disease. EURJ PHYS REHABIL MED 2009:35:215-29

M. E. HACKNEY AND G. M. EARHART, "Health-related quality of life and alternative forms of exercise in Parkinson disease," Parkinsonism and Related Disorders, vol. 15, no. 9, pp. 644-648, 2009.

M. E. HACKNEY AND G. M. EARHART, "Tai Chi improves balance and mobility in people with Parkinson disease," Gait and Posture, vol. 28, no. 3, pp. 456-460, 2008.

MACHT M, et al. Predictors of freezing in Parkinson's disease: a survey of 6,620 patients. Mov Disord 2007; 22:953-6. 
MAKI, B. E.; HOLLIDAY, P. J.; TOPPER, A. K. A prospective study of postural balance and risk of falling in an ambulatory and independent elderly population. Journal of gerontology, v. 49, n. 2, p. M72-M84, 1994. ISSN 0022-1422.

MATIDA AB, VIANNA LG, LIMA RM, PEREIRA MM, BEZERRA LMA, SÁ EJT. Tai Chi Chuan em mulheres idosas: Efeitos na ergoespirometria e composição corporal. R. bras. Ci. e Mov 2013

MATSUDO, S. E. A. Questionário internacional de atividade física (IPAQ): estudo de validade e reprodutibilidade no Brasil. Revista Brasileira de Atividade Física e Saúde., v. Vol. 6, n. n. 2, p. 18,2001.

MATSUDO, S. M. M. Envelhecimento e atividade física. Londrina: Midiograf, 2001.

MATTHEWS MM, WILLIAMS HG (2008) Can Tai Chi enhance cognitive vitality? A preliminary study of cognitive exercise control in older adults after A Tai Chi intervention. J S C Med Assoc 104: 255-257.

MELZER, I.; BENJUYA, N.; KAPLANSKI, J. Postural stability in the elderly: a comparison between fallers and non-fallers. Age and ageing, v. 33, n. 6, p. 602-607, 2004. ISSN 0002-0729.

MIYAMOTO S.T., LOMBARDI J., BERG L.R.RAMOS L.R., NATOUR J. Brazilian version of the Berg balance scale, Brazilian Journal of Medical and Biological Research (2004) 37: 1411-1421

MORETTIN M, MARIOTTO LD, COSTA FILHO OA. Avaliação da efetividade da reabilitação vestibular em pacientes com queixas vestibulares. Arq Int Otorrinolaringol. 2007; 11(3):284-92.

MORO K., YAMADA T., TANABE M., TAKEUTI T., IKAWA T., KAWAMOTO H., FURUSAWA J., OHTANI M., FUJII H., KOYASU S.,MOYER, V. A. (2012). Prevention of falls in community-dwelling older adults: U.S. preventive services task force recommendation statement. Annals of Internal Medicine, 157(3), 197-204. doi: 10.7326/0003-4819-157-3-201208070-00462

NEPOMUCENO MM, FORMIGONI CE, FERRIOLI E. Estudo do equilíbrio corporal em adultos idosos avaliados em posturografia computadorizada. Acta ORL/Técnicas em Otorrinolaringologia. 2010;28:44-51.

NERI G. R. S. Estudo de Associação entre Adiposidade Corporal, Força Muscular, Distribuição de Pressão Plantar, Estabilidade Postural e Risco de Quedas em Mulheres Idosa. 144 f. Dissertação (Mestrado em Educação Física) - Programa de Pós-Graduação em Educação Física - Universidade de Brasília, Brasília, 2016

NI X., LIU S., 3 , Lu F., SHI X., GUO X. Efficacy and Safety of Tai Chi for Parkinson's Disease: A Systematic Review and Meta-Analysis of Randomized Controlled Trials. PLOS ONE Tai Chi for Parkinson's Disease. June 2014 | Volume 9 | Issue 6 | e9937 
NICE - National Institute for Health and Care Excellence. Falls: assessment and prevention of falls in older people. Last updated June 2013. (http://guidance.nice.org.uk/CG161)

NIGG, B. M., \& HERZOG, W. (2007). Biomechanics of the muscle-skeletal system (3rd ed.). New Jersey: Wiley.

O'SULLIVAN, S.B. - Doença de Parkinson. In: O'SULLIVAN _SCHMITZ, T.J.O'BRIEN M, DODD KJ, BILNEY B. A qualitative analysis of a progressive resistance exercise programme for people with Parkinson's disease. Disabil Rehabil. 2008; 30(18):1350-1357.

OKUMA, S.S.; Um modelo pedagógico de educação física para idosos. . In: SAFONS, M.P.; PEREIRA, M.M. (Org). Educação Física para Idoso: Por uma Prática Fundamentalista. 2. ed. Brasília: CERF-DF, 2007. p. 105-112.

OXTOBY, Marie; WILLIAMS, Adrian. Tudo sobre doença de Parkinson: respostas às suas dúvidas. São Paulo: Andrei, 2000.

PAHWA R, LYONS KE. Handbook of Parkinson's disease. 4th ed. New York: Informa Heathcare USA; 2007

PAIVA, Lílian Saldanha. Avaliação do equilíbrio em pessoas com doença de Parkinson por meio de exame de posturografia em unidade virtual. $87 \mathrm{f}$. Dissertações (Mestrado em Ciências Médicas) - Universidade Federal do Rio Grande do Sul, Porto Alegre, 2011

PALERMO S, BASTOS ICC, MENDES MFX, TAVARES EF, SANTOS DCL, RIBEIRO AFC. Avaliação e intervenção fonoaudiológica na doença de Parkinson. Análise clínica-epidemiológica de 32 pessoas. Rev Bras Neurol 2009; 45:17-24.

PANDEY S. Parkinson's disease: recent advances. J Assoc Physicians India. Jun 2012; 60:30-32)

PARK A, ZID D, RUSSELL J, MALONE A, RENDON A, WEHR A, LI X. Effects of a formal exercise program on Parkinson's disease: a pilot study using a delayed start design. Parkinsonism Relat Disord. 2014;20:106-11

PAULISTA, H. R. A Instabilidade Postural na Doença de Parkinson e os Efeitos do Treinamento de Força. 2013. 91 f. Dissertação (Mestrado em Educação Física) Programa de Pós-Graduação em Educação Física - Universidade de Brasília, Brasília, 2013

PEREIRA, M.M, GOMES. L., PAULA. A.P., e SAFONS, M.P. Tai Chi Chuan nos tratamentos da dor em Idosos: Revista Efdeportes, Revista digital, Buenos Aires, Ano13, № 123, 2008

PEREIRA, M.M. Efeitos do Tai Chi Chuan na força dos músculos extensores dos joelhos e no equilíbrio em mulheres idosas. 2005. 77 f. Dissertação (Mestrado em 
Educação Física) - Programa de Pós-Graduação em Educação Física Universidade Católica de Brasília, Brasília, 2005.

PEREIRA, M.M.; SILVA, N. A.; L.; COSTA, J.N.A.; GONÇALVES, C.D.; MATIDA, A.B.; SAFONS, M.P; PAULA, A.P.; GOMES, L.; Protocolo de intervenção de Tai Chi Chuan para idosos. Revista Digital Lecturas Educacion Física $Y$ Deportes, Revista Digital- http://www.efdeportes.com/efd139/protocolo-de-intervencao-de-taichichuan. htm - Buenos Aires - Año 14 - № 139 - Diciembre de 2009. Acessado em physical therapy program in someone with Parkinson's disease: A case report.

PIERUCCINI-FARIA F, MENUCHI MRTP, VITÓRIO R, GOBBI LTB, STELLA F, GOBBI S. Parâmetros cinemáticos da marcha com obstáculos em idosos com doença de Parkinson, com e sem efeito da levodopa: um estudo piloto. Rev Bras Fisioter 2006; 10:233-9.

PIIRTOLA, M.; ERA, P. Force platform measurements as predictors of falls among older people-a review. Gerontology, v. 52, n. 1, p. 1-16, 2006. ISSN 1423-0003

PODSIADLO, D.; RICHARDSON, S. The timed "Up \& Go": a test of basic functional mobility for frail elderly persons. J Am Geriatr Soc, v. 39, n. 2, p. 142-8, 1991.

R.G. ROBINSON, P.R. MCHUGH, Measurement of appetite disturbances in psychiatric disorders .Journal of Psychiatric Research Volume 12, Issue 1, April 1975, Pages 59-68

RASCOL, O.; LOZANO, A.; STERN, M.; POEWE, W. Milestones in Parkinson's.

REBELATTO JR, CALVO JI, OREJUELA JR, POTILHO JC. Influência de um programa de atividade física de longa duração sobre força muscular e a flexibilidade corporal de mulheres idosas. Rev. Bras. Fisioterapia 2006; 10: 127-32.

REIS T. Doença de Parkinson: pessoas, familiares e cuidadores. Porto Alegre: Palloti, 2004.

RICCI, NATALIA AQUARONI; GAZZOLA, JULIANA MARIA; COIMBRA, IBSEN BELLINI. Sistemas sensoriais no equilíbrio corporal de idosos. Arq. Bras. Ciên. Saúde, Santo André, v.34, n.2, p.94-100, 2009.

RIKLI RE, JONES JC. Teste de Aptidão Física para Idosos. Human Kinetics. (Tradução de Sonia Regina de Castro Bidutte), Manole, São Paulo, 2008.

RIKLI, R.E.; Evalution functional ability of older adults. In: SAFONS, M.P.; PEREIRA, M.M. (Org). Educação Física para Idoso: Por uma Prática Fundamentalista. Brasíli: CREF/DF. 2007. p. 73-84.

ROBERTSON MC, DEVLIN N, GARDNER MM, CAMPBELL AJ. Effectiveness and economic evaluation of a nurse delivered home exercise programme to prevent falls. 1: Randomised controlled trial. Br Med J. 2001;322:697-9. 
RODRIGUEZ P, CANCELA JM, AYAN C, DO NASCIMENTO C, SEIJOMARTINEZ $M$. Effects of aquatic physical exercise on the kinematic gait pattern in patients with Parkinson's disease: a pilot study. Rev Neurol. 2013;56(6):315- 20. Epub 2013/03/14.

SAFONS, M.P.; PEREIRA, M.M.; COSTA, J.N.A; Metodologia gerontologias aplicados ao exercício físico para idoso. In:FREITAS, E.V.; PY,L.; (2011)

SAMII A, NUTT JG, RANSOM BR, Parkinson's disease. Lancet. 2004 May 29; 363(9423):1783-93.

SCHAPIRA AH, TOLOSA E: Molecular and clinical prodrome of Parkinson disease: implications for treatment. Nat Rev Neurol 2010; 6(6):309-317.

SCHENKMAN, M., ELLIS, T., CHRISTIANSEN, C., BARON, A. E., TICKLEDEGNEN, L., HALL, D. A., et al. (2012). Exercise for People in Early- or Mid-

SCHRAG, A.; BEN-SHLOMO, Y.; QUINN, N. How valid is the clinical diagnosis of Parkinson's disease in the community? J Neurol Neurosurg Psychiatry, v. 73, n. 5, p. 529-34, 2002.

SERAPIONI, M. (2000). Métodos qualitativos e quantitativos na pesquisa social em saúde: algumas estratégias para a integração. Ciência \& Saúde Coletiva, 5, 12, 187-192.

SETHI KD. Clinical aspects of Parkinson disease. Curr Opin Neurol. Aug 2002; 15(4):457-460.

SHENKMAN M. L.; CLARK K.; XIE T.; KUCHIBHATLA M.; SHINBERG M.; RAY L.; Spinal movement and performance of standing reach task in participants with and without Parkinson disease. Phys Ther, vol. 81, p. 1400-1411, 2001

SHUMWAY-COOK, A. \& WOOLLACOTT, M. Controle motor: Teoria e aplicações práticas. Ed. Manole, 2010, 632p.

SILVA, P. F. C.; PEREIRA, R. P. R.; SILVA, S. M.; CORRÊA, J. C. F. Correlação entre perfil clínico, qualidade de vida e incapacidade dos pacientes da Associação Brasil Parkinson. ConScientiae Saúde, v. 10, n. 4, p. 650-656, 2011

SMIDT N, DE VET HC, BOUTER LM, et al. Effectiveness of exercise therapy: a bestevidence summary of systematic reviews. Aust J Physiother. 2005; 51(2):71-85.

SOARES, A.V. A contribuição visual para o controle postural. Revista Neurociências, 2010.

SPEELMAN, A. D. et al. How might physical activity benefit patients with Parkinson disease? Nat Rev Neurol, v. 7, n. 9, p. 528-34, 2011.

STAMEY W., JANKOVIC J. (2008) Impulse control disorders and pathological gambling in patients with Parkinson disease. Neurologist 14: 89-99 
STANKOVIC I. The effect of physical therapy on balance of patients with Parkinson's disease. Int J Rehabil Res. Mar 2004; 27(1):53-57.

STENO R.; CARLO T.; LUCIO M.; ALESSIA A.; PAOLO M.; FRANCESCO F.; FRANCESCO P.; AND A. C. Balance Dysfunction in Parkinson's Disease. BioMed Research International Volume 2015, Article ID 434683, 10 pages http://dx.doi.org/10.1155/2015/434683

SUN, X.S.; XU, Y.G. \& XIA, Y.J. Determination of E-rosette-forming lymphocyte in aged subjects with Tai Ji Quan exercise. International Journal of Sports Medicine, v. 10, p. 217-219, 1989.

TAKAKUSAKI, K.; SAITO, H.K.; HARADA, H.; KASHIWAYANAGI, M. Role of basal ganglia-brainstem pathways in the control of motor behaviors. Neuroscience Research, v.50, p.137-51, 2004

TANNER CM, ROSS GW, JEWELL SA, HAUSER RA, JANKOVIC J, FACTOR SA, et al. Occupation and risk of Parkinsonism: a multicenter case-control study. Arch Neurol. 2009;66(9):1106-1113.

TEIVE HAG. Etiopatogenia da doença de Parkinson. Rev Neurocienc 2005; 13:20114.

THOMAS, J., NELSON J. K. Métodos de Pesquisa em Atividade Física. 6ª ed. Porto Alegre: 2012.

TSANG WWN, Hui-Chan CWY. Effects of tai chi on joint proprioception and stability limits in elderly subjects. Med. Sci. Sports Exerc. 2003; 35.

TUNG, T. Wushu: O guia chinês para a saúde e o preparo físico da família. Rio de Janeiro: Record, 1981. $144 \mathrm{p}$

UMPHRED, Darcy Ann. Reabilitação Neurológica. Rio de Janeiro: Elsevier, 2009

VISSER JE, CARPENTER MG, KOOIJ HVD, BLOEM BR. The clinical utility of posturography. Clin Neurophysiol. 2008;119:2424-3

WAHBEH H., SIEGWARD., ELSAS., AND BARRY S. OKEN. Mind-body interventions: Applications in neurology. Neurology. 2008 June 10; 70(24): 23212328

WIECZOREK, SILVANA APARECIDA. Equilíbrio em adultos e idosos: relação entre tempos de movimento e acurácia durante movimentos voluntários na postura em pé. 96 f. Dissertação (Mestrado em Educação Física) - Universidade de São Paulo, São Paulo, 2003.

WU GE, ZHAO FANG, ZHOU XINGLONG, WEI LIU. Improvement of isokinetic knee extensor strength and reduction of postural sway in the elderly from long-term Tai Chi 
exercise. Archives of Physical Medicine and Rehabilitation Volume 83, Issue 10, October 2016, Pages 1364-1369

XAVIER, J.J.S, Equilíbrio em Idosos e Prática de Tai Chi Chuan. 2008, 156 f. Dissertação (Mestrado) na faculdade de Medicina de Ribeirão Preto - Área de concentração Saúde na Comunidade. Ribeirão Preto. São Paulo, 2008

YAN YANG, YAN-LEI HAO, WEN-JING TIAN, LI GONG, KUI ZHANG, QI-GUANG SHI, DA-FANG SUN, CUI-LAN LI AND ZHI-LING ZHAO. The effectiveness of Tai Chi for patients with Parkinson's disease: study protocol for a randomized controlled trial. Yang et al. Trials (2015) 16:111 DOI 10.1186/s13063-015-0639-8

YORITAKA A. Sleep Disturbances in Parkinson's disease. J Neurol Disord Stroke 2014. 2(2): 1043.

ZHANG Y, JIN L, ZHAO L, WANG J, Decreased serum ceruloplasmin levels characteristically aggrave nigral iron deposition in Parkinson's disiase. Brain. 2011; 134(1) 50-58.

ZHANG D., LIU X., CHEN J., LIU B., WANG J. (2015). Widespread increase of functional connectivity in Parkinson's disease with tremor: a resting-state FMRI study. Front. Aging. Neurosci.7: 6.10.3389/ fnagi.2015.00006 


\section{LISTA DE ANEXOS}

ANEXO I - Cartaz de divulgação do programa...................................................84

ANEXO II - Parecer do Comitê de Ética em Pesquisa (CEP) …............................85

ANEXO III - Termo de Consentimento Livre e Esclarecido (TCLE) ........................86

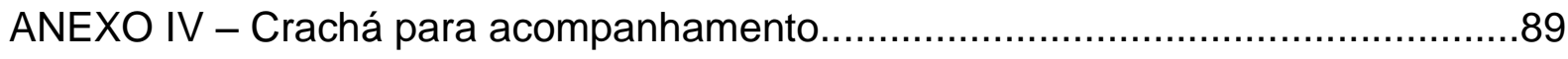

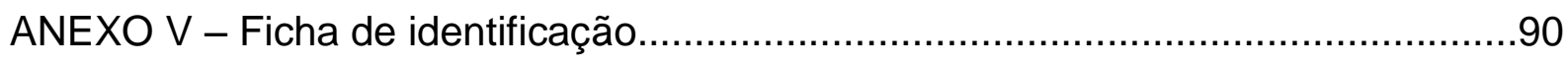

ANEXO VI - Mini Exame do Estado Mental ..........................................................

ANEXO VII - Escala de Equilíbrio de Berg.....................................................94

ANEXO VIII - MDS-UPDRS III - Exame motor..................................................100 
ANEXO I

CARTAZ DE DIVULGAÇÃO DO PROGRAMA

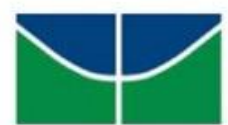

Universidade de Brasília

Faculdade de Educação Física

\section{ATIVIDADE FÍSICA PARA PESSOAS COM DOENÇA DE PARKINSON}

O programa VIVA ATIVO convida todas as pessoas diagnosticas com a doença de Parkinson para participarem de nossas modalidades de atividade física orientada e GRATUITA.

Local: Centro Olímpico da Universidade de Brasília

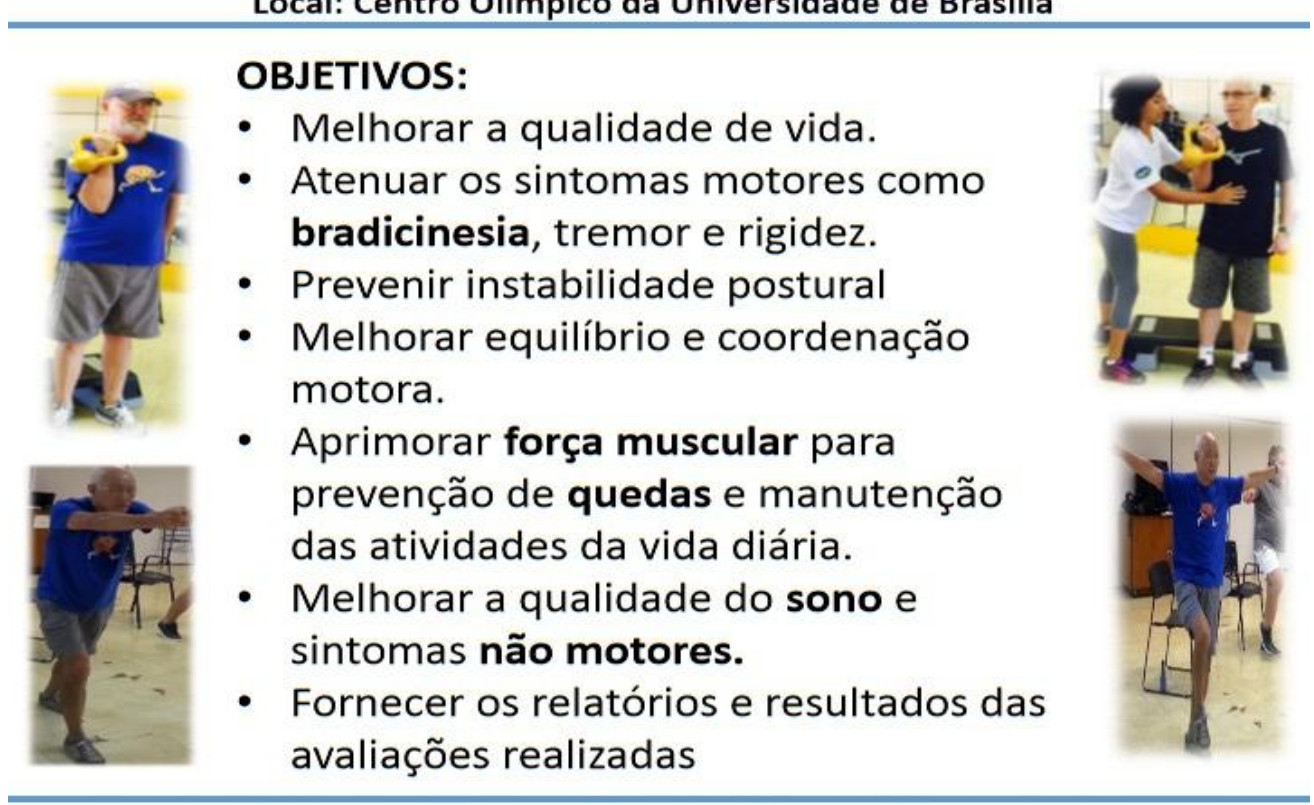

AVALIAÇÕES : DENSITOMETRIA ÓSSEA (composição corporal), FORÇA MUSCULAR, EQUILÍBRIO, DESEMPENHO FUNCIONAL, QUALIDADE DO SONO.

Supervisão e Orientação: Professora Dra. Lídia Bezerra
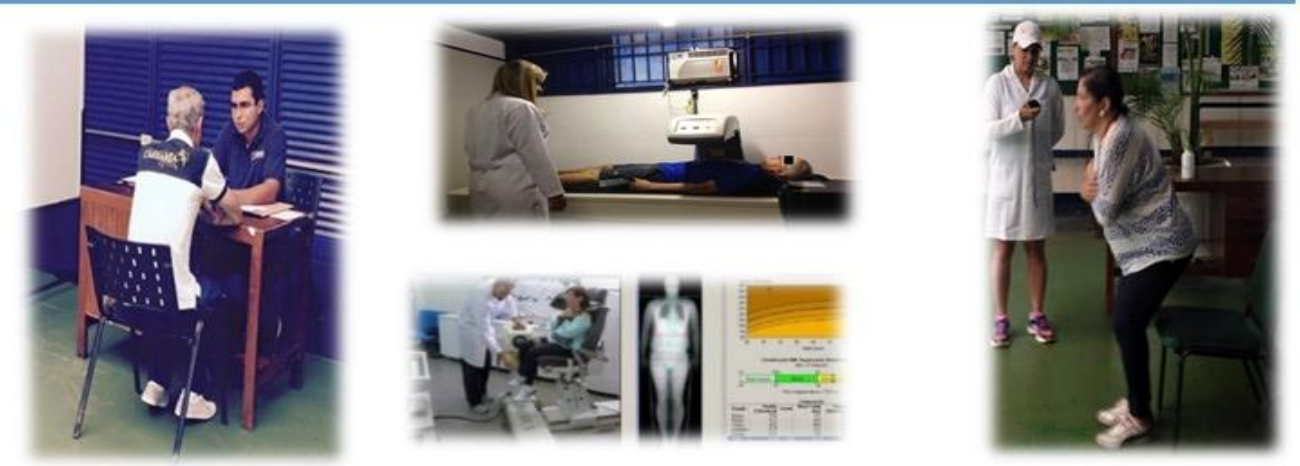

Camila Wells - (61) 9961-1703 - e-mail-camilawells@yahoo.com.br Junhiti Nagazawa- (61) 9994-2337-e-mail junhiti@gmail.com 
ANEXO II

PARECER DO COMITÊ DE ÉTICA EM PESQUISA (CEP)

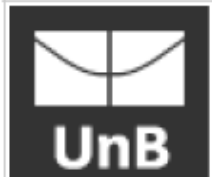

UNB - FACULDADE DE CIÊNCIAS DA SAÚDE

Plateoforma

\section{COMPROVANTE DE ENVIO DO PROJETO}

DADOS DO PROJETO DE PESQUISA

Título da Pesquisa: $\quad$ EFEITOS DO TAI CHI CHUAN NA FUNCIONALIDADE, COMPOSIÇÃO CORPORAL E QUALIDADE DE VIDA EM INDIVÍDUOS COM DOENÇA DE PARKINSON.

Pesquisador: lidia mara aguiar bezerra

Versão: 2

CAAE: $\quad 52721415.2 .0000 .0030$

Instituição Proponente:

Faculdade de Ciências da Saúde da Universidade de Brasília

DADOS DO COMPROVANTE

Número do Comprovante:

004323/2016

Patrocionador Principal:

Financiamento Próprio

Informamos que o projeto EFEITOS DO TAI CHI CHUAN NA FUNCIONALIDADE, COMPOSIÇÃO CORPORAL E QUALIDADE DE VIDA EM INDIVÍDUOS COM DOENÇA DE PARKINSON. que tem como pesquisador responsável lidia mara aguiar bezerra, foi recebido para análise ética no CEP UnB Faculdade de Ciências da Saúde em 26/01/2016 às 09:17.

Endereço: Faculdade de Ciências da Saúde - Campus Darcy Ribeiro

Bairro: Asa Norte

CEP: $70.910-900$

UF: DF Município: BRASILIA

Telefone: (61)3107-1947

E-mail: cepfsunb@gmail.com 


\begin{abstract}
ANEXO III
TERMO DE CONSENTIMENTO LIVRE E ESCLARECIDO (TCLE)
\end{abstract}

\author{
vivallativo \\ UNIVERSIDADE DE BRASÍLIA \\ FACULDADE DE EDUCAÇÃO FÍSICA \\ CAMPUS UNIVERSITÁRIO DARCY RIBEIRO - BRASÍLIA/DF \\ Telefone: (61) 3107-2500 \\ http://www.fef.unb.br/
}

Convidamos o (a) Senhor (a) a participar do projeto de pesquisa "Efeitos do Tai Chi Chuan sobre a capacidade funcional, composição corporal e qualidade de vida em pessoas acometidas com doença de Parkinson", sob responsabilidade do pesquisador Junhiti Nagazawa. A pesquisa tem como objetivo: verificar qual o efeito de um programa de treinamento com Tai Chi Chuan sobre a força muscular, equilíbrio, estabilidade postural, flexibilidade e velocidade para executar uma tarefa motora e sintomas não motores. $O$ intuito da pesquisa é promover um maior conhecimento sobre os sintomas motores e não motores da doença de Parkinson, melhorar a qualidade de vida e a capacidade funcional.

O (a) senhor (a) receberá todos os esclarecimentos necessários antes e no decorrer da pesquisa e the asseguramos que seu nome não aparecerá, sendo mantido o mais rigoroso sigilo pela omissão total de quaisquer informações que permitam identificá-lo (a).

As pesquisas ocorrerão em três fases:

a) Avaliação inicial (todos os voluntários passarão por uma bateria de testes físicos, avaliação motora, questionários para avaliação da qualidade de vida e função cognitiva, avaliação da composição corporal;

b) Programa de treinamento de Tai Chi Chuan com duração de 3 meses (2 vezes por semana durante 50 minutos);

c) Avaliação após 3 meses (será repetida toda a bateria de teste da avaliação inicial).

Todos que estão sobre tratamento dopaminérgico serão submetidos a uma avaliação motora feita por testes motores da Escala Unificada de avaliação para Doença de Parkinson (UPDRS seção III) no período ON da medicação, que é o momento de melhor resposta motora porque a medicação está no auge do seu 
efeito, sendo que tal estado normalmente ocorre cerca de 30 minutos a 1 hora após tomar a medicação dopaminérgica.

Previamente a estas avaliações será realizada uma avaliação da condição clínica geral (anamnese) e do estado cognitivo por meio de um questionário chamado Mini Exame do Estado Mental (MEEM). A qualidade de vida será avaliada por meio de um questionário chamado de Questionário de Qualidade de Vida para Doença de Parkinson (PDQL), a força de preensão manual será avaliada por um dinamômetro hidráulico de preensão manual e a força muscular será avaliada por um aparelho isocinético.

Além disso, serão realizados testes funcionais e um exame da composição corporal. O senhor (a) poderá optar em participar de cada uma das fases. O tempo de permanência na FEF para a realização das avaliações será de no mínimo 30 minutos e no máximo 90 minutos. Os horários de sua participação serão previamente agendados e você deverá estar nos locais designados nos dias e horários marcados e informar ao pesquisador responsável qualquer desconforto que por acaso venha a perceber.

Todas as avaliações serão realizadas na Faculdade de Educação Física (FEF) da Universidade de Brasília e o programa de treinamento do Tai Chi Chuan e Treinamento Resistido com pesos será no Centro Olímpico, sempre sob a supervisão de um profissional capacitado da área de Educação Física.

Esta pesquisa não lhe acarretará gastos e as avaliações não possuem contraindicações, porém, fica garantida a indenização diante de eventuais danos, comprovadamente decorrentes da participação na pesquisa. Esta pesquisa não deverá ser aplicada em pessoas que tenham sequelas de outras patologias neurológicas que não seja a doença de Parkinson e nem em pessoas que tenham próteses ou usem órteses em membros superiores e inferiores, ou apresentem qualquer patologia ou lesão muscular ou óssea que atrapalhe a realização de movimentos ativos livres dos membros.

Com os resultados desta pesquisa poderemos contribuir para uma melhor avaliação motora, gerando um melhor acompanhamento da progressão dos sintomas motores e possibilitando favorecer um diagnóstico clínico precoce a partir de novas pesquisas realizadas com base nesse estudo. Desta forma, estaremos auxiliando os profissionais de saúde na avaliação, tratamento e acompanhamento da progressão da doença de Parkinson. Os dados e materiais utilizados na pesquisa ficarão sob a guarda dos pesquisadores por um período mínimo de cinco anos, sendo que as informações obtidas neste experimento poderão ser utilizadas como dados de pesquisa científica, podendo ser publicadas e divulgadas. Você poderá ter acesso aos seus resultados, por intermédio do pesquisador responsável.

A pesquisa será imediatamente suspensa, caso o pesquisador perceba algum risco ou dano à sua saúde. No improvável dano físico resultante da participação nesta pesquisa, o tratamento será viabilizado no local mais próximo e apropriado de assistência médica; porém, nenhum benefício especial será concedido para compensação ou pagamento de um possível tratamento. A sua participação nesta pesquisa é voluntária, isto é, não há pagamento por sua colaboração. O senhor (a) estará livre para parar em qualquer momento ou desistir de participar da pesquisa. 
Se o Senhor (a) tiver qualquer dúvida ou reclamação, poderá entrar em contato com o pesquisador responsável, Junhiti Nagazawa no telefone (61) 9994 2337 ou no e-mail: junhiti@gmail, bem como com a Prof.. Dr.. Lídia Mara Bezerra Aguiar de Melo, Coordenadora do presente projeto, telefone (61) 99958907 ou no email:lidia.bezerra@gmail.com.

Este projeto foi aprovado pelo Comitê de Ética em Pesquisa da Faculdade de Ciências da Saúde da Universidade de Brasília (CEP-FS/UnB). O CEP é composto por profissionais de diferentes áreas cuja função é defender os interesses dos participantes da pesquisa em sua integridade e dignidade e contribuir no desenvolvimento da pesquisa dentro de padrões éticos. As duvidas com relação ao TLCE - o Comitê de Ética e Pesquisa da Faculdade de Ciência da Saúde da UnB (CEP/FS) poderão ser sanadas no telefone (61) 31071947 ou pelo e-mail cepfs@unb.br ou cepfsunb@gmail.com, horário de atendimento de 10:00hs às 12:00hs e de 13:30hs às 15:30hs, de segunda a sexta-feira. O CEP/FS se localiza na Faculdade de Ciências da Saúde, Campus Universitário Darcy Ribeiro, Universidade de Brasília, Asa Norte.

Caso concorde em participar, após ter lido e esclarecido suas dúvidas, pedimos que assine este documento que foi elaborado em duas vias, uma ficará com o pesquisador e outra com Senhor (a).

Data: 1

\section{Assinatura do participante}

Nome: $R G$ :

\section{Assinatura da testemunha}

Nome: $R G$ : 


\section{ANEXO IV}

CRACHÁ PARA ACOMPANHAMENTO

NOME:

ID:

Data da Avaliação:

Data Nascimento:

Peso Corporal: $\mathrm{Kg}$

Altura: $\mathrm{cm}$

Cintura: cm Quadril: $\mathrm{cm}$

AVALIAÇÃO 1 (LABORATÓRIO):

( ) EQUILÍBRIO/ PRESSÃO PLANTAR

AVALIAÇÃO 2 (FUNCIONAIS):

( ) TUG

AVALIAÇÃO 3 (QUESTIONÁRIOS):

( ) MEEM

( ) UPDRS III

( ) BERG 


\section{ANEXO V}

FICHA DE IDENTIFICAÇÃO

Nome:

Contato:

Emergência:

Data de Nascimento:

Cor:

Estado Civil:

Sexo: ( ) Mac. ( ) Fem.

Endereço:

Naturalidade:

Possui Plano de Saúde? ( ) Sim ～( ) Não

Convenio:

Hipertensão arterial? ( ) Sim ( ) Não Fumante? ( ) Sim ( ) Não

Tempo de Diagnóstico:

Laudo Médico:

Trabalho Renumerado: ( ) Sim ( ) Não

Aposentado: ( ) Sim ( ) Não

Ocupação Atual (ou anterior, caso aposentado):

Escolaridade:

Alergia? ( ) Sim ( ) Não Quais? 


\begin{tabular}{|l|l|l|}
\hline Medicamentos & Dosagem & Horários \\
\hline & & \\
\hline & & \\
\hline & & \\
\hline & & \\
\hline & & \\
\hline & & \\
\hline & & \\
\hline
\end{tabular}




\section{ANEXO VI}

\section{MINI-EXAME DO ESTADO MENTAL (MEEM)}

Universidade de Brasília

Faculdade de Educação Fisica viva Yativo

Data:

\section{Linguagem}

6. Aponte para um lápis e um relógio (caso não haja relógio, aponte para a mesa). Faça o voluntário dizer o nome desses objetos conforme você os aponta.

\begin{tabular}{c|c|} 
Pt. Obtido & Pt. Máx \\
\hline & 2 \\
\hline
\end{tabular}

2. Onde estamos?

\begin{tabular}{l|c|c} 
& Pt. Obtido & Pt. Máx \\
\hline Local? & & 1 \\
\hline Instituição (casa, rua? & & 1 \\
\hline Bairro? & & 1 \\
\hline Cidade? & & 1 \\
\hline Estado? & & 1 \\
\hline
\end{tabular}

\section{Registros}

3. Mencione 3 palavras levando 1 segundo para cada uma. Peça ao paciente para repetir as 3 palavas que você mencionou. Estabeleça um ponto para cada resposta correta.

$$
\begin{aligned}
& \text { - VASO - CARRO - TIJOLO - } \\
& \qquad \begin{array}{c|c}
\text { Pt. Obtido } & \text { Pt. Máx } \\
\hline & 3 \\
\hline
\end{array}
\end{aligned}
$$

\section{Atenção é cálculo}

4. Sete seriado:(100-7=93-7=86-7=79-7=72-7=65)

Ou soletrar a palavra MUNDO de trás para frente.

Estabeleça um ponto para cada resposta correta. Interrompa após cinco respostas.

\begin{tabular}{c|c} 
Pt. Obtido & Pt. Máx \\
\hline & 5 \\
\hline
\end{tabular}

\section{Lembranças (memória de evocação)}

5. Pergunte o nome das 3 palavras aprendidas na questão 2. Estabeleça um ponto para cada resposta correta.

\begin{tabular}{c|c|} 
Pt. Obtido & Pt. Máx \\
\hline & 3 \\
\hline
\end{tabular}

7. Faça o voluntário repetir

"NEM AQUI, NEM ALI, NEM LÁ"

\begin{tabular}{c|c|} 
Pt. Obtido & Pt. Máx \\
\hline & 1 \\
\hline
\end{tabular}

8. Faça o voluntário seguir o comando de 3 estágios:

"PEGUE O PAPEL"

"DOBRE O PAPEL AO MEIO" "COLOQUE O PAPEL NA MESA COM A MÃO DIREITA"

\begin{tabular}{c|c|} 
Pt. Obtido & Pt. Máx \\
\hline & 3 \\
\hline
\end{tabular}

9. Faça o voluntário ler e obedecer o comando:

"FECHE OS OLHOS"

\begin{tabular}{c|c|} 
Pt. Obtido & Pt. Máx \\
\hline & 1 \\
\hline
\end{tabular}

10. Faça o voluntário escrever uma frase. (A frase deve conter um sujeito e um objeto e fazer sentido). (Ignore erros de ortografia ao marcar o ponto).

\begin{tabular}{c|c} 
Pt. Obtido & Pt. Máx \\
\hline & 1 \\
\hline
\end{tabular}

11. Faça o voluntário copiar o desenho da folha. Estabeleça $\mathrm{m}$ ponto se todos os lados e ângulos forem preservados e se os lados da interseção formarem um quadrilátero.

\begin{tabular}{c|c|} 
Pt. Obtido & Pt. Máx \\
\hline & 1 \\
\hline
\end{tabular}




$$
\bar{\phi}
$$


ANEXO VII

ESCALA DE EQUILÍBRIO DE BERG

\section{viva Yativo}

Nome:

Data:

ÍTENS

Pontuação (0-4)

1. Sentado para em pé

2. Em pé sem apoio

3. Sentado sem apoio

4. Em pé para sentado

5. Transferências

6. Em pé com os olhos fechados

7. Em pé com os pés juntos

8. Reclinar à frente com os braços estendidos

9. Apanhar objeto do chão

10. Virando-se para olhar para trás

11. Girando 360 graus

12. Colocar os pés alternadamente sobre um banco

13. Em pé com um pé em frente ao outro

14. Em pé apoiado em um dos pés

TOTAL

\section{SENTADO PARA EM PÉ}

- INSTRUÇÕES: Por favor, fique de pé. Tente não usar suas mãos como suporte.

( ) 4 capaz de permanecer em pé sem o auxílio das mãos e estabilizar de maneira independente

( ) 3 capaz de permanecer em pé independentemente usando as mãos

( ) 2 capaz de permanecer em pé usando as mão após várias tentativas

( ) 1 necessidade de ajuda mínima para ficar em pé ou estabilizar

( ) 0 necessidade de moderada ou máxima assistência para permanecer em pé 


\section{EM PÉ SEM APOIO}

- $\quad$ INSTRUÇÕES: Por favor, fique de pé por dois minutos sem se segurar em nada.

( ) 4 capaz de permanecer em pé com segurança por 2 minutos

( ) 3 capaz de permanecer em pé durante 2 minutos com supervisão

( ) 2 capaz de permanecer em pé durante 30 segundos sem suporte

( ) 1 necessidade de várias tentativas para permanecer 30 segundos sem suporte

( ) 0 incapaz de permanecer em pé por 30 segundos sem assistência

- Se o sujeito é capaz de permanecer em pé por 2 minutos sem apoio, marque pontuação máxima na situação sentado sem suporte. Siga diretamente para o item \#4.

\section{SENTADO SEM SUPORTE PARA AS COSTAS, MAS COM OS PÉS APOIADOS SOBRE O CHÃO OU SOBRE UM BANCO.}

- INSTRUÇÕES: Por favor, sente-se com os braços cruzados durante 2 minutos.

( ) 4 capaz de sentar com segurança por 2 minutos

( ) 3 capaz de sentar com por 2 minutos sob supervisão

( ) 2 capaz de sentar durante 30 segundos

( ) 1 capaz de sentar durante 10 segundos

( ) 0 incapaz de sentar sem suporte durante 10 segundos

\section{EM PÉ PARA SENTADO}

- INSTRUÇÕES: Por favor, sente-se.

( ) 4 senta com segurança com o mínimo uso das mão

( ) 3 controla descida utilizando as mãos

( ) 2 apóia a parte posterior das pernas na cadeira para controlar a descida

( ) 1 senta independentemente mas apresenta descida descontrolada

( ) 0 necessita de ajuda para sentar

\section{TRANSFERÊNCIAS}


- INSTRUÇÕES: Pedir ao sujeito para passar de uma cadeira com descanso de braços para outra sem descanso de braços (ou uma cama)

( ) 4 capaz de passar com segurança com o mínimo uso das mãos

( ) 3 capaz de passar com segurança com uso das mãos evidente

( ) 2 capaz de passar com pistas verbais e/ou supervisão

( ) 1 necessidade de assistência de uma pessoa

( ) 0 necessidade de assistência de duas pessoas ou supervisão para segurança

\section{EM PÉ SEM SUPORTE COM OLHOS FECHADOS}

- INSTRUÇÕES: Por favor, feche os olhos e permaneça parado por 10 segundos

( ) 4 capaz de permanecer em pé com segurança por 10 segundos

( ) 3 capaz de permanecer em pé com segurança por 10 segundos com supervisão

( ) 2 capaz de permanecer em pé durante 3 segundos

( ) 1 incapaz de manter os olhos fechados por 3 segundos mas permanecer em pé

( ) 0 necessidade de ajuda para evitar queda

\section{EM PÉ SEM SUPORTE COM OS PÉS JUNTOS}

- INSTRUÇÕES: Por favor, mantenha os pés juntos e permaneça em pé sem se segurar

( ) 4 capaz de permanecer em pé com os pés juntos independentemente com segurança por 1 minuto

( ) 3 capaz de permanecer em pé com os pés juntos independentemente com segurança por 1 minuto, com supervisão

( ) 2 capaz de permanecer em pé com os pés juntos independentemente e se manter por 30 segundos

( ) 1 necessidade de ajuda para manter a posição mas capaz de ficar em pé por 15 segundos com os pés juntos

( ) 0 necessidade de ajuda para manter a posição mas incapaz de se manter por 15 segundos

\section{ALCANCE A FRENTE COM OS BRAÇOS EXTENDIDOS PERMANECENDO EM PÉ}


- INSTRUÇÕES: Mantenha os braços estendidos a 90 graus. Estenda os dedos e tente alcançar a maior distância possível. (o examinador coloca uma régua no final dos dedos quando os braços estão a 90 graus. Os dedos não devem tocar a régua enquanto executam a tarefa. A medida registrada é a distância que os dedos conseguem alcançar enquanto o sujeito está na máxima inclinação para frente possível. Se possível, pedir ao sujeito que execute a tarefa com os dois braços para evitar rotação do tronco.)

( ) 4 capaz de alcançar com confiabilidade acima de $25 \mathrm{~cm}$ (10 polegadas)

( ) 3 capaz de alcançar acima de $12,5 \mathrm{~cm}$ (5 polegadas)

( ) 2 capaz de alcançar acima de $5 \mathrm{~cm}$ (2 polegadas)

( ) 1 capaz de alcançar mas com necessidade de supervisão

( ) 0 perda de equilíbrio durante as tentativas / necessidade de suporte externo

\section{APANHAR UM OBJETO DO CHÃO A PARTIR DA POSIÇÃO EM PÉ}

- INSTRUÇÕES: Pegar um sapato/chinelo localizado a frente de seus pés

( ) 4 capaz de apanhar o chinelo facilmente e com segurança

( ) 3 capaz de apanhar o chinelo, mas necessita supervisão

( ) 2 incapaz de apanhar o chinelo, mas alcança $2-5 \mathrm{~cm}$ (1-2 polegadas) do chinelo e manter o equilíbrio de maneira independente

( ) 1 incapaz de apanhar e necessita supervisão enquanto tenta

( ) 0 incapaz de tentar / necessita assistência para evitar perda de equilíbrio ou queda

\section{EM PÉ, VIRAR E OLHAR PARA TRÁS SOBRE OS OMBROS DIREITO E ESQUERDO}

- INSTRUÇÕES: Virar e olhar para trás sobre o ombro esquerdo. Repetir para o direito. O examinador pode pegar um objeto para olhar e colocá-lo atrás do sujeito para encorajá-lo a realizar o giro.

( ) 4 olha para trás por ambos os lados com mudança de peso adequada

( ) 3 olha para trás por ambos por apenas um dos lados, o outro lado mostra menor mudança de peso

( ) 2 apenas vira para os dois lados, mas mantém o equilíbrio

( ) 1 necessita de supervisão ao virar

( ) 0 necessita assistência para evitar perda de equilíbrio ou queda 


\section{VIRAR EM 360 GRAUS}

- INSTRUÇÕES: Virar completamente fazendo um círculo completo. Pausa. Fazer o mesmo na outra direção

( ) 4 capaz de virar 360 graus com segurança em 4 segundos ou menos

( ) 3 capaz de virar 360 graus com segurança para apenas um lado em 4 segundos ou menos

( ) 2 capaz de virar 360 graus com segurança mas lentamente

( ) 1 necessita de supervisão ou orientação verbal

( ) 0 necessita de assistência enquanto vira

\section{COLOCAR PÉS ALTERNADOS SOBRE DEGRAU OU BANCO PERMANECENDO EM PÉ E SEM APOIO}

- INSTRUÇÕES: Colocar cada pé alternadamente sobre o degrau/banco. Continuar até cada pé ter tocado o degrau/banco quatro vezes.

( ) 4 capaz de ficar em pé independentemente e com segurança e completar 8 passos em 20 segundos

( ) 3 capaz de ficar em pé independentemente e completar 8 passos em mais de 20 segundos

( ) 2 capaz de completar 4 passos sem ajuda mas com supervisão

( ) 1 capaz de completar mais de 2 passos necessitando de mínima assistência

( ) 0 necessita de assistência para prevenir queda / incapaz de tentar

\section{PERMANECER EM PÉ SEM APOIO COM OUTRO PÉ A FRENTE}

- INSTRUÇÕES: (DEMOSTRAR PARA O SUJEITO - Colocar um pé diretamente em frente do outro. Se você perceber que não pode colocar o pé diretamente na frente, tente dar um passo largo o suficiente para que o calcanhar de seu pé permaneça à frente do dedo de seu outro pé. (Para obter 3 pontos, o comprimento do passo poderá exceder o comprimento do outro pé e a largura da base de apoio pode se aproximar da posição normal de passo do sujeito).

( ) 4 capaz de posicionar o pé independentemente e manter por 30 segundos

( ) 3 capaz de posicionar o pé para frente do outro independentemente e manter por 30 segundos 
( ) 2 capaz de dar um pequeno passo independentemente e manter por 30 segundos

( ) 1 necessidade de ajuda para dar o passo mas pode manter por 15 segundos

( ) 0 perda de equilíbrio enquanto dá o passo ou enquanto fica de pé

\section{PERMANECER EM PÉ APOIADO EM UMA PERNA}

- INSTRUÇõES: Permaneça apoiado em uma perna o quanto você puder, sem se apoiar

( ) 4 capaz de levantar a perna independentemente e manter por mais de 10 segundos

( ) 3 capaz de levantar a perna independentemente e manter entre 5 e 10 segundos

( ) 2 capaz de levantar a perna independentemente e manter por 3 segundos ou mais

( ) 1 tenta levantar a perna e é incapaz de manter 3 segundos, mas permanece em pé independentemente

( ) 0 incapaz de tentar ou precisa de assistência para evitar queda

( ) PONTUAÇÃO TOTAL (máximo = 56)

Ass. Avaliador: Data: 
ANEXO VII

MDS-UPDRS III - EXAME MOTOR

Universidade de Brasilia

Faculdade de Educação Fisica

\section{viva Yativo}

DATA:

\section{MDS-UPDRS III - EXAME MOTOR}

a) O paciente usa medicamento para o tratamento dos sintomas da DP? ( ) sim ( ) não

b) Estado clínico do paciente: ( ) ON ( ) OFF

c) Tempo desde a última dose do medicamento:

Medicamentos:

1. Fala

0 . Normal.

1. Leve: perda discreta da expressão, dicção ou volume, mas as palavras ainda são facilmente entendidas.

2. Médio: perda discreta da expressão, dicção ou volume, com poucas palavras não compreendidas mas com a maioria das sentenças facilmente entendidas.

3. Moderado: fala difícil de ser entendida com sentenças pobremente compreendida.

4. Severo: a maioria da fala é incompreensível.

\section{Expressão facial}

0 . Normal.

1. Hipomimia mínima com diminuição na frequência do piscar.

2. Face em máscara com leve comprometimento dos movimentos da boca e diminuição da frequência do piscar.

3. Hipomimia moderada com face em máscara e lábios entreabertos por algum tempo.

4. Face em máscara com perda grave da expressão facial e lábios entreabertos por maior período de tempo.

\section{Rigidez}

0 . Ausente

1. Rigidez apenas com ativação manual.

2. Rigidez detectada sem ativação manual mas com amplitude completa de movimento facilmente alcançada.

3. Rigidez detectada sem ativação manual mas a amplitude completa de movimento é alcançada com esforço.

4. Rigidez detectada sem ativação manual e a amplitude completa de movimento não é alcançada.

\begin{tabular}{|l|l|l|l|l|l|}
\hline Item & a)Pescoço & $\begin{array}{l}\text { b)Braço } \\
\text { direito }\end{array}$ & $\begin{array}{l}\text { c)Braço } \\
\text { esquerdo }\end{array}$ & $\begin{array}{l}\text { d)Perna } \\
\text { direita }\end{array}$ & $\begin{array}{l}\text { e)Perna } \\
\text { esquerda }\end{array}$ \\
\hline Pontuação & & & & & \\
\hline
\end{tabular}


4. Finger Tapping (bater dedos continuamente - polegar no indicador em sequências rápidas e com maior amplitude possível, avaliar as mãos separadamente)

0. Normal

1. a) Quebra do ritmo regular com 1 ou 2 interrupções ou hesitações; b) lentidão suave; c) decréscimo da amplitude próximo ao final dos 10 taps.

2. a) Quebra do ritmo regular com 3 ou 5 interrupções ou hesitações; b) lentidão leve; c) decréscimo da amplitude no meio da sequência dos 10 taps.

3. a) Quebra do ritmo regular com mais de 5 interrupções ou freezing no decorrer do movimento; b) lentidão moderada; c) decréscimo da amplitude de movimento logo após o $1^{\circ}$ tap.

4. Incapaz ou mal consegue realizar o teste por causa da lentidão, interrupções ou decréscimo do movimento.

\begin{tabular}{|l|l|l|}
\hline Item & a) Direita & b) Esquerda \\
\hline Pontuação & & \\
\hline
\end{tabular}

5. Movimentos das mãos (abrir e fechar as mãos sucessivamente em movimentos rápidos e com maior amplitude possível, avaliar as mãos separadamente)

0 . Normal.

1. a) Quebra do ritmo regular com 1 ou 2 interrupções ou hesitações; b) lentidão suave; c) decréscimo da amplitude próximo ao final dos 10 taps.

2. a) Quebra do ritmo regular com 3 ou 5 interrupções ou hesitações; b) lentidão leve; c) decréscimo da amplitude no meio da sequência dos 10 taps.

3. a) Quebra do ritmo regular com mais de 5 interrupções ou freezing no decorrer do movimento; b) lentidão moderada; c) decréscimo da amplitude de movimento logo após o $1^{\circ}$ tap.

4. Incapaz ou mal consegue realizar o teste por causa da lentidão, interrupções ou decréscimo do movimento.

\begin{tabular}{|l|l|l|}
\hline Item & a) Direita & b) Esquerda \\
\hline Pontuação & & \\
\hline
\end{tabular}

6.Pronação/ supinação das mãos (movimentos rápidos e com maior amplitude possível, avaliar as mãos separadamente)

0 . Normal.

1. a) Quebra do ritmo regular com 1 ou 2 interrupções ou hesitações; b) lentidão suave; c) decréscimo da amplitude próximo ao final dos 10 taps.

2. a) Quebra do ritmo regular com 3 ou 5 interrupções ou hesitações; b) lentidão leve; c) decréscimo da amplitude no meio da sequência dos 10 taps.

3. a) Quebra do ritmo regular com mais de 5 interrupções ou freezing no decorrer do movimento; b) lentidão moderada; c) decréscimo da amplitude de movimento logo após o $1^{\circ}$ tap.

4. Incapaz ou mal consegue realizar o teste por causa da lentidão, interrupções ou decréscimo do movimento.

\begin{tabular}{|l|l|l|}
\hline Item & a) Direita & b) Esquerda \\
\hline Pontuação & & \\
\hline
\end{tabular}

7.Toe tapping (paciente sentado com o calcanhar apoiado vai realizar o movimento de bater os dedos do pé continuamente no chão com movimentos rápidos e com maior amplitude possível, avaliar os pés separadamente). 
0 . Normal.

1. a) Quebra do ritmo regular com 1 ou 2 interrupções ou hesitações; b) lentidão suave; c) decréscimo da amplitude próximo ao final dos 10 taps.

2. a) Quebra do ritmo regular com 3 ou 5 interrupções ou hesitações; b) lentidão leve; c) decréscimo da amplitude no meio da sequência dos 10 taps.

3. a) Quebra do ritmo regular com mais de 5 interrupções ou freezing no decorrer do movimento; b) lentidão moderada; c) decréscimo da amplitude de movimento logo após o $1^{\circ}$ tap.

4. Incapaz ou mal consegue realizar o teste por causa da lentidão, interrupções ou decréscimo do movimento.

\begin{tabular}{|l|l|l|}
\hline Item & a) Direita & b) Esquerda \\
\hline Pontuação & & \\
\hline
\end{tabular}

8. Agilidade das pernas (levantar e bater os pés no chão em movimentos sucessivos o mais rápido possível e com maior amplitude possível, avaliar as pernas separadamente)

0 . Normal.

1. a) Quebra do ritmo regular com 1 ou 2 interrupções ou hesitações; b) lentidão suave; c) decréscimo da amplitude próximo ao final dos 10 taps.

2. a) Quebra do ritmo regular com 3 ou 5 interrupções ou hesitações; b) lentidão leve; c) decréscimo da amplitude no meio da sequência dos 10 taps.

3. a) Quebra do ritmo regular com mais de 5 interrupções ou freezing no decorrer do movimento; b) lentidão moderada; c) decréscimo da amplitude de movimento logo após o $1^{\circ}$ tap.

4. Incapaz ou mal consegue realizar o teste por causa da lentidão, interrupções ou decréscimo do movimento.

\begin{tabular}{|l|l|l|}
\hline Item & a) Direita & b) Esquerda \\
\hline Pontuação & & \\
\hline
\end{tabular}

9. Levantar da cadeira (paciente sentado confortavelmente com os pés apoiados no chão deverá cruzar os braços em frente ao peito e se levantar da cadeira. Atenção: observar a postura dele em pé do item 13)

0 . Normal.

1. Levanta-se lentamente ou pode precisar de mais de uma tentativa. Mas não precisa ajudar com os braços.

2. Levanta-se apoiando nos braços da cadeira.

3. Precisa auxiliar com os braços, mas tende a cair para trás ou precisa tentar se levantar mais de uma vez. Mas é capaz de se levantar sem ajuda.

4. Incapaz de levantar-se sem ajuda.

10. Marcha (o paciente deverá andar cerca de $10 \mathrm{~m}$ ou 30 passos fazer a volta e retornar ao local de avaliação)

0 . Normal.

1. Alteração leve da marcha podendo arrastar o pé ou apresentar passadas curtas. Não há festinação ou propulsão.

2. Marcha independente mas com mais dificuldade, pode apresentar festinação, passos curtos ou propulsão.

3. Necessita de assistência para caminhar, mas consegui realizar uma marcha independente com equipamento auxiliar não necessitando da ajuda de uma pessoa.

4. Não consegui andar sozinho ou anda com grande dificuldade mesmo com auxílio de uma pessoa. 
11. Freezing da marcha (avaliar a presença de algum episódio de freezing na marcha durante a avaliação do item 10)

0 . Sem freezing.

1. Freezing no início da marcha, quando faz a volta ou ao passar pela porta com um único episódio em algum desses momentos. Mas durante a caminhada não apresenta freezing.

2. Freezing no início da marcha, quando faz a volta ou ao passar pela porta com mais de um episódio em algum desses momentos. Mas durante a caminhada não apresenta freezing.

3. Freezing uma vez durante a marcha.

4. Freezing múltiplas vezes durante a marcha.

12. Estabilidade postural (resposta ao deslocamento súbito para trás. Deve ser realizado com o paciente em pé, de olhos abertos, pés separados e avisado a respeito do teste. $\mathrm{O}$ avaliador deverá puxar os ombros do paciente para trás na avaliação da postura no item 13).

0 . Normal. Capaz de recuperar o equilíbrio com um ou dois passos.

1. Precisa de 3 a 5 passos mas se recupera sem ajuda.

2. Precisa de mais de 5 passos mais se recupera sem ajuda.

3. Se mantem em pé mas sem resposta postural adequada, cairia se não fosse auxiliado pelo examinador.

4. Muito instável, tende a perder o equilíbrio espontaneamente ou com uma puxada gentil nos ombros.

13. Postura (deve-se observar a postura do paciente em diferentes situações: em pé logo após o item 9 , durante a caminhada do item 10 , e enquanto testa-se o reflexo postural no item 12 . Observar se há flexão ou inclinação de tronco para os lados)

0. Normal em posição ereta.

1. Não bem ereto, levemente curvado para frente, mas pode ser normal para pessoas mais velhas.

2. Moderadamente curvado para frente, com presença de escoliose ou inclinação para um dos lados, mas é capaz de corrigir a postura quando solicitado.

3. Acentuadamente curvado para frente com escoliose ou inclinação para um dos lados não sendo capaz de corrigir a postura voluntariamente.

4. Grande flexão com anormalidade acentuada da postura.

14. Bradicinesia corporal (observar lentidão, hesitação, pequena amplitude e pobreza geral do movimento espontâneo).

0 . Normal.

1. Sutil lentidão global e pobreza no movimento espontâneo.

2. Maior grau de lentidão global e pobreza do movimento espontâneo.

3. Moderada lentidão global e pobreza do movimento espontâneo.

4. Severa lentidão global e pobreza do movimento espontâneo.

15. Tremor postural das mãos (paciente com as mãos apoiadas em repouso e separadas, deve-se observar a postura por 10 segundos e avaliar a maior amplitude observada).

0 . Ausente.

1. Tremor presente mas com amplitude menor que $1 \mathrm{~cm}$.

2. Tremor com amplitude de pelo menos $1 \mathrm{~cm}$ mas menor que $3 \mathrm{~cm}$

3. Tremor com amplitude de pelo menos $3 \mathrm{~cm}$ mas menor que $10 \mathrm{~cm}$. 
4. Tremor com pelo menos $10 \mathrm{~cm}$ de amplitude.

\begin{tabular}{|l|l|l|}
\hline Item & a) Direita & b) Esquerda \\
\hline Pontuação & & \\
\hline
\end{tabular}

16. Tremor de ação das mãos (testar com a manobra de levar o dedo no nariz)

0 . Ausente.

1. Tremor presente mas com amplitude menor que $1 \mathrm{~cm}$.

2. Tremor com amplitude de pelo menos $1 \mathrm{~cm}$ mas menor que $3 \mathrm{~cm}$.

3. Tremor com amplitude de pelo menos $3 \mathrm{~cm}$ mas menor que $10 \mathrm{~cm}$.

4. Tremor com pelo menos $10 \mathrm{~cm}$ de amplitude.

\begin{tabular}{|l|l|l|}
\hline Item & a) Direita & b) Esquerda \\
\hline Pontuação & & \\
\hline
\end{tabular}

17. Amplitude do tremor de repouso (observar durante o repouso e avaliar os quatro membros e lábios/queixo).

\section{MEMBROS:}

0 . Normal: sem tremor.

1. Leve: com máxima amplitude menor que $1 \mathrm{~cm}$.

2. Médio: com máxima amplitude maior que $1 \mathrm{~cm}$ e menor que $3 \mathrm{~cm}$.

3. Moderado: com máxima amplitude de $3-10 \mathrm{~cm}$.

4. Severo: com amplitude máxima maior que $10 \mathrm{~cm}$.

\section{LÁBIOS/ QUEIXO:}

0 . Normal: sem tremor.

1. Leve: com máxima amplitude menor que $1 \mathrm{~cm}$.

2. Médio: com máxima amplitude maior que $1 \mathrm{~cm}$ e menor que $2 \mathrm{~cm}$.

3. Moderado: com máxima amplitude maior que $2 \mathrm{~cm}$ e menor que $3 \mathrm{~cm}$.

4. Severo: com amplitude máxima maior que $3 \mathrm{~cm}$.

\begin{tabular}{|l|l|l|ll|l|l|}
\hline Item & $\begin{array}{l}\text { a)MS } \\
\text { direito }\end{array}$ & $\begin{array}{l}\text { b) } \\
\text { esquerdo }\end{array}$ & $\begin{array}{l}\text { c) } \\
\text { MI } \\
\text { direito }\end{array}$ & $\begin{array}{l}\text { d) MI } \\
\text { esquerdo }\end{array}$ & e)Lábios/queixo \\
\hline Pontuação & & & & & & \\
\hline
\end{tabular}

\section{Constância do tremor de repouso}

0 . Normal: sem tremor.

1. Leve: Tremor de repouso presente durante menos de $25 \%$ do período de teste.

2. Médio: Tremor de repouso presente durante $26-50 \%$ de todo período de teste.

3. Moderado: Tremor de repouso presente durante $51-75 \%$ do período total de teste.

4. Severo: Tremor de repouso presente durante em mais de $75 \%$ do período total de teste.

\section{IMPACTO DA DISCINESIA A PARTE III DO UPDRS:}

a) Há discinesia presente durante a avaliação? ( ) sim ( ) não

b) Se sim, a discinesia interferiu na avaliação? ( ) sim ( ) não 